\title{
Joint-Industry Partnership to Develop a Hollow Sphere Dual-Gradient Drilling System Final Report
}

September 30, 2002 to February 28, 2003

\author{
by
}

William C. Maurer, Ph.D.

Colin Ruan, Ph.D.

Greg Deskins

May 2003

DE-AC26-02NT41641

MAURER TECHNOLOGY INC.

13135 South Dairy Ashford, Suite 800

Sugar Land, Texas 77478-3686

TR03-6 


\section{Disclaimer}

This report was prepared as an account of work sponsored by an agency of the United States Government. Neither the United States Government nor any agency thereof, nor any of their employees, makes any warranty, express or implied, or assumes any legal liability or responsibility for the accuracy, completeness, or usefulness of any information, apparatus, product, or process disclosed, or represents that its use would not infringe privately owned rights. Reference herein to any specific commercial product, process, or service by trade name, trademark, manufacturer, or otherwise does not necessarily constitute or imply its endorsement, recommendation, or favoring by the United States Government or any agency thereof. The views and opinions of authors expressed herein do not necessarily state or reflect those of the United States Government or any agency thereof. 


\section{Abstract}

Maurer Technology Inc. (MTI) formed a joint-industry partnership to fund the development of a hollow sphere dual-gradient drilling (DGD) system. Phase I consisted of collecting, compiling, analyzing, and distributing information and data regarding a new DGD system for use by the oil and gas industry. Near the end of Phase I, DOE provided funding to the project that was used to conduct a series of critical follow-on tests investigating sphere separation in weighted waterbase and oilbase muds.

Drilling costs in deep water are high because seawater pressure on the ocean floor creates a situation where many strings of casing are required due to the relatively close spacing between fracture and pore pressure curves. Approximately $\$ 100$ million have been spent during the past five years on DGD systems that place pumps on the seafloor to reduce these drilling problems by reducing the annulus fluid pressure at the bottom of the riser. BP estimates that a DGD system can save $\$ 9$ million per well in the Thunderhorse Field and Conoco estimates it can save $\$ 5$ to $\$ 15$ million per well in its deepwater operations. Unfortunately, previous DGD development projects have been unsuccessful due to the high costs ( $\$ 20$ to $\$ 50$ million) and reliability problems with seafloor pump systems.

MTI has been developing a simple DGD system concept that would pump hollow glass spheres into the bottom of the riser to reduce density of the mud in the riser. This eliminates the requirement for seafloor pumps and replaces them with low cost mud pumps, shale shakers, and other oilfield equipment that can be operated on the rig by conventional crews.

A $\$ 1.8$ million Phase I joint-industry project funded by five service companies and three operators showed that hollow spheres could be pumped well, but difficulties were encountered in separating the spheres from a polymer mud supplied by Halliburton due to the high viscosity of this mud at the low shear rates encountered on oilfield shale shaker screens. As a result, an excessive amount of this polymer mud flowed across the screen with the beads instead of through the screen.

At the completion of the Phase I project, it was concluded that the hollow sphere system would not work effectively with the polymer mud tested. ExxonMobil and Shell engineers proposed that additional sphere separation tests needed to be conducted with weighted oilfield waterbase and oilbase muds to determine if the DGD system would work with these muds. 
The DOE agreed to provide a $\$ 200,000$ grant for these tests. The DOE-funded tests, described in this report, showed that the spheres could be pumped with conventional oilfield centrifugal and triplex mud pumps and separated effectively from both oilfield waterbase and oilbase muds using conventional oilfield shale shakers and hydrocyclones.

As a result of the success of these DOE tests, this DGD system is ready for fullscale field testing, first on land wells and later in the offshore environment. Maurer Technology Inc. is currently proposing a Phase II project to oil companies to further develop this DGD concept. This project would be funded by four to eight operators. If Phase II tests are successful, Noble plans to commercialize this system with a service company partner that will market and operate the DGD system on Noble's and other drilling contractors' rigs. 


\section{Table of Contents}

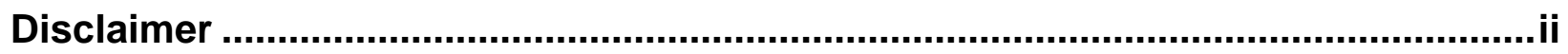

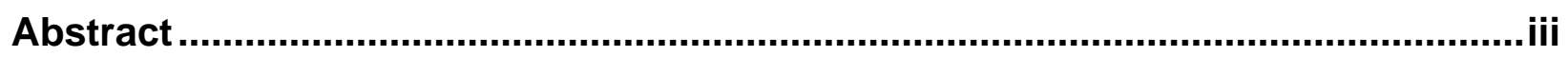

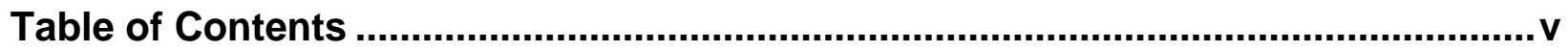

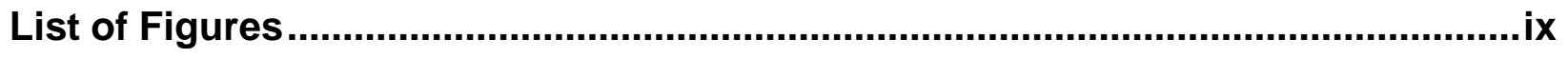

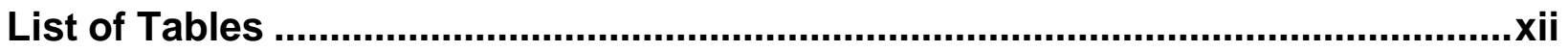

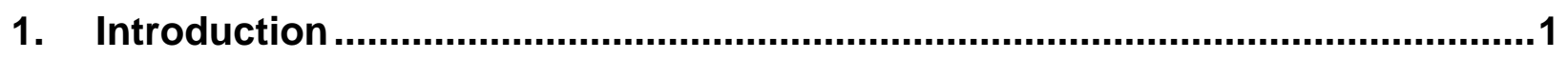

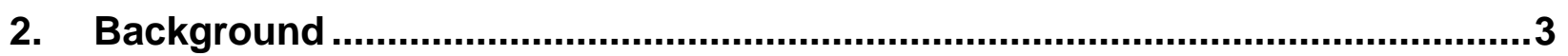

2.1 Previous Development of Seafloor Pump DGD Systems …........................... 3

2.2 New Hollow-Sphere DGD System ......................................................

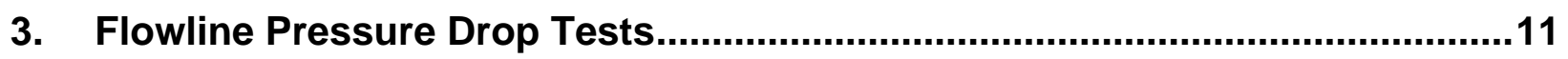

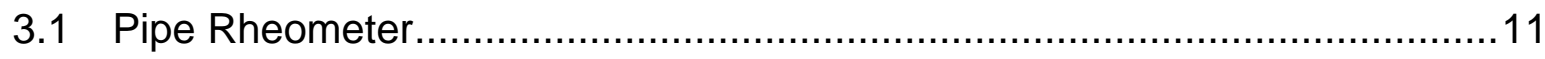

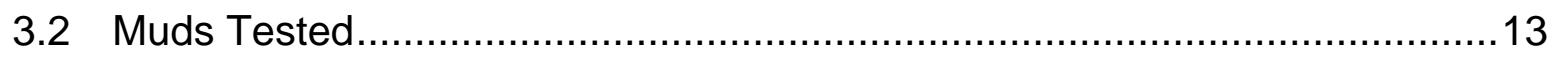

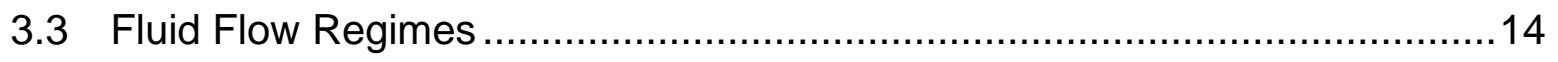

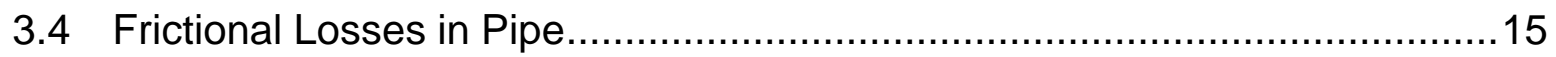

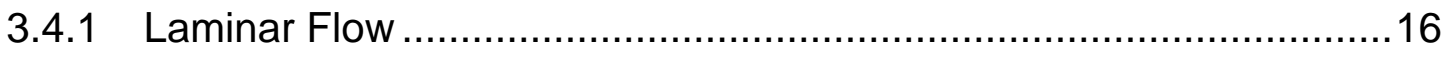

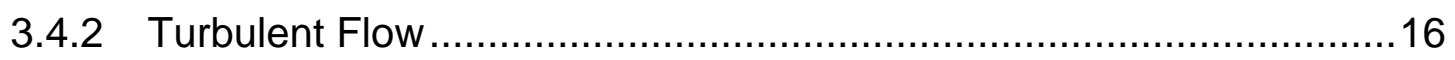

3.4.3 Flow Pattern Transition ........................................................... 17

3.5 Pipe Rheometer Tests (Oilfield Waterbase Mud) …...................................17

3.6 Sphere Flotation Tests (Waterbase Mud + Polymer) .................................18

3.7 Pipe Rheometer Tests (Oilfield Synthetic Oil Mud) ....................................20

3.8 Pressure-Drop Extrapolations (Waterbase Mud) …....................................21

3.9 Pressure-Drop Extrapolations (Synthetic Oil Mud) ......................................22

3.10 Higher Sphere Concentrations ..........................................................24

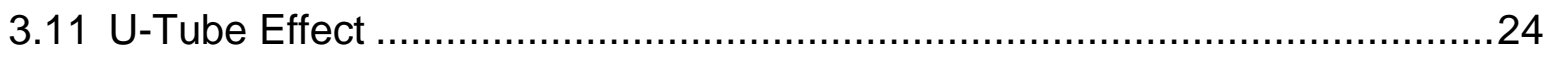

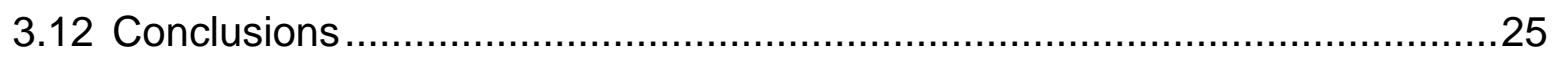




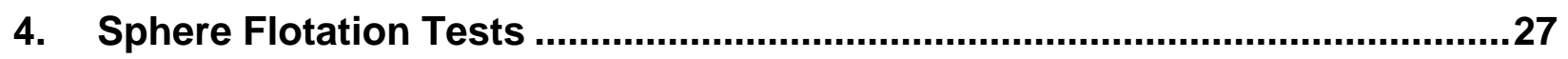

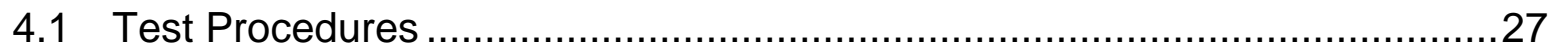

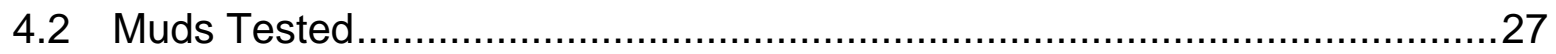

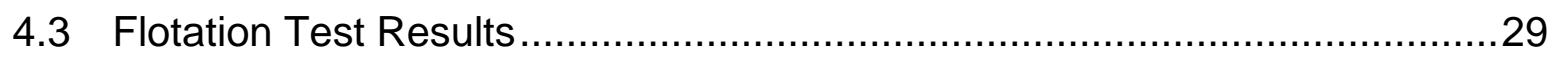

4.3.1 Flotation Tests (Waterbase Mud + Polymer) …...........................30

4.3.2 Flotation Tests (Water) …………………................................. 31

4.3.3 Flotation Tests (Polymer Mud) ................................................... 31

4.3.4 Flotation Tests (Waterbase Mud) ...............................................

4.3.5 Flotation Tests (Synthetic Oil Mud) …….....................................33

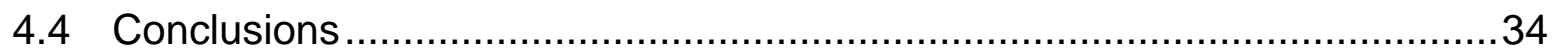

5. Varco Shale Shaker Tests (Synthetic Oil Mud)..................................................

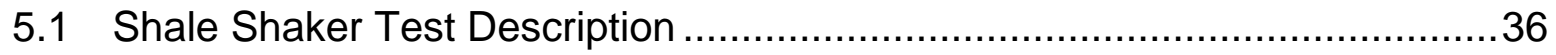

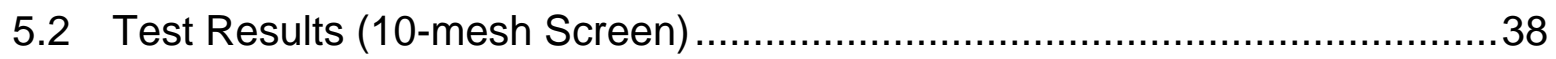

5.3 Test Results (20-Mesh Screen) …..................................................... 42

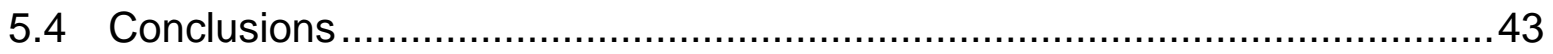

6. DRC Shale Shaker Tests (Waterbase Mud)....................................................45

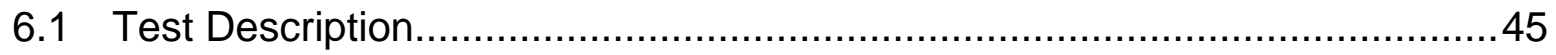

6.2 Sphere Separation Tests (Variable Screen Size) ….................................47

6.3 Cuttings Separation Tests ...................................................................

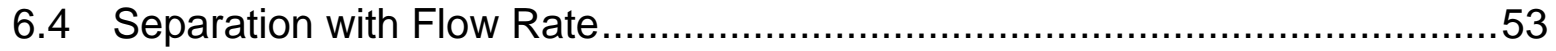

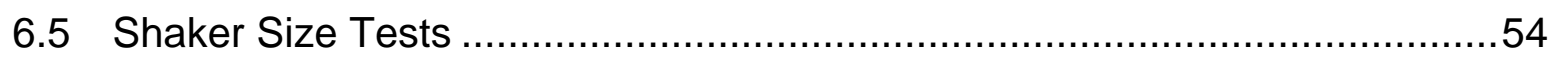

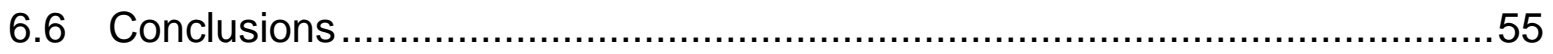

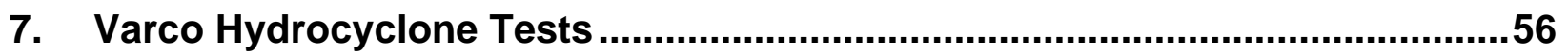

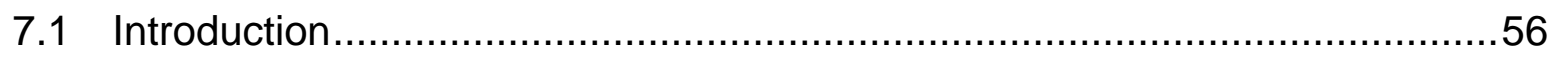

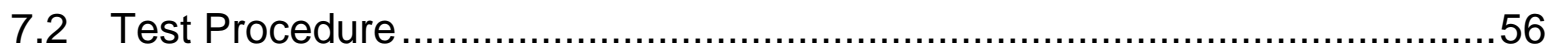

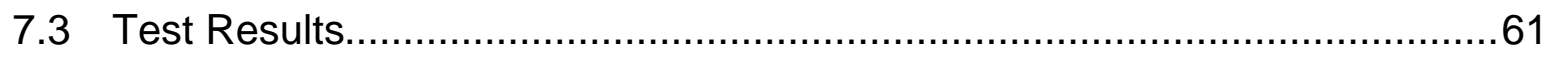

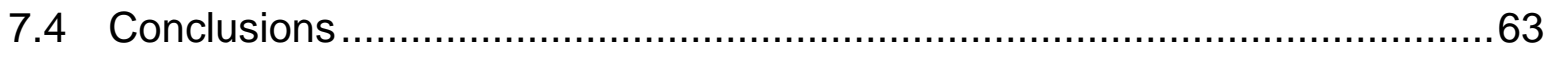


8. Flow Loop Tests (Oilfield Waterbase Mud) ..................................................64

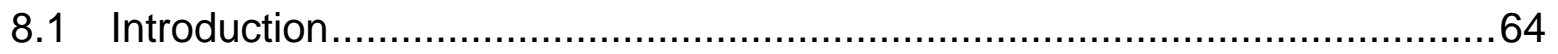

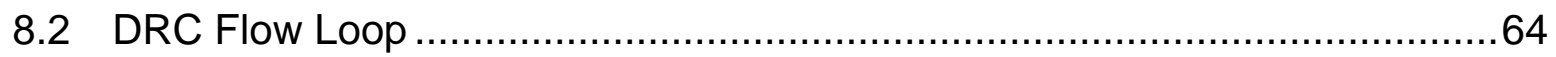

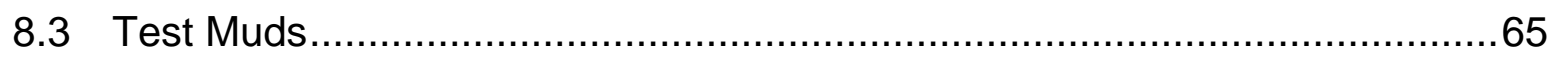

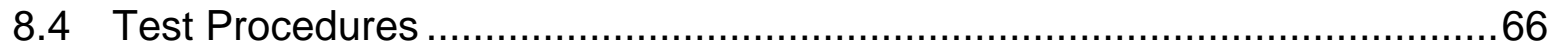

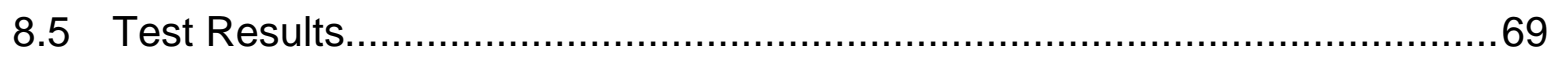

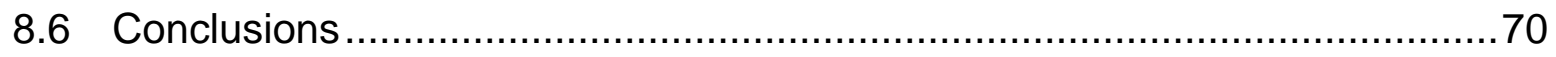

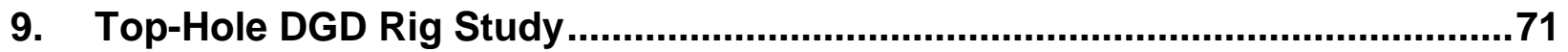

9.1 Conventional Deepwater Rigs ............................................................

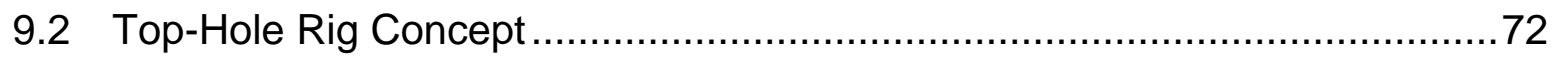

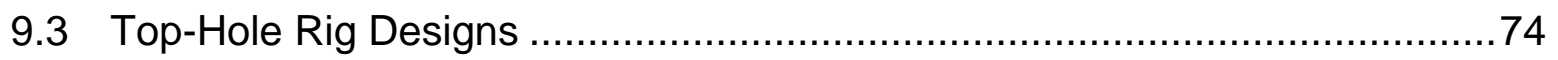

9.3.1 Riserless Top-Hole Rig (Pump and Dump) ...................................74

9.3.2 Riserless Top-Hole Rig (Hollow Sphere DGD) ...............................75

9.3.3 Riserless Top-Hole Rig (Seafloor Pumps) …...................................76

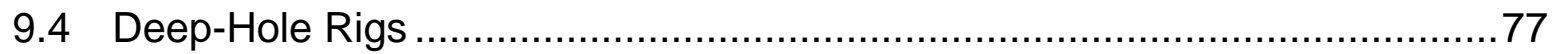

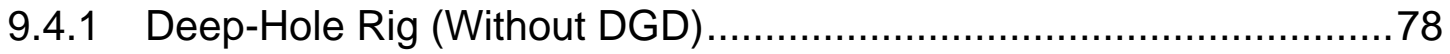

9.4.2 Deep-Hole Rig (Hollow Sphere DGD) .........................................78

9.4.3 Deep-Hole Rig (Seafloor Pump DGD) .........................................79

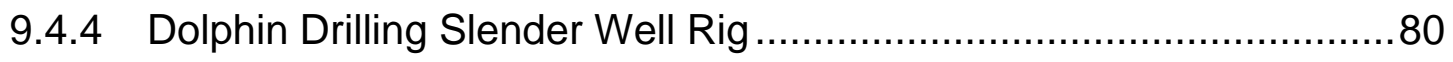

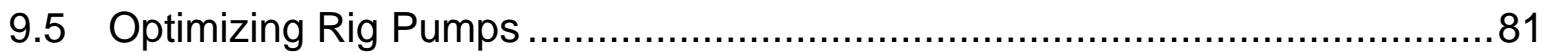

9.6 Engineering Considerations for Top-Hole DGD Rigs...................................82

9.6.1 Advantages of Top-Hole DGD Rigs ................................................

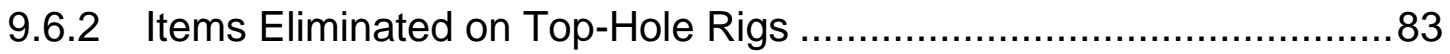

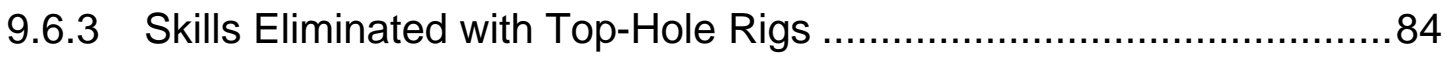

9.6.4 Conventional Items Required on Top-Hole Rigs..............................84

9.6.5 Equipment Added to Top-Hole Rigs (Hollow Sphere System) ...........85

9.6.6 DGD Equipment Added to Top-Hole Rigs (Mudlift DGD System) ......86

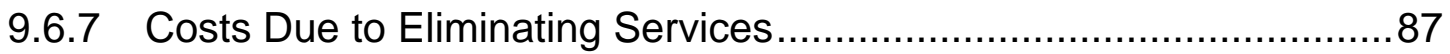

9.6.8 Additional Opportunities for Top-Hole Rigs.....................................87

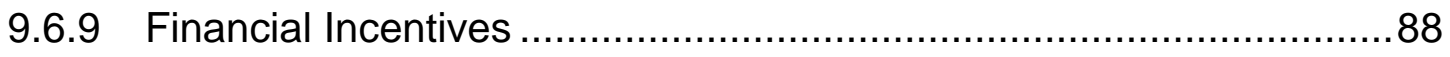




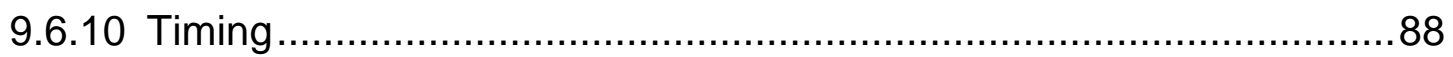

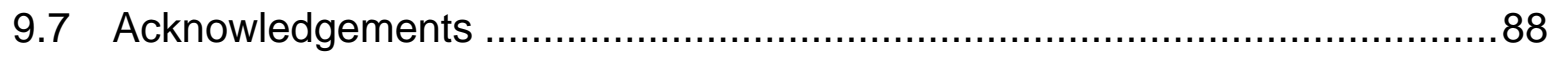

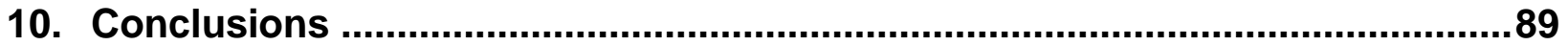

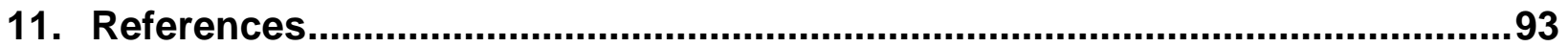




\section{List of Figures}

Figure 1. MTI Hollow Sphere Dual-Gradient Drilling System ................................... 1

Figure 2. DGD System Based on Subsea Pumps (Peterman, 1998)............................

Figure 3. DGD Hydrostatic Gradients (Snyder, 1998) ................................................. 4

Figure 4. Casing Program for Conventional vs. DGD (Snyder, 1998)............................5

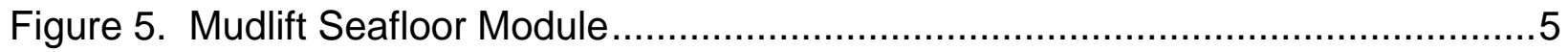

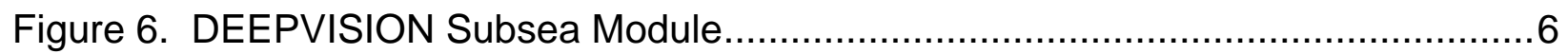

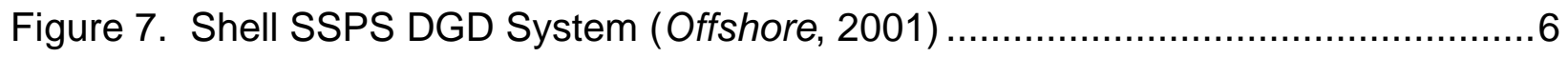

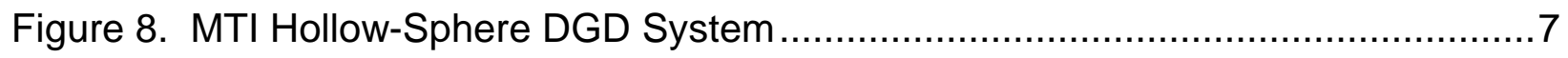

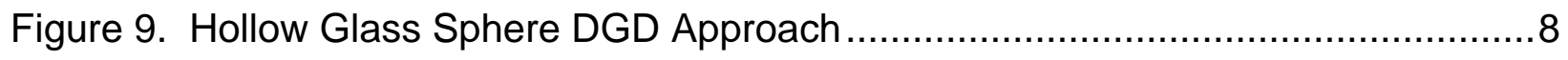

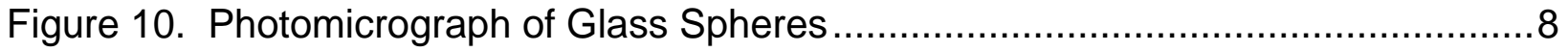

Figure 11. Sea Water Density Mud (50\% Spheres) …............................................. 9

Figure 12. Hollow Sphere Separation System ....................................................... 9

Figure 13. New Seafloor Equipment Required ................................................... 10

Figure 14. Pipe Rheometer for Measuring Pressure Drop.......................................11

Figure 15. DRC Centrifugal Pump and Flowmeter ................................................. 12

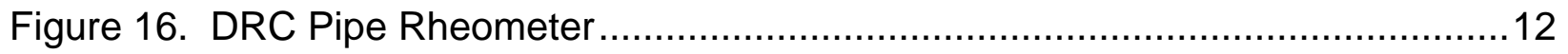

Figure 17. Rheometer Data-Acquisition System ...................................................13

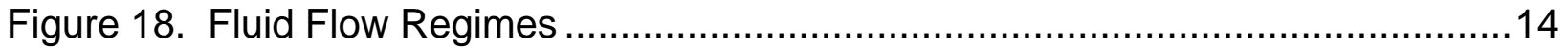

Figure 19. Effect of Flow Type on Pressure Drops ...............................................15

Figure 20. Pipe Rheometer Test (10.8-ppg Waterbase Mud) ...................................18

Figure 21. Pressure Drops for 10.8-ppg Waterbase Mud with Polymer.......................19

Figure 22. Pipe Rheometer Test (12-ppg Waterbase Polymer Mud) ...........................20

Figure 23. Pipe Rheometer Test (12.8-ppg Synthetic Oil Muds) ..............................20

Figure 24. Predicted Pressure Drops with 10.8-ppg Waterbase Mud (25\% Spheres) ..21

Figure 25. Predicted Pressure Drops with 12.8-ppg Synthetic Oil Mud (35\% Spheres)23

Figure 26. Sphere Flotation Test Apparatus .27 


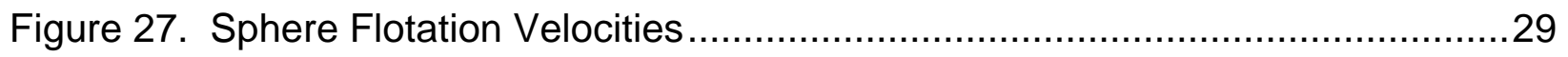

Figure 28. Effect of Polymer on Sphere Flotation Velocity......................................... 31

Figure 29. Balmoral Spheres Suspended in 8.34-ppg Polymer Mud ...........................32

Figure 30. 3M Sphere Flotation in 10.8-ppg Waterbase Mud (7.87 ft/min) ..................32

Figure 31. Balmoral Sphere Flotation in 10.8-ppg Waterbase mud $(15.4 \mathrm{ft} / \mathrm{min})$..........33

Figure 32. 3M Sphere Flotation in 12.8-ppg Synthetic Oil Mud $(0.048 \mathrm{ft} / \mathrm{min})$..............34

Figure 33. Balmoral Sphere Flotation in 12.8-ppg Synthetic Oil Mud (0.17 ft/min) .......34

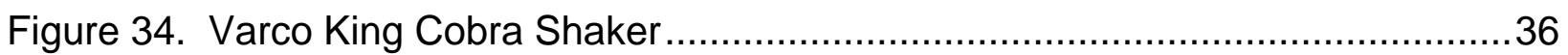

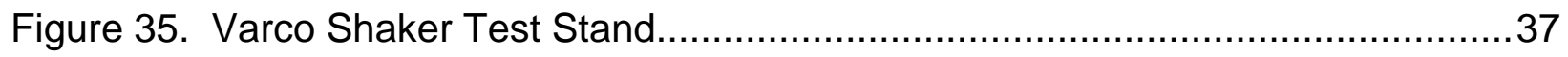

Figure 36. Mud with 25\% Spheres in Mixing Tank ....................................................

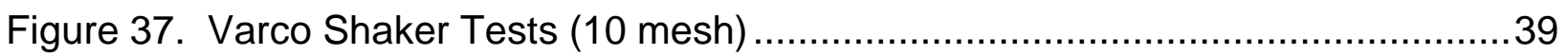

Figure 38. Wetted Beads in 10-mesh Overflow (300 gpm feed) ...............................40

Figure 39. Wetted Beads in 10-Mesh Overflow (300 gpm feed) ...............................40

Figure 40. 50\% Beads in Overflow (430 gpm feed) ................................................4

Figure 41. 40\% Beads in Overflow (720 gpm feed) .............................................. 41

Figure 42. Varco Shaker Test (20 mesh) …....................................................... 42

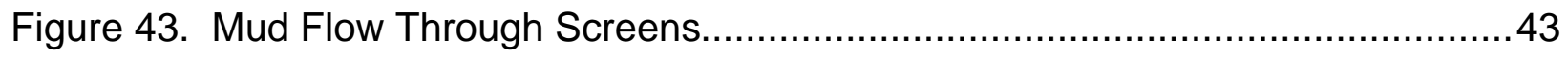

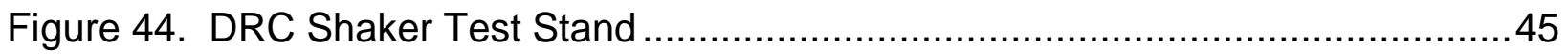

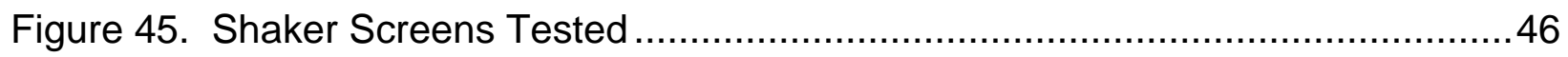

Figure 46. Effect of Screen Size on Sphere Separation ........................................47

Figure 47. Shaker Sphere Recovery Tests (10.4-ppg Waterbase Mud) ......................48

Figure 48. Shaker Flow Rate Tests (10.4-ppg Waterbase Mud) ................................49

Figure 49. 4-Mesh Shaker Test (3M Spheres, Waterbase Mud) ................................49

Figure 50. 10-Mesh Screen Overflow (3M Spheres, Waterbase Mud) .......................50

Figure 51. 10-Mesh Screen Underflow (3M Spheres, Waterbase Mud) …...................50

Figure 52. Apparatus for Putting Pebbles Into Mud .................................................51

Figure 53. Pebbles Used to Simulate Cuttings in the Mud.......................................52

Figure 54. Pebbles Removed by 4-Mesh Screen ......................................................

Figure 55. Effect of Flow Rate on Shaker Performance .........................................53 


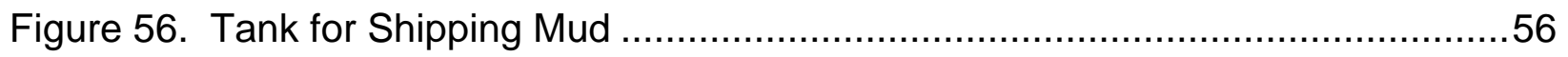

Figure 57. Schematic of Hydrocyclone Flow Loop................................................57

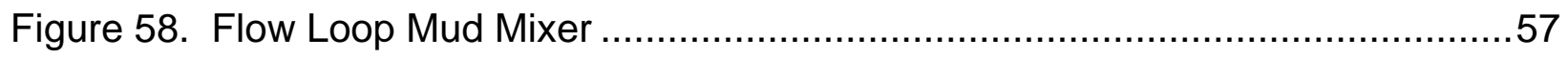

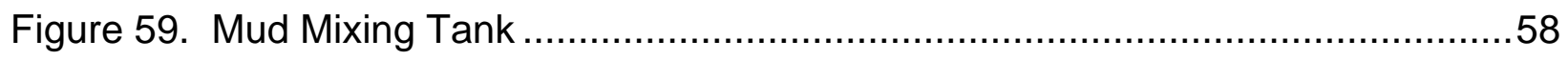

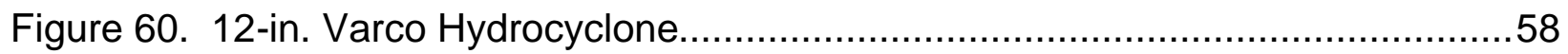

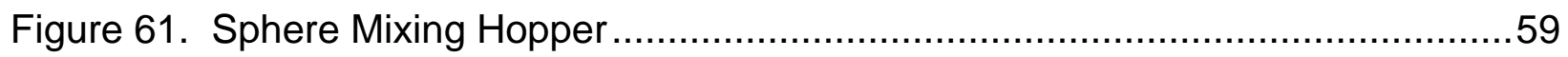

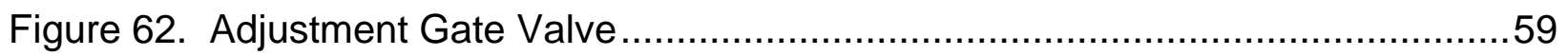

Figure 63. Samples for Post-Test Evaluation ............................................................60

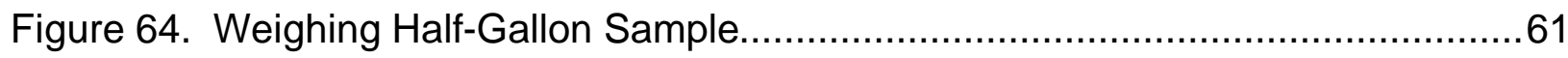

Figure 65. Typical Separation with 12-inch Varco Hydrocyclone .................................62

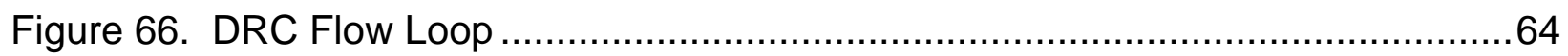

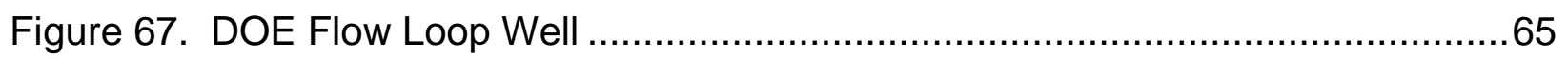

Figure 68. National Oilwell T180 Shale Shaker on Mixing Tank ................................66

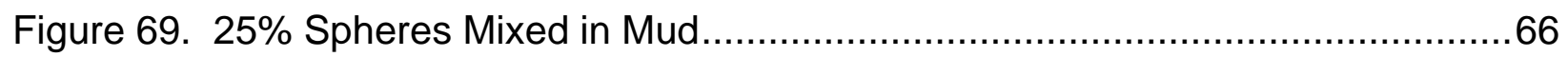

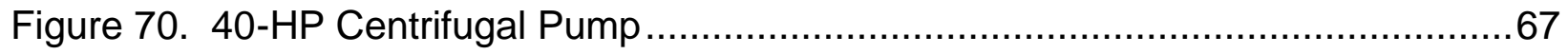

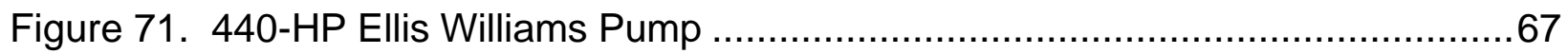

Figure 72. Steel Flowline to Wellhead and Hose Return .........................................68

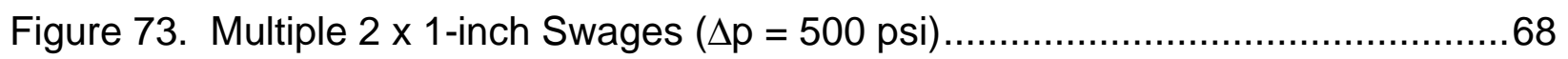

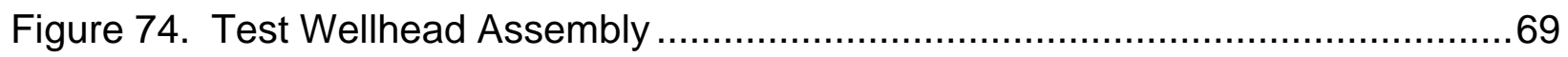

Figure 75. Conventional Deep-Water Rig with 21-inch Riser....................................71

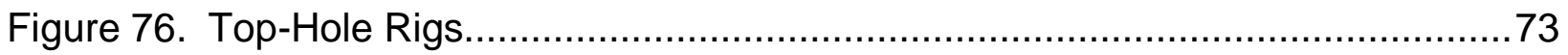

Figure 77. Top-Hole Rig Drilling Concept …....................................................... 73

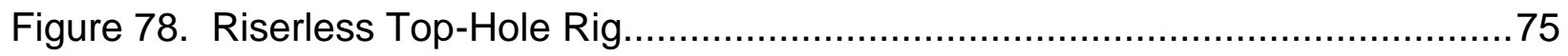

Figure 79. Riserless Top-Hole Rig (Hollow Sphere System) …...............................76

Figure 80. Riserless Top-Hole Rig (Seafloor Pumping System) ….............................77

Figure 81. Rig without DGD for Deep Sections of Hole .......................................... 78

Figure 82. Deep-Hole DGD Rig (Hollow Sphere System) ..........................................79

Figure 83. Deep-Hole DGD Rig (Seafloor Pumping System) …............................... 80

Figure 84. Dolphin Drilling's Slender Riser Rig ................................................... 81 


\section{List of Tables}

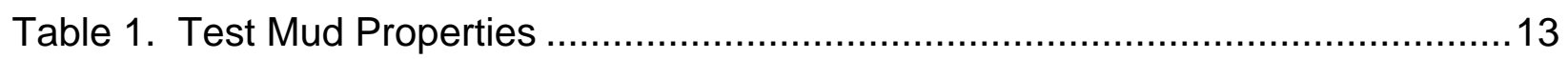

Table 2. Predicted Pressure Drops with 10.8-ppg Waterbase Mud (25\% Spheres) .....22

Table 3. Predicted Pressure Drops with 12.8-ppg Synthetic Oil Mud (35\% Spheres)...23

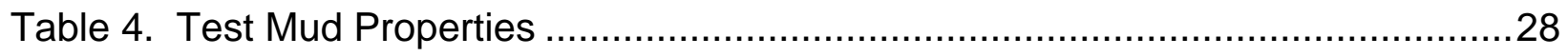

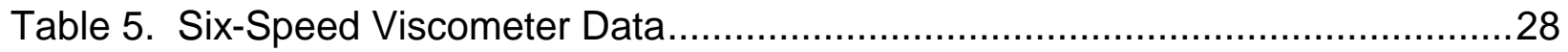

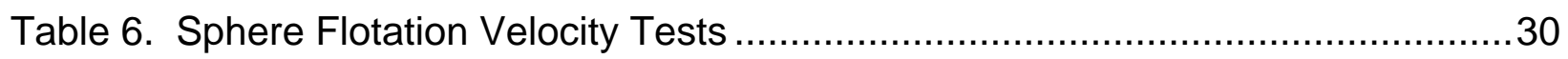

Table 7. Varco King Cobra Shale Shaker Specifications ............................................37

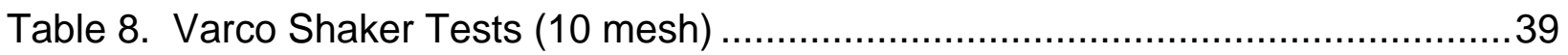

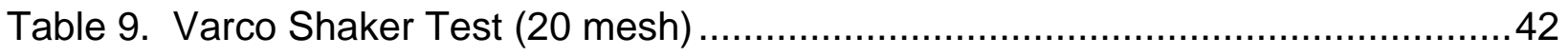

Table 10. National Oilwell T180 Shaker................................................................ 45

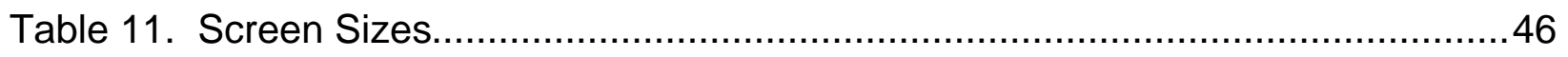

Table 12. National Oilwell Shaker Tests ..............................................................48

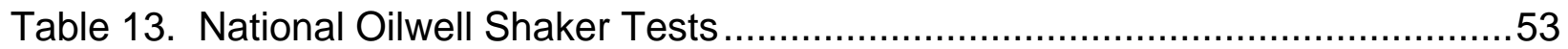

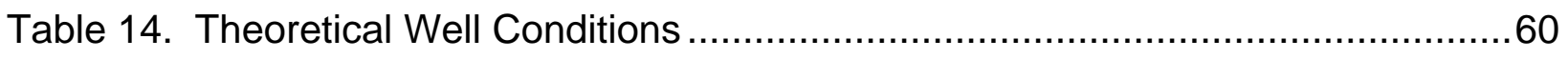

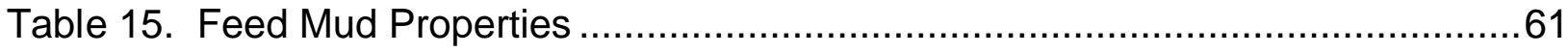

Table 16. Varco Hydrocyclone Test Results (20\% Spheres, 3\% Solids) .....................62

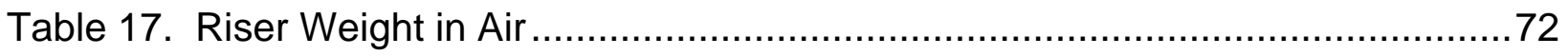

Table 18. Example Savings Due to Eliminating Services on Top-Hole Rigs.................87 


\section{Introduction}

Maurer Technology Inc. (MTI) formed a joint-industry partnership to fund the development of a hollow sphere, dual-gradient drilling (DGD) system. The project is organized into phases. Phase I consists of collection, compiling, analyzing, and distribution of information and data regarding the new DGD system for use by the oil and gas industry. DOE desired to contribute to the effort, which was viewed as an important project with potential to reduce offshore drilling costs in the US. Therefore, DOE provided funding to the development that was used to conduct a series of important tests on sphere separation in weighted waterbase and oilbase muds.

MTI has developed a simple DGD system concept (Figure 1) based on pumping hollow glass spheres into the bottom of the riser to reduce density of the mud in the riser. A $\$ 1.8$ million Phase I joint-industry project (JIP) was funded by five service companies and three operators. A range of tests and analyses showed that hollow spheres could be pumped successfully, but difficulties were encountered in separating the spheres from a polymer mud supplied by Halliburton due to the high viscosity of this mud at the low shear rates encountered on oilfield shale shaker screens. As a result, an excessive amount of this polymer mud flowed across the screen with the beads instead of through the screen.

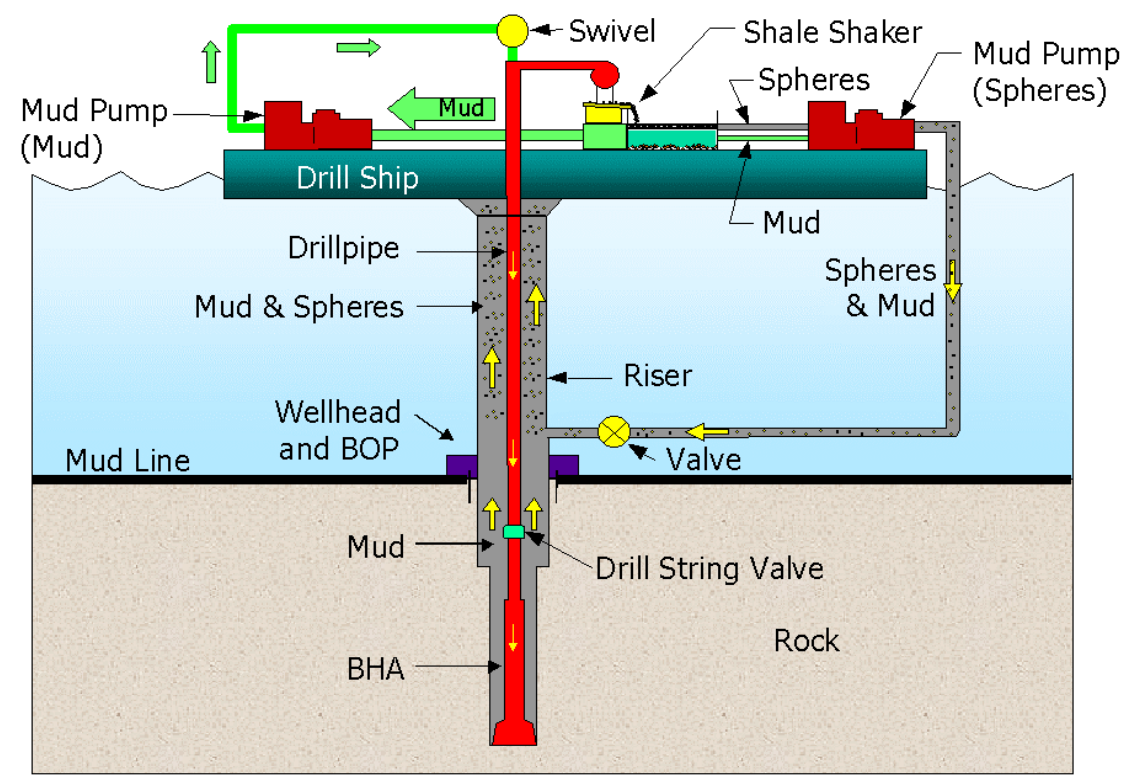

Figure 1. MTI Hollow Sphere Dual-Gradient Drilling System

At the completion of the Phase I project, it was concluded that the hollow sphere system would not work effectively with the polymer muds tested. ExxonMobil and Shell 
engineers proposed that additional sphere separation tests be conducted with weighted oilfield waterbase and oilbase muds to determine if the DGD system would work with these types of mud common in the offshore environment.

The DOE agreed to furnish a $\$ 200,000$ grant for these follow-on tests. These DOE tests are described in this report, and showed that the spheres could be pumped with conventional oilfield centrifugal and triplex mud pumps and separated effectively using conventional oilfield shale shakers and hydrocyclones.

The general background of DGD systems is summarized in Chapter 2, including previous systems based on subsea pumps, and the new sphere-based DGD system. Each series of laboratory tests is described and results presented in a separate chapter (Chapters 3 through 9). Conclusions for the DOE tests are summarized in Chapter 10. 


\section{Background}

\subsection{PREVIOUS DEVELOPMENT OF SEAFLOOR PUMP DGD SYSTEMS}

With conventional offshore drilling, a riser extends from the seafloor to the drillship. Fluid is circulated down the drill string, through the bit, and returns up the riser to the drillship. The weight of the column of mud in the riser annulus exerts high pressure at the seafloor, making drilling difficult.

To overcome this problem, several companies have sought to develop DualGradient Drilling (DGD) systems where subsea pumps are placed on the seafloor to reduce pressure in the annulus of the wellbore (Figure 2). Special seafloor assemblies pump the mud back to the surface through risers or smaller return riser lines (so-called "riserless drilling").

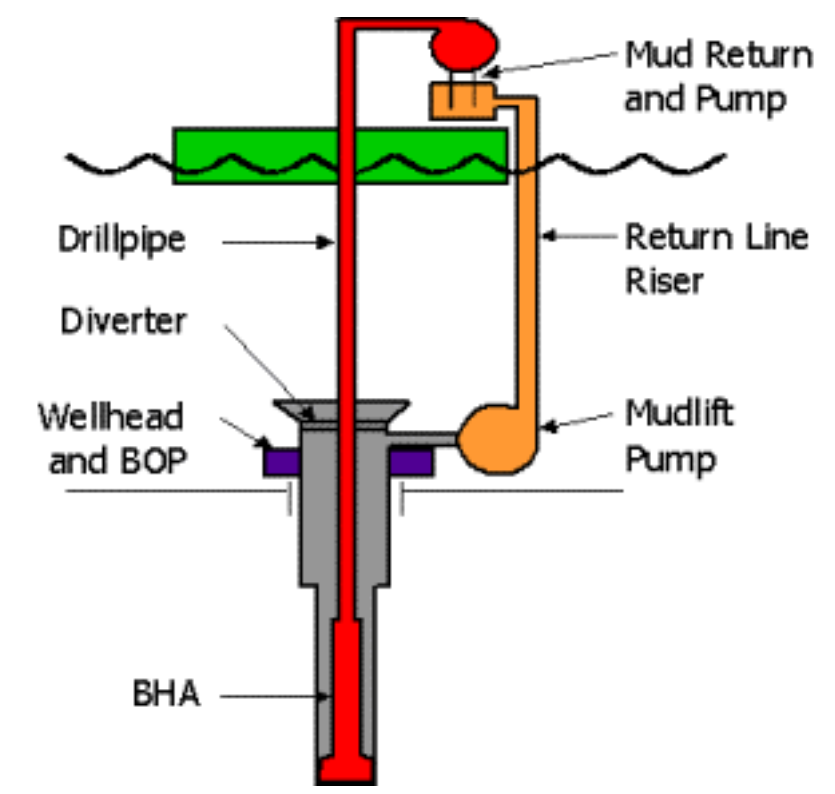

Figure 2. DGD System Based on Subsea Pumps (Peterman, 1998)

Figure 3 illustrates mud hydrostatic pressure gradients for conventional and riserless (DGD) drilling. Because of the seawater column, and the unconsolidated nature of the sediments near the seafloor, curves for pore pressure $(A)$ and fracture pressure (B) are often close together, making it difficult to maintain wellbore annulus pressure safely between these curves. 


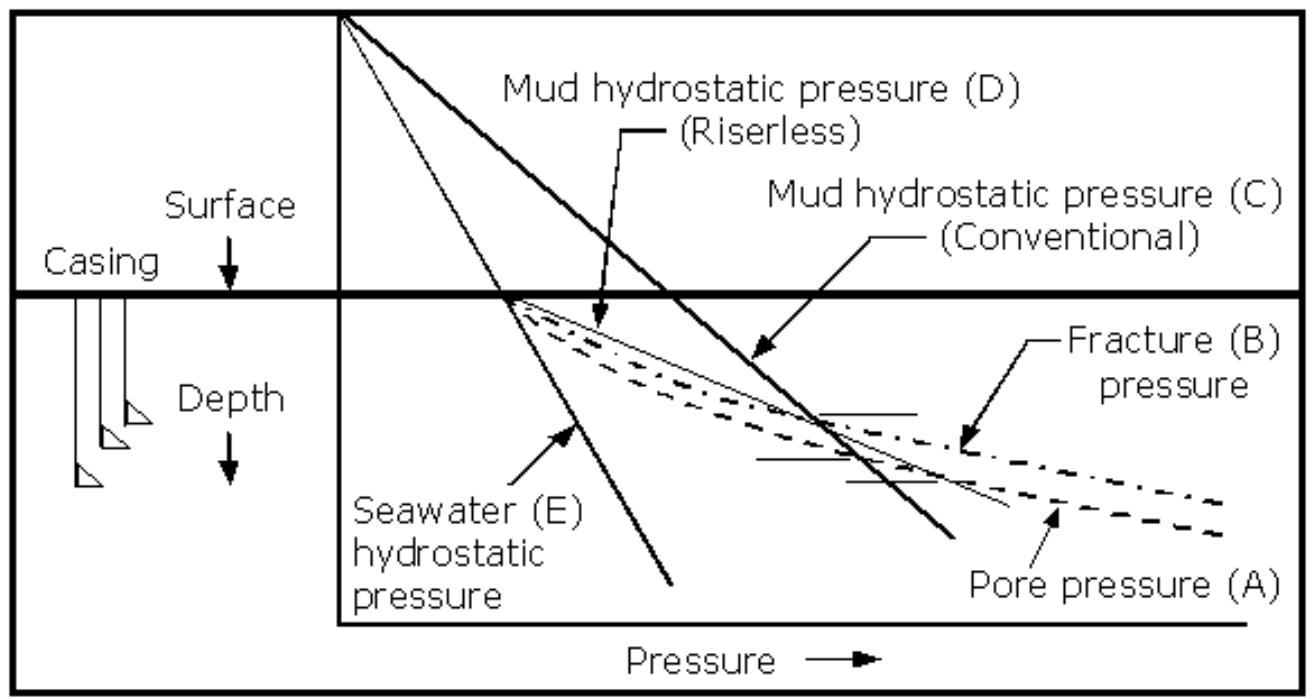

Figure 3. DGD Hydrostatic Gradients (Snyder, 1998)

With conventional drilling with a riser, the mud hydrostatic pressure gradient (C) is a straight line extending from the floating drillship (see Figure 3). This hydrostatic gradient line traverses the pore and fracture gradients over a short vertical distance, resulting in the requirement for setting numerous casing strings.

If the annular pressure at the seafloor is reduced to that of seawater by a dualgradient (riserless) system, the hydrostatic curve (D) becomes a straight line that extends from the seafloor. The slope of this line is significantly reduced, allowing a much greater vertical distance to be drilled while maintaining pressures safely between the pore and fracture gradient curves, resulting in fewer casing strings, smaller drillships, and reduced drilling costs.

Figure 4 shows conventional and riserless casing programs for a Gulf of Mexico well where riserless drilling reduces the number of casing strings from 8 to 5 , saving $\$ 3$ million (each casing string costs $\$ 1$ million) (Gault, 1996). 


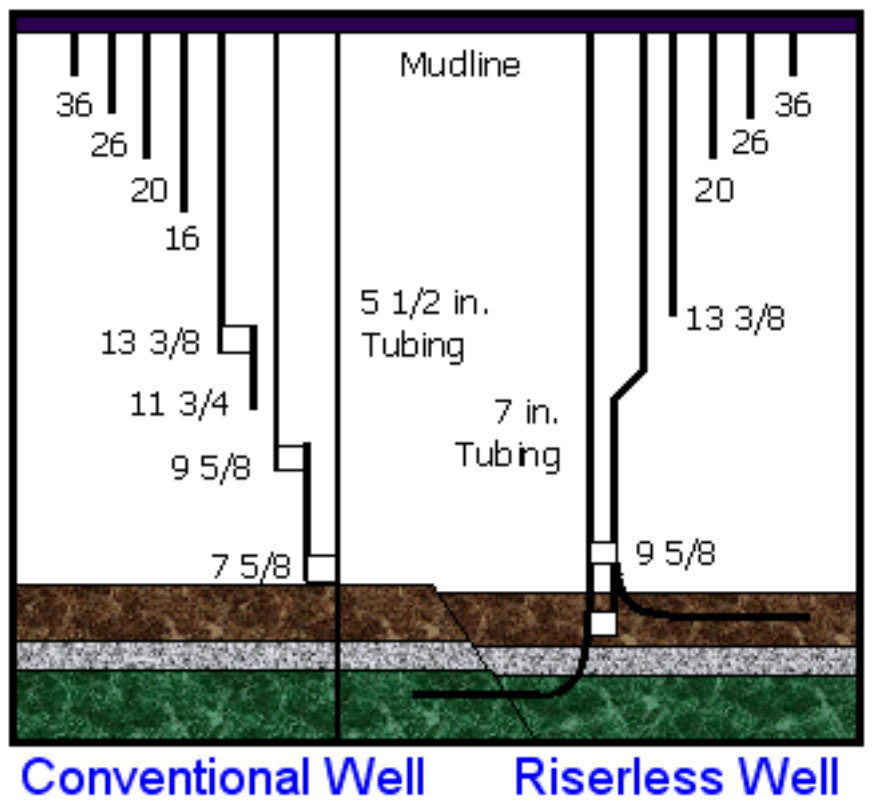

Figure 4. Casing Program for Conventional vs. DGD (Snyder, 1998)

Based on the promise of DGD, approximately $\$ 100$ million has been spent by various teams in the oil industry attempting to develop and implement seafloor pumps for DGD drilling as shown in Figures 5 to 7.

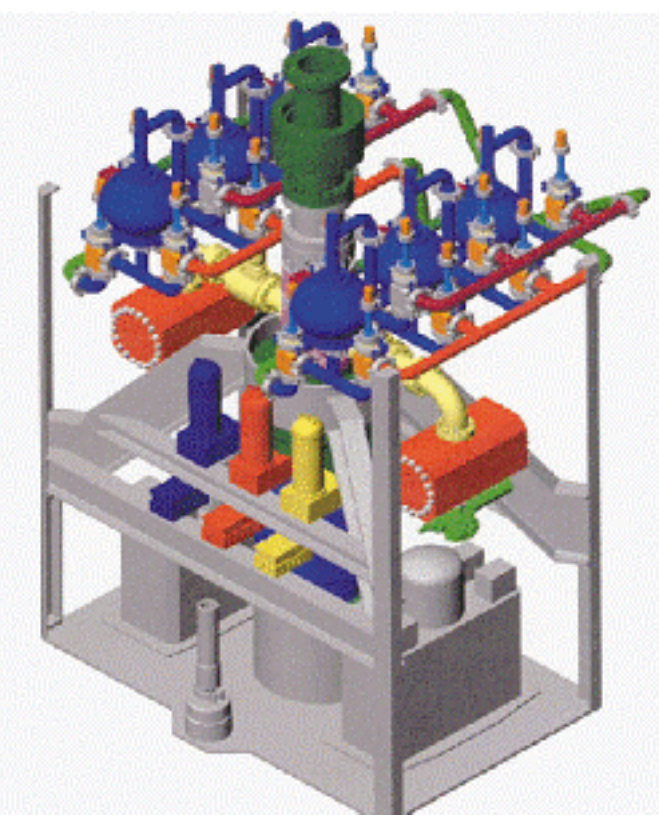

Figure 5. Mudlift Seafloor Module 


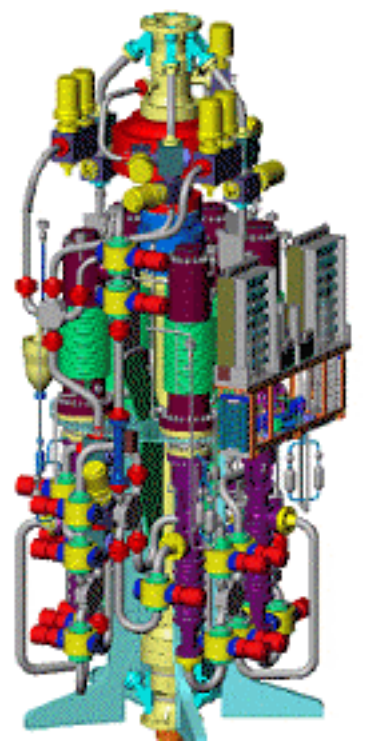

\section{$10,000 \mathrm{ft}$ Pump Station}

- 5-pump module station

- Size: $15^{\prime} * 17^{\prime} * 40^{\prime}$

- Weight: 350 kips

- Max. available hhp 4050

- ANSI 2500 (6250 psi) rated

- Standard riser joint connection

- Independent of BOP MUX control system

- Self contained power and control

Figure 6. DEEPVISION Subsea Module

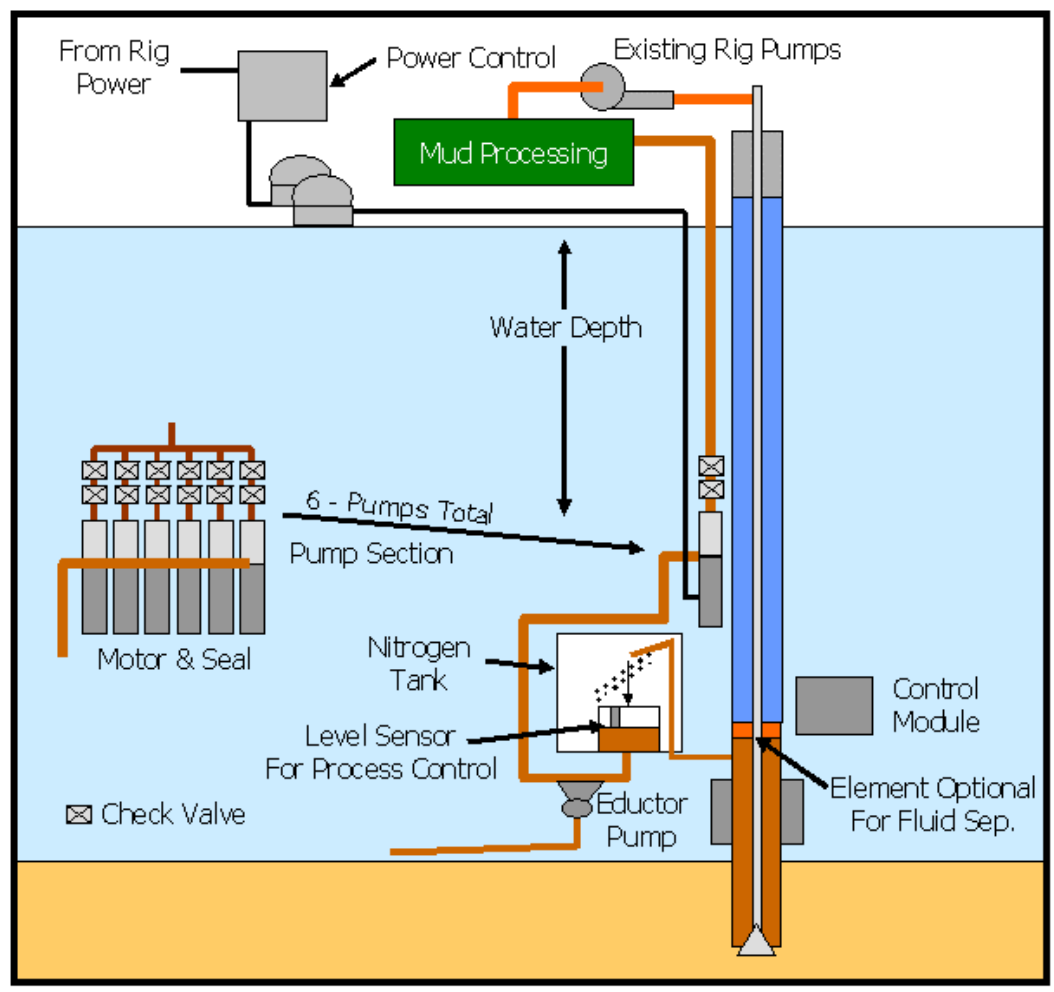

Figure 7. Shell SSPS DGD System (Offshore, 2001)

Companies that developed these systems estimate that it would cost from $\$ 25$ to $\$ 50$ million to install a seafloor pumping system on a Generation $V$ offshore rig. Major challenges have been reported in each of these developments. A major problem with seafloor pumps is that they are complicated and are therefore difficult to keep operating reliably. All of the drill cuttings must pass through the Mudlift and Deepvision pumps - 
another important problem. The Shell system dumps the large drill cuttings on the seafloor which creates an environmental problem. With all three of these systems, the riser must be pulled to repair the pumps, which is an expensive four-day procedure.

The hollow sphere system being developed on this project eliminates seafloor pumps and uses conventional oilfield equipment (e.g., mud pumps, shale shakers, mud tanks, etc.) on the rig that can be operated and maintained by rig crews, resulting in a much lower cost and more reliable system than those incorporating seafloor pumps.

As a result of the challenges with the three subsea pump DGD systems, work has been abandoned related to putting subsea pumping systems on Generation V rigs.

\subsection{NEW HOLLOW-SPHERE DGD SYSTEM}

As a result of significant challenges with DGD systems based on seafloor pumps, Maurer Technology Inc. (MTI) is pursuing a completely different approach to dualgradient drilling. An innovative system is under development based on adding lightweight hollow spheres to the drilling fluid in the riser. Hollow spheres (glass, plastic, composite, metal, etc.) are pumped to the seafloor and injected into the bottom of the riser to reduce the density of the mud in the riser to that of seawater (Figure 8). Density of the mud in the drill string and wellbore annulus below the seafloor is not affected.

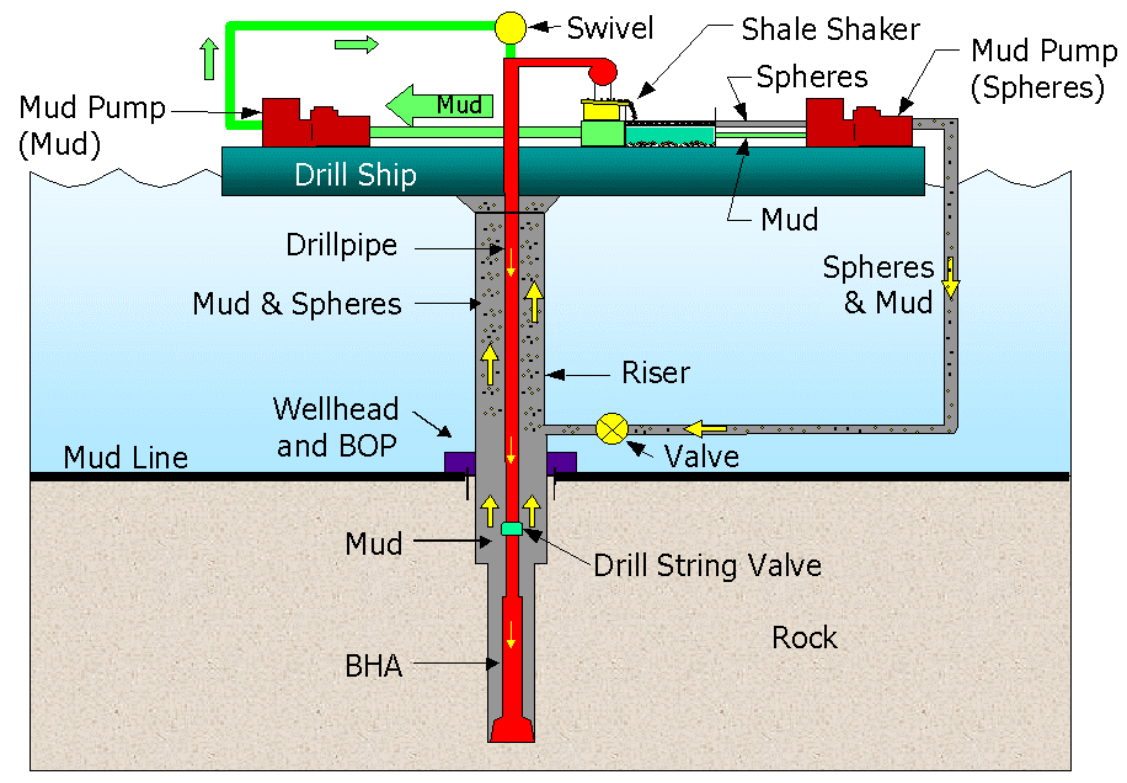

Figure 8. MTI Hollow-Sphere DGD System 
Mud and spheres are mixed together at the surface, pumped to the seafloor as a slurry and injected into the riser to reduce the density of the mud from that point back up to the surface (Figure 9).

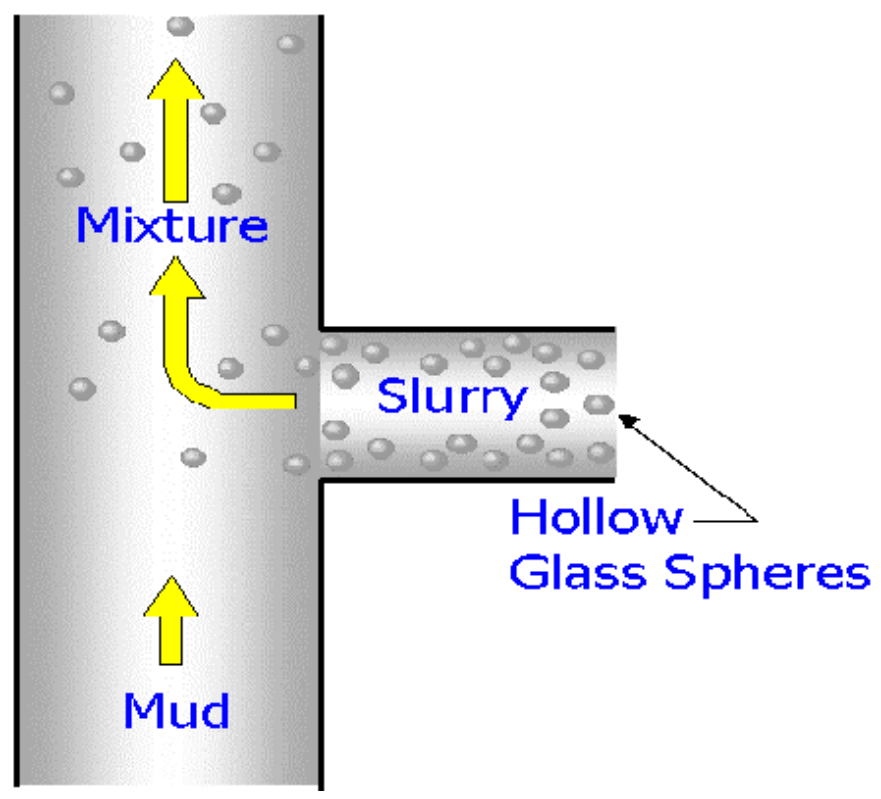

Figure 9. Hollow Glass Sphere DGD Approach

The hollow spheres can be made of glass, composites, plastics, or other materials. Figure 10 shows hollow glass microspheres (10 to 100 micron diameter) manufactured by $3 \mathrm{M}$ that have a specific gravity of 0.38 . Adding $50 \%$ by volume of these microspheres to a 14-ppg mud will reduce the density of the mud to that of seawater (8.56 ppg) as illustrated in Figure 11.

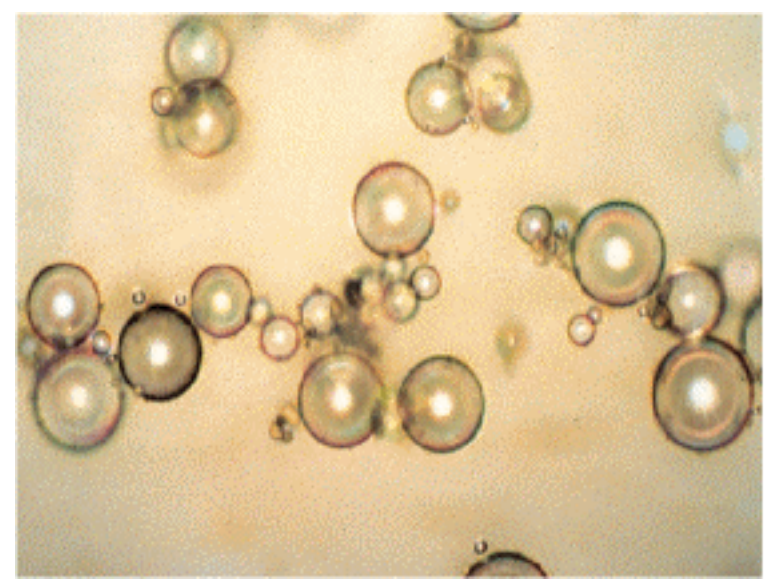

Figure 10. Photomicrograph of Glass Spheres 


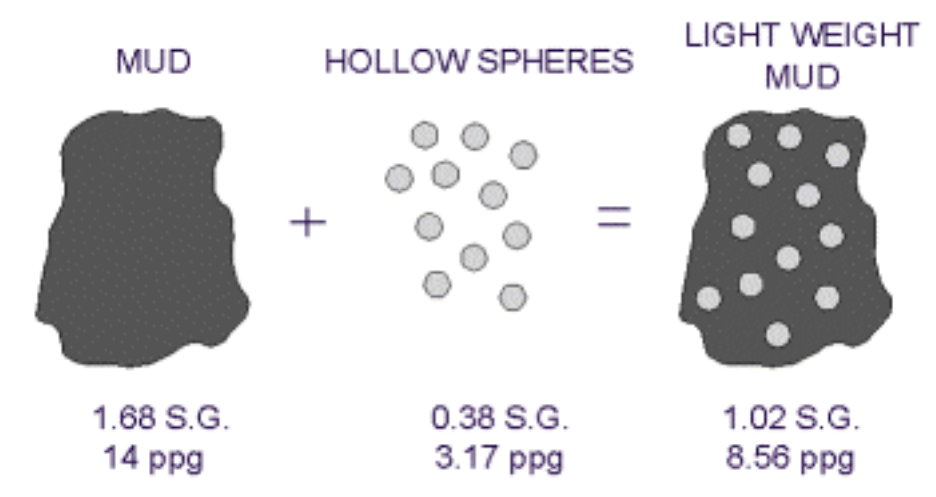

Figure 11. Sea Water Density Mud (50\% Spheres)

As the spheres return up the riser to the drill rig, they are removed from the mud with shale shakers as shown in Figure 12. Heavy mud (without spheres) is then circulated down the drillpipe to the hole bottom while a slurry containing the spheres is circulated to the seafloor through a special flowline and re-injected into the riser.

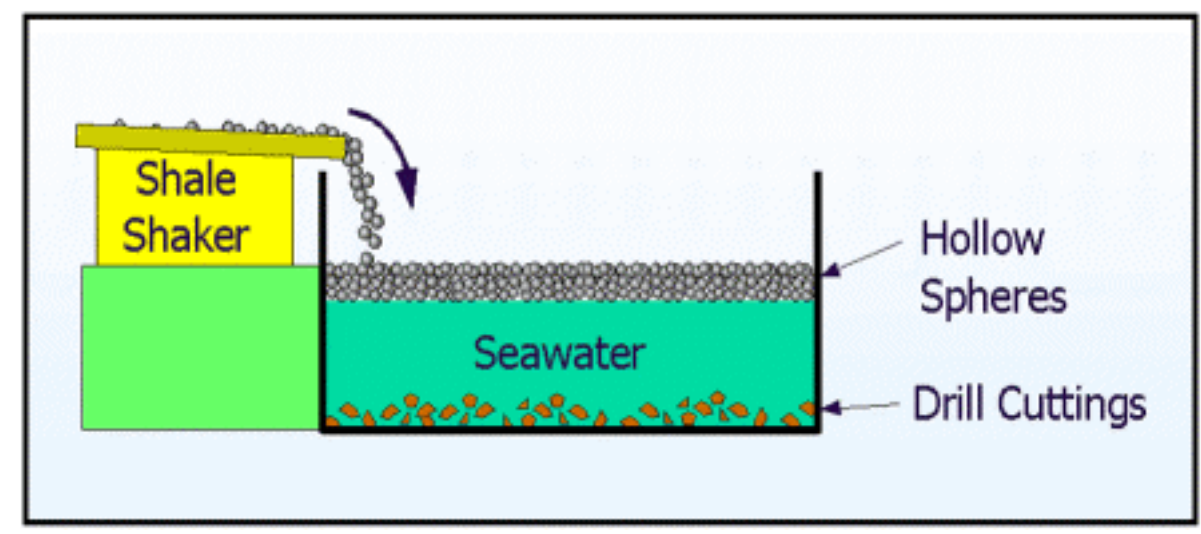

Figure 12. Hollow Sphere Separation System

A major advantage of this sphere-based DGD system is that no new equipment is needed on the seafloor except a remotely controlled valve (Figure 13). Analysis and testing during the Phase I project showed that all components of the hollow sphere DGD can be developed using conventional equipment. 

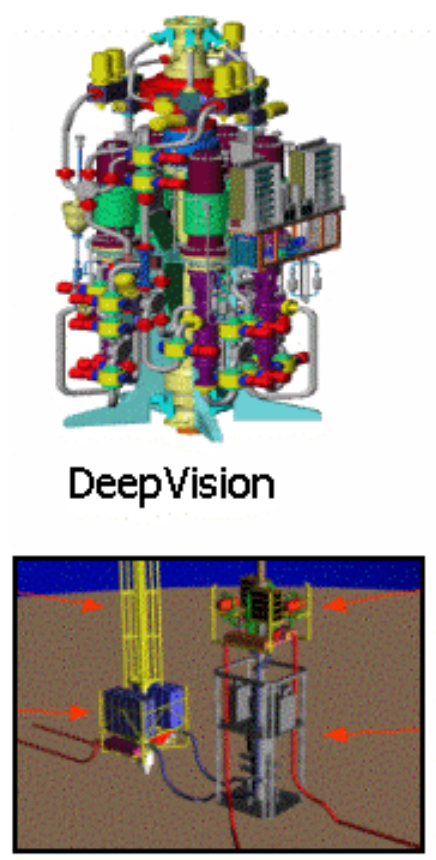

Shell SSPS

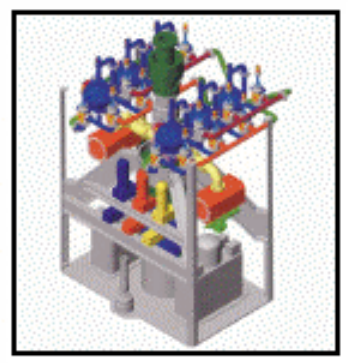

Mudlift

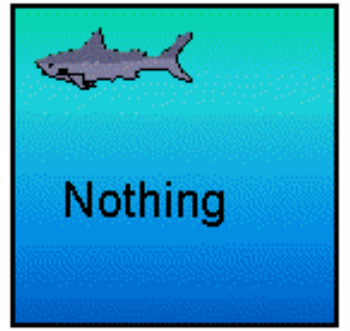

Maurer

Figure 13. New Seafloor Equipment Required

A $\$ 1.8$ million Phase I joint-industry project (JIP) to develop this system was conducted in 2001 and 2002 and funded by five service companies and three operators. A range of tests and analyses showed that hollow spheres could be pumped well, but difficulties were encountered in separating the spheres from a polymer mud supplied by Halliburton due to the high viscosity of this mud at the low shear rates encountered on oilfield shale shaker screens. As a result, an excessive amount of this polymer mud flowed across the screen with the beads instead of through the screen.

At the completion of the Phase I project, it was concluded that the hollow sphere system would not work effectively with the polymer muds tested. ExxonMobil and Shell engineers proposed that additional sphere separation tests be conducted with weighted oilfield waterbase and oilbase muds to determine if the DGD system would work with these types of mud.

The DOE agreed to furnish a $\$ 200,000$ grant for these follow-on tests. The DOE tests were very successful and are described in Chapters 3 through 9 . Results showed that spheres could be pumped with conventional oilfield centrifugal and triplex mud pumps and separated effectively using conventional oilfield shale shakers and hydrocyclones. 


\section{Flowline Pressure Drop Tests}

\subsection{PIPE RHEOMETER}

A series of tests was conducted to determine pressure drops within flowlines with hollow sphere muds to determine if these pressure drops are excessive. These tests were conducted using a Drilling Research Center (DRC) pipe rheometer (3 inch diameter $\times 14 \mathrm{ft}$ length) mounted on a stand with a centrifugal pump and EM flow meter (Figure 14).

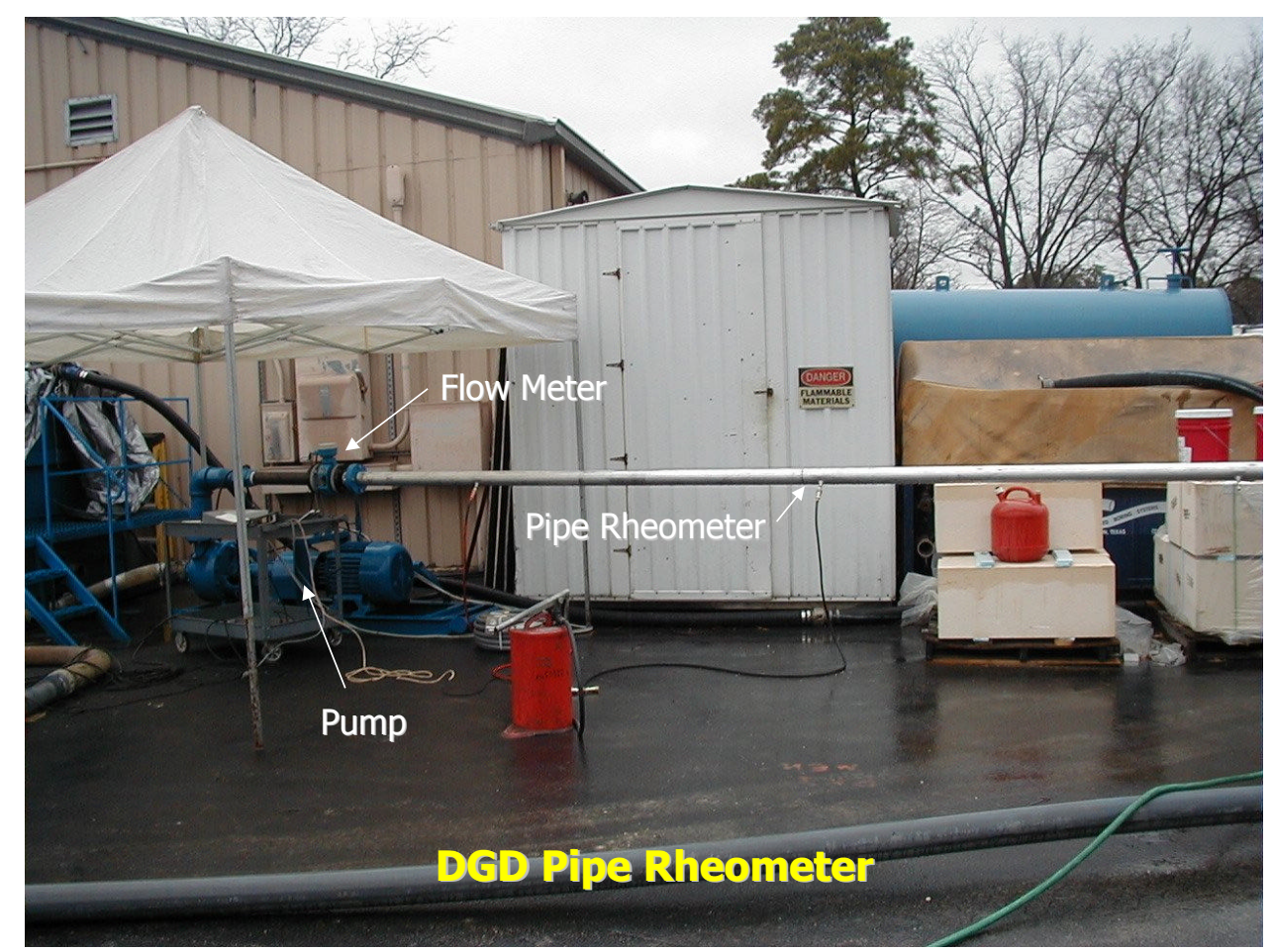

Figure 14. Pipe Rheometer for Measuring Pressure Drop

Viscosity of a mud/sphere mixture can be measured with a "pipe rheometer" by pumping the mud through a pipe and measuring the pressure drop along the pipe. Pipe rheometers with diameters of 1.059 inch, 2.068 inch, and 3.067 inch (all $14 \mathrm{ft}$ long) were developed for use on this DGD project.

The closer the diameter of the pipe rheometer tube is to the actual flowline diameter, the more accurate the pressure drop calculations. Therefore, most of the tests were conducted with the 3.067-inch rheometer since this diameter is closest to the 
4- to 6-inch diameter flowlines that would be used to pump mud/sphere mixtures to the seafloor.

Figure 15 shows the 6" $\times 4$ " centrifugal pump used to pump sphere mixtures through the pipe rheometer and an EM flowmeter.

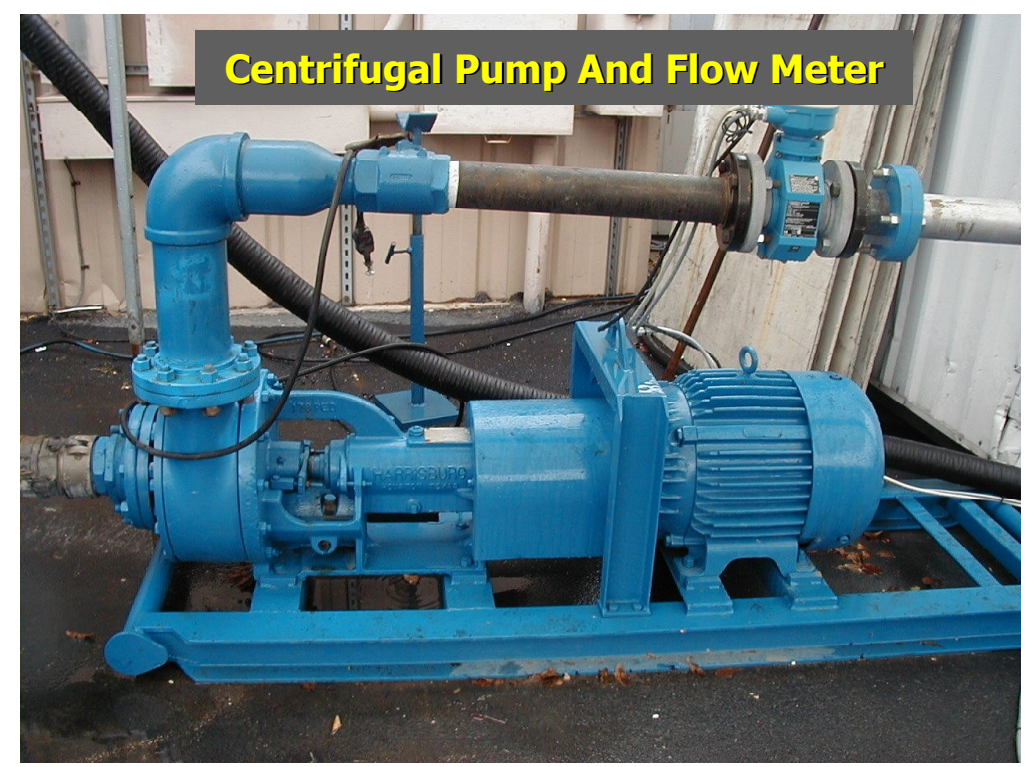

Figure 15. DRC Centrifugal Pump and Flowmeter

Figure 16 shows the differential pressure gauge used to measure pressure drop along the tube. Figure 17 shows the flowmeter and pressure recording instruments.

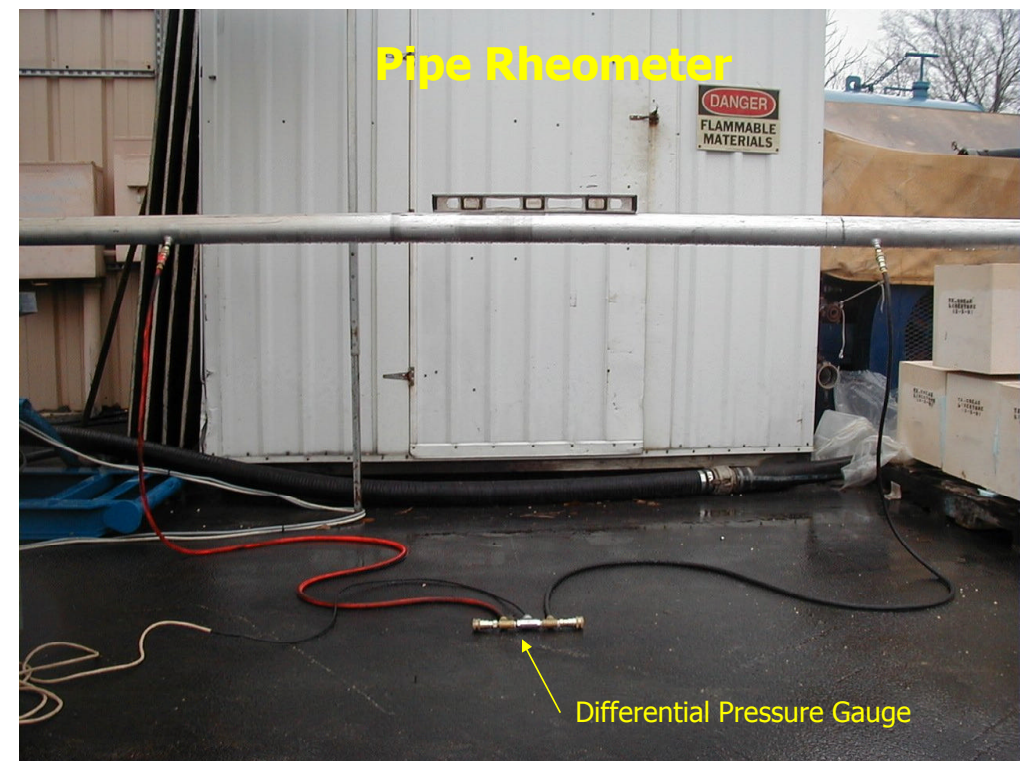

Figure 16. DRC Pipe Rheometer 


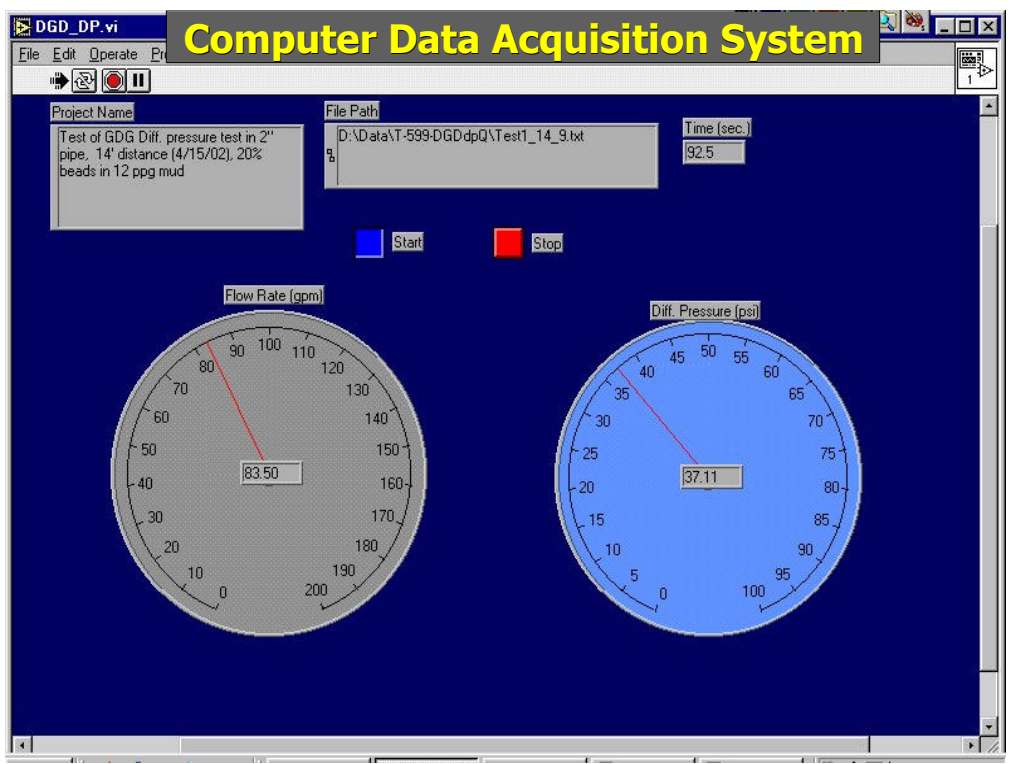

Figure 17. Rheometer Data-Acquisition System

\subsection{MUDS TESTED}

DOE funds were used to conduct shale shaker and hydrocyclones sphere separation tests with oilfield waterbase and synthetic muds provided by Halliburton (Table 1). Six-speed viscometer data for these muds are presented in Table 5 in Chapter 4.

Table 1. Test Mud Properties

\begin{tabular}{lcccrr|}
\hline Type & Weight & PV & YP & \multicolumn{2}{c|}{ Flotation Velocity (fpm) } \\
\hline & (ppg) & (cp) & (lbf/100 sq ft) & $3 \mathrm{M}$ & Balmoral \\
\hline Water & 8.33 & 1 & 0 & 22.10 & 46.5 \\
Polymer & 8.34 & 19 & 49 & 0.00 & 0.0 \\
Waterbase & 10.8 & 17 & 21 & 7.87 & 15.4 \\
WB \& Polymer & 9.9 & 15 & 32 & 0.50 & 3.0 \\
WB \& Polymer & 10.8 & 23 & 31 & 0.67 & 10.0 \\
WB \& Polymer & 12.0 & 29 & 21 & 0.75 & 17.1 \\
Synthetic Oil & 12.8 & 112 & 96 & 0.05 & 0.2 \\
\hline
\end{tabular}

WB $=$ Waterbase Mud (Bentonite)

1. Mud used with DRC Shaker Tests (Chapter 6) and Flowline Pressure Drop Tests (Chapter 3) 2.Mud used with Varco Shaker Tests (Chapter 5) and Flowline Pressure Drop Tests (Chapter 3) 
The waterbase and synthetic oil muds were Halliburton rental muds, so they are representative of muds used on offshore wells.

\subsection{FLUID FLOW REGIMES}

When the flow rate of a fluid is increased in a pipe, the flow transitions from "laminar" to "turbulent" flow regimes as illustrated in Figure 18.

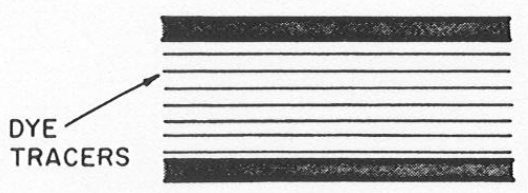

Laminar Flow

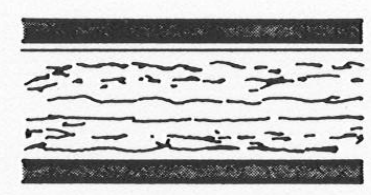

Transition Flow

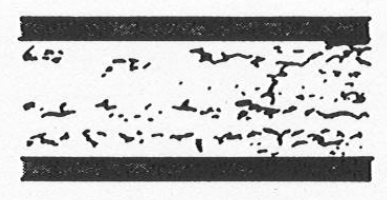

Turbulent Flow

Figure 18. Fluid Flow Regimes

At low flow rates, the fluid is in "laminar" flow where the fluid particles move parallel to the pipe walls and the pressure drops are typically low and vary as:

$$
\Delta p \propto(\text { Flow Rate })^{1.0} \quad \text { Laminar Flow }
$$

At high flow rates, the fluid is in "turbulent" flow where the fluid particles move in a chaotic, diffused manner. Here, pressure losses are high and vary as:

$$
\Delta p \propto(\text { Flow Rate })^{1.75}
$$

Turbulent Flow

Flow transitions from laminar to turbulent flow at Reynolds numbers of about 2100. Appendix A ("DGD Software Mathematics") in the DGD Phase I Final Report includes more details on Reynolds Number and pressure drop calculations.

Eqs. 4-1 and 4-2 show that the pressure drop with laminar flow increases with flow rate to the 1.0 power, whereas with turbulent flow pressure drop increases with flow rate to the 1.75 power. As a result, pressure drops can be very high with turbulent flow (e.g., in drillpipe and flowlines) as shown in Figure 19. This shows that it is important to maintain flow in the laminar regime if possible. 


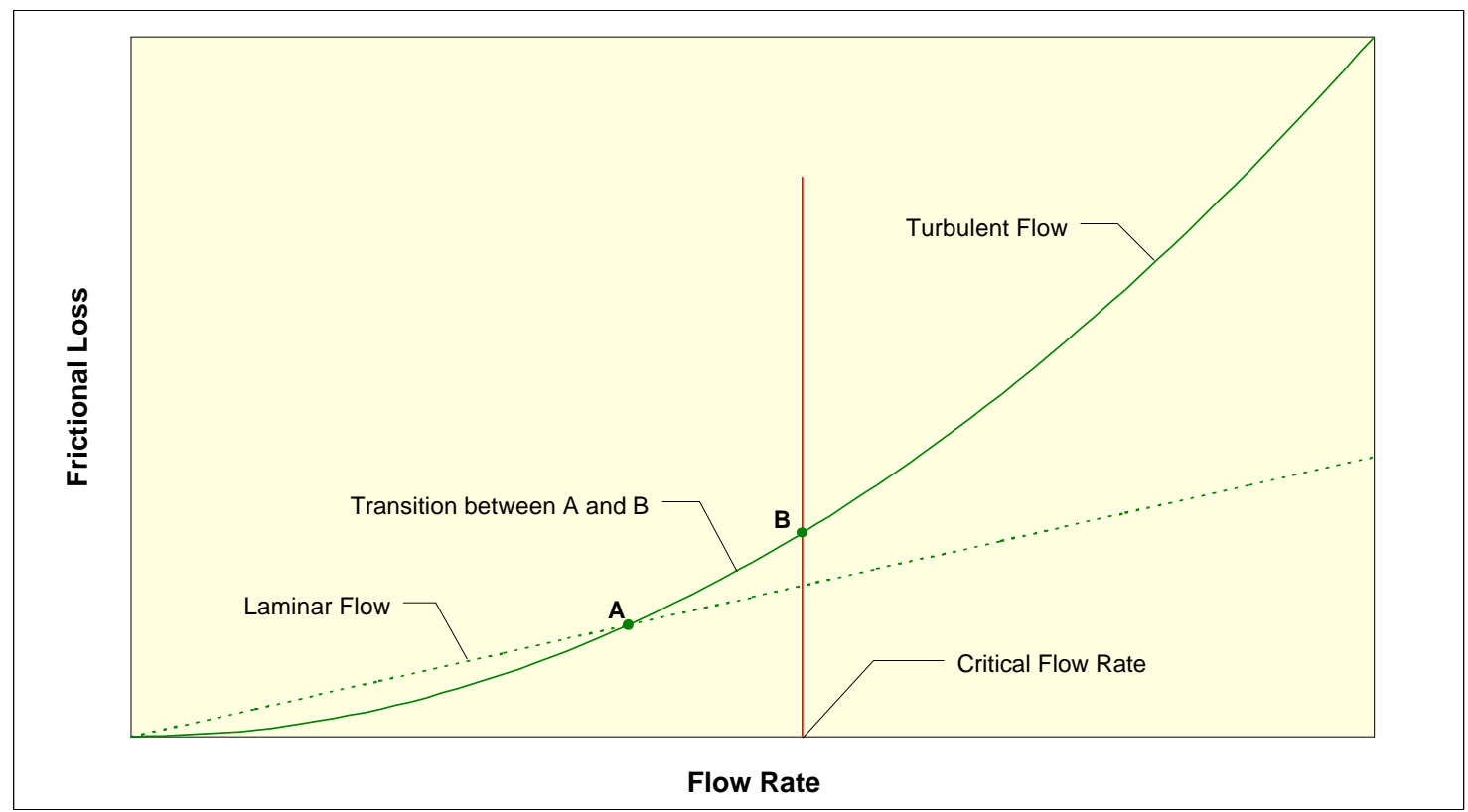

Figure 19. Effect of Flow Type on Pressure Drops

With laminar flow, pressure drop is controlled by the viscosity of the mud, whereas with turbulent flow it is controlled by the density of the mud. Consequently, the effects of the spheres decrease with turbulent flow.

Pipe and rheometer tests described in the next section show that spheres tend to delay the onset of turbulent flow. Therefore, at high flow rates, pressure drops with muds containing spheres can be lower than muds without spheres.

This was a surprising finding, because it was always assumed that the spheres would increase pressure drop. This phenomenon greatly enhances the potential of this DGD system.

\subsection{FRICTIONAL LOSSES IN PIPE}

Consider a fluid in a pipe with the following properties:

$$
\begin{array}{lll}
\rho & = & \text { Mud weight, ppg } \\
\mu & = & \text { Newtonian viscosity, } \mathrm{cp} \\
P V & = & \text { Plastic viscosity, } \mathrm{cp} \\
Y P & = & \text { Yield point, lbf/100sq.ft } \\
d & = & \text { Pipe diameter, inch }
\end{array}
$$


as well as the following flow parameters:

$\begin{array}{lll}\mathrm{v} & = & \text { Average flow velocity, } \mathrm{ft} / \mathrm{sec} \\ R e & = & \text { Reynolds number } \\ R e_{C} & = & \text { Critical Reynolds number } \\ \mathrm{He} & = & \text { Hedstrom number } \\ f & = & \text { Fann friction factor } \\ d P / d L= & \text { Frictional loss, psi/ft }\end{array}$

Mathematical development of frictional loss for fluid flow in circular straight pipes is well established (e.g., Bourgoyne et al., 1984). The equations for Newtonian, Bingham, and power-law fluids are summarized here.

\subsubsection{Laminar Flow}

In laminar flow, pressure drop per unit length of hole $\frac{\mathrm{dP}}{\mathrm{dL}}$ is controlled by the viscosity of the fluid and varies as:

$$
\frac{d P}{d L}= \begin{cases}\frac{\mu v}{1,500 d^{2}} & \text { Newtonian } \\ \frac{P V v}{1,500 d^{2}}+\frac{Y P}{225 d} & \text { Bingham }\end{cases}
$$

\subsubsection{Turbulent Flow}

In turbulent flow, pressure drop per unit length $\frac{\mathrm{dP}}{\mathrm{dL}}$ for both Newtonian and Bingham fluids is controlled by the density of the fluid and varies as:

$$
\frac{d P}{d L}=\frac{f \rho v^{2}}{25.8 d}
$$

For smooth pipe and moderate Reynolds numbers, the following simplified equation is often used for Newtonian and Bingham fluids: 


$$
\frac{d P}{d L}=\frac{\rho^{0.75} v^{1.75} P V^{0.25}}{1,800 d^{1.25}}
$$

\subsubsection{Flow Pattern Transition}

The dimensionless Reynolds number is commonly used to determine the flow pattern. In field units, the Reynolds number can be calculated as

$$
\operatorname{Re}= \begin{cases}\frac{928 \rho v d}{\mu} & \text { Newtonian } \\ \frac{928 \rho v d}{\mathrm{PV}} & \text { Bingham }\end{cases}
$$

The transition from laminar flow to turbulent flow ("transition point" or "critical point") occurs when the Reynolds number exceeds the critical Reynolds number as defined below:

For Newtonian fluids:

$$
\operatorname{Re}_{C}=2,100
$$

For Bingham fluids:

$$
\operatorname{Re}_{\mathrm{C}}=1798.64-0.002 \mathrm{He}+15.7373 \sqrt{\mathrm{He}}+3.73 \times 10^{-11} \mathrm{He}^{2}
$$

where the Hedstrom number equals:

$$
\mathrm{He}=\frac{37,100 \rho \mathrm{YPd}^{2}}{\mathrm{PV}^{2}}
$$

\subsection{PIPE RHEOMETER TESTS (OILFIELD WATERBASE MUD)}

Halliburton provided waterbase and synthetic oil muds from its mud rental yard are part of the DOE add-on project. These muds are representative of muds used on offshore rigs.

Figure 20 shows that at $80 \mathrm{gpm}$, pressure drop in the 3-inch pipe rheometer was $0.022 \mathrm{psi} / \mathrm{ft}$ with the 10.8-ppg waterbase mud with no spheres, compared to $0.046 \mathrm{psi} / \mathrm{ft}$ with mud containing $25 \% 3 \mathrm{M}$ spheres (2 to $3 \mathrm{~mm}$ ) - a $109 \%$ increase. 


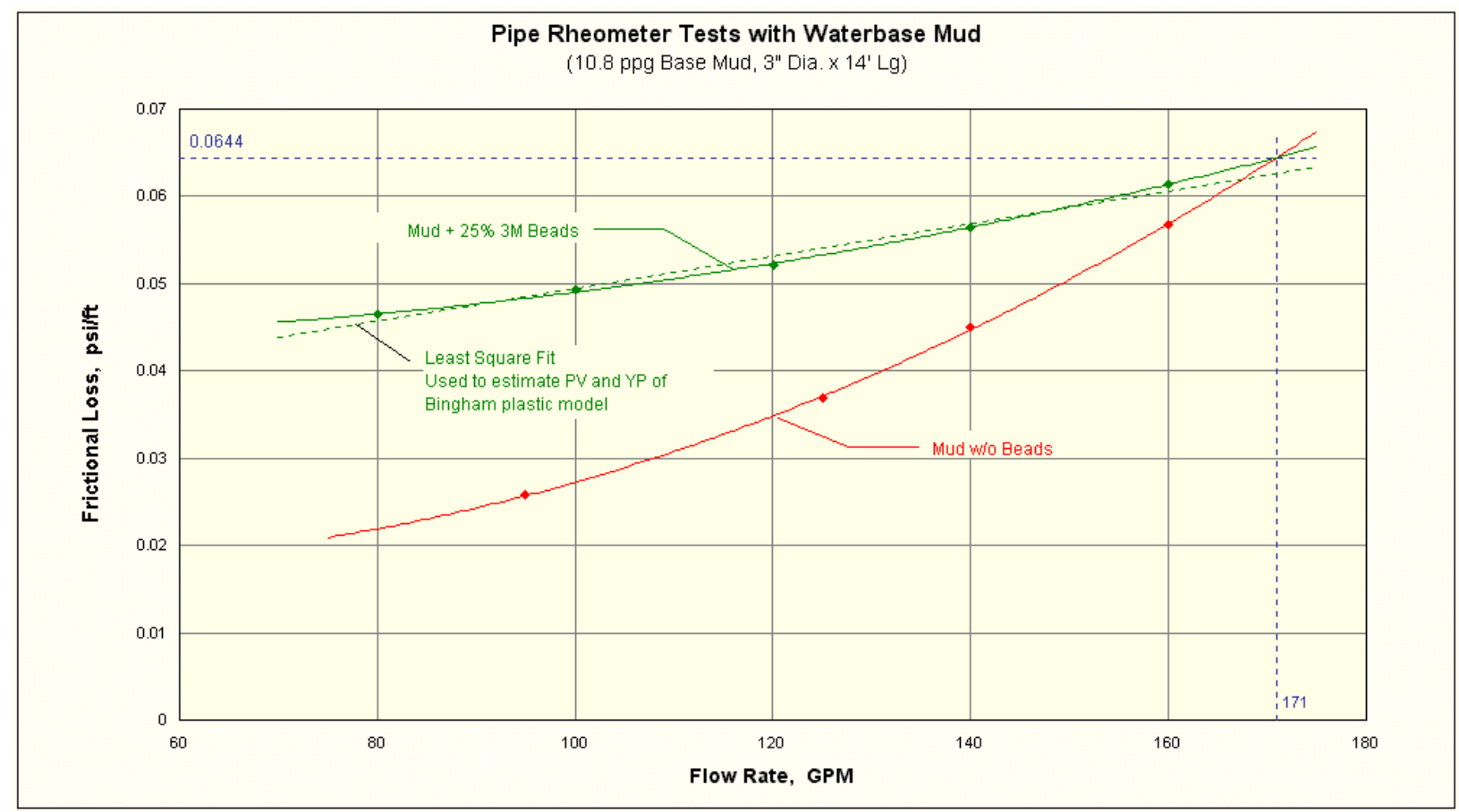

Figure 20. Pipe Rheometer Test (10.8-ppg Waterbase Mud)

As flow rate was increased, the curves become closer together because the mud without spheres is in turbulent flow (higher pressure drop) while the mud with $25 \%$ spheres remains in laminar flow.

At $171 \mathrm{gpm}$, pressure drops of the muds with and without spheres are equal at $0.0644 \mathrm{psi} / \mathrm{ft}$. This shows that at high flow rates, spheres have little effect on the pressure drop with this 10.8-ppg waterbase mud.

At $170 \mathrm{gpm}$ flow rate, pressure drop is $0.064 \mathrm{psi} / \mathrm{ft}$ with both fluids which corresponds to a pressure drop of only $384 \mathrm{psi} / \mathrm{ft}$ in a 6000 flowline. This low pressure drop shows that total pressure drops with the DGD system should not be excessive.

\subsection{SPHERE FLOTATION TESTS (WATERBASE MUD + POLYMER)}

Flotation tests (see Chapter 4) conducted with 10.8-ppg oilfield waterbase mud without polymer showed that sphere flotation velocities with $3 \mathrm{M}$ spheres (2 to $3 \mathrm{~mm}$ ) were excessive $(7.87 \mathrm{ft} / \mathrm{min})$. Addition of polymer to this mud reduced flotation velocity from 7.87 to less than $1 \mathrm{ft} / \mathrm{min}$ while keeping the pressure loss to acceptable levels. 
Figure 21 shows how pressure drop with 10.8-ppg mud with polymer increased as sphere concentration was increased from 0 to $50 \%$ and as flow rate was increased from 50 to $200 \mathrm{gpm}$.

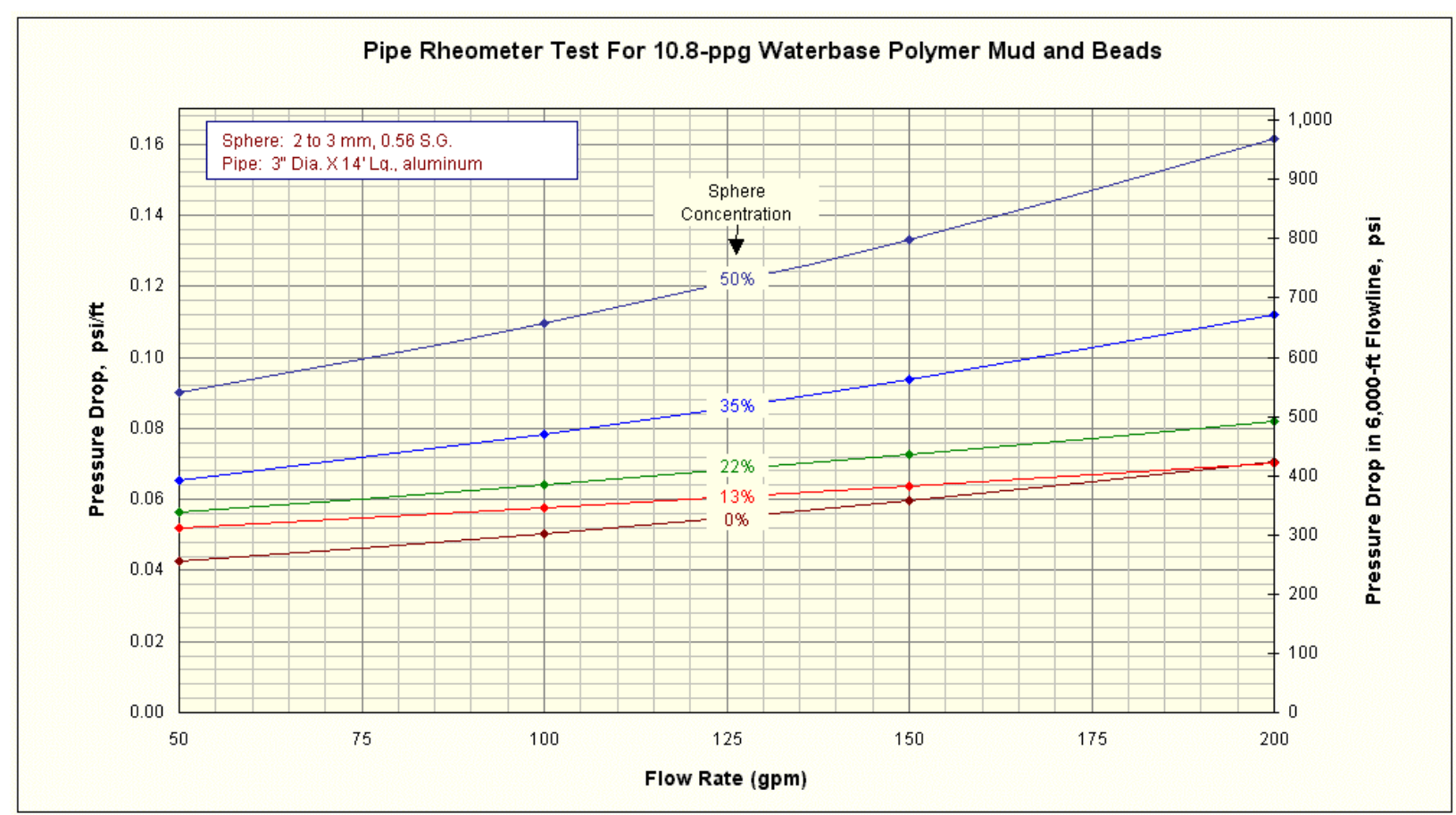

Figure 21. Pressure Drops for 10.8-ppg Waterbase Mud with Polymer

These pressure drops are similar to those for 10.8-ppg waterbase mud without spheres (see Figure 20), showing that the polymer significantly helps reduce sphere flotation without creating pressure drop problems.

Following these tests, barite was used to increase the density of this mud from 10.8 to $12.0 \mathrm{ppg}$. The pressure drops for this mud (Figure 22) were nearly identical to those for the 10.8-ppg mud. 


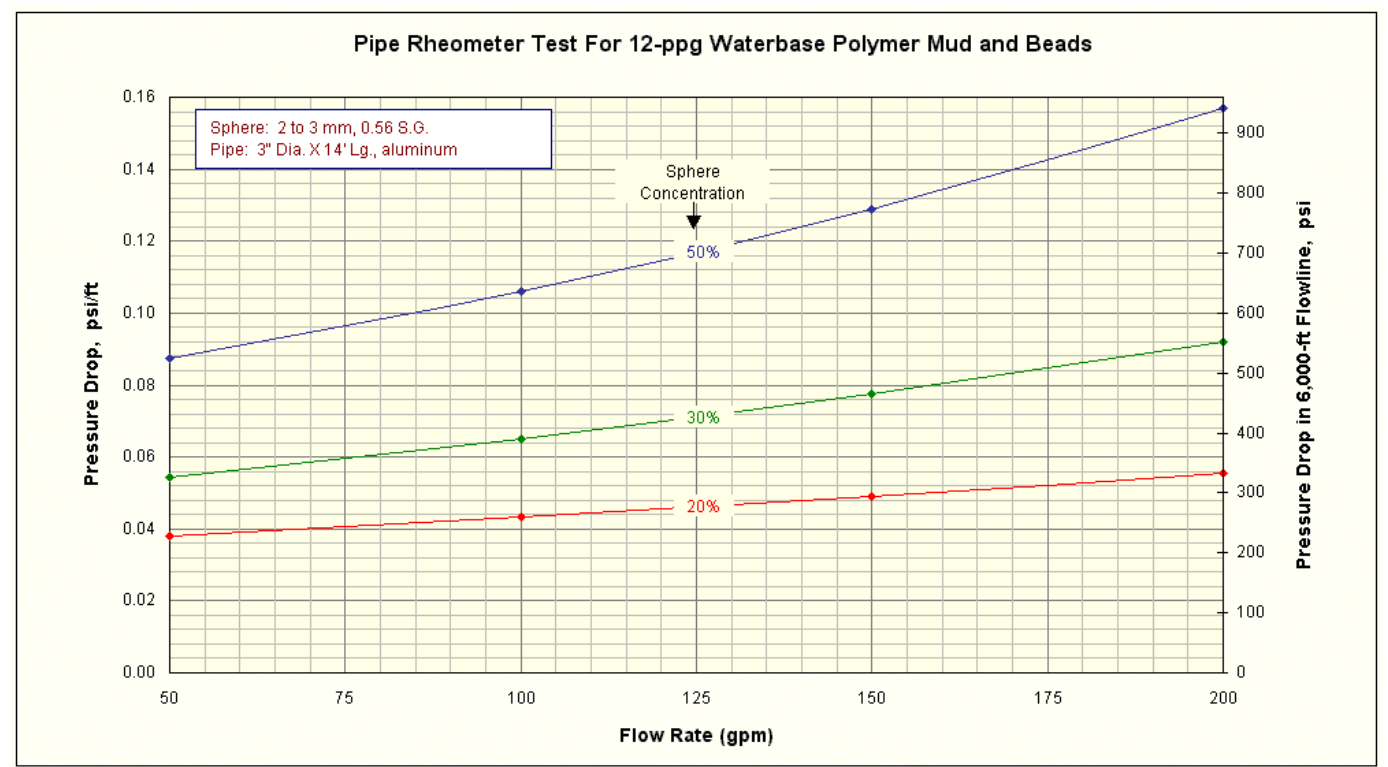

Figure 22. Pipe Rheometer Test (12-ppg Waterbase Polymer Mud)

These tests show that polymer can be added to waterbase muds to reduce sphere flotation velocities without producing excessive pressure drops.

\subsection{PIPE RHEOMETER TESTS (OILFIELD SYNTHETIC OIL MUD)}

Figure 23 shows pressure-drop data for a 12.8-ppg synthetic oil mud provided by Halliburton as part of the DOE add-on project.

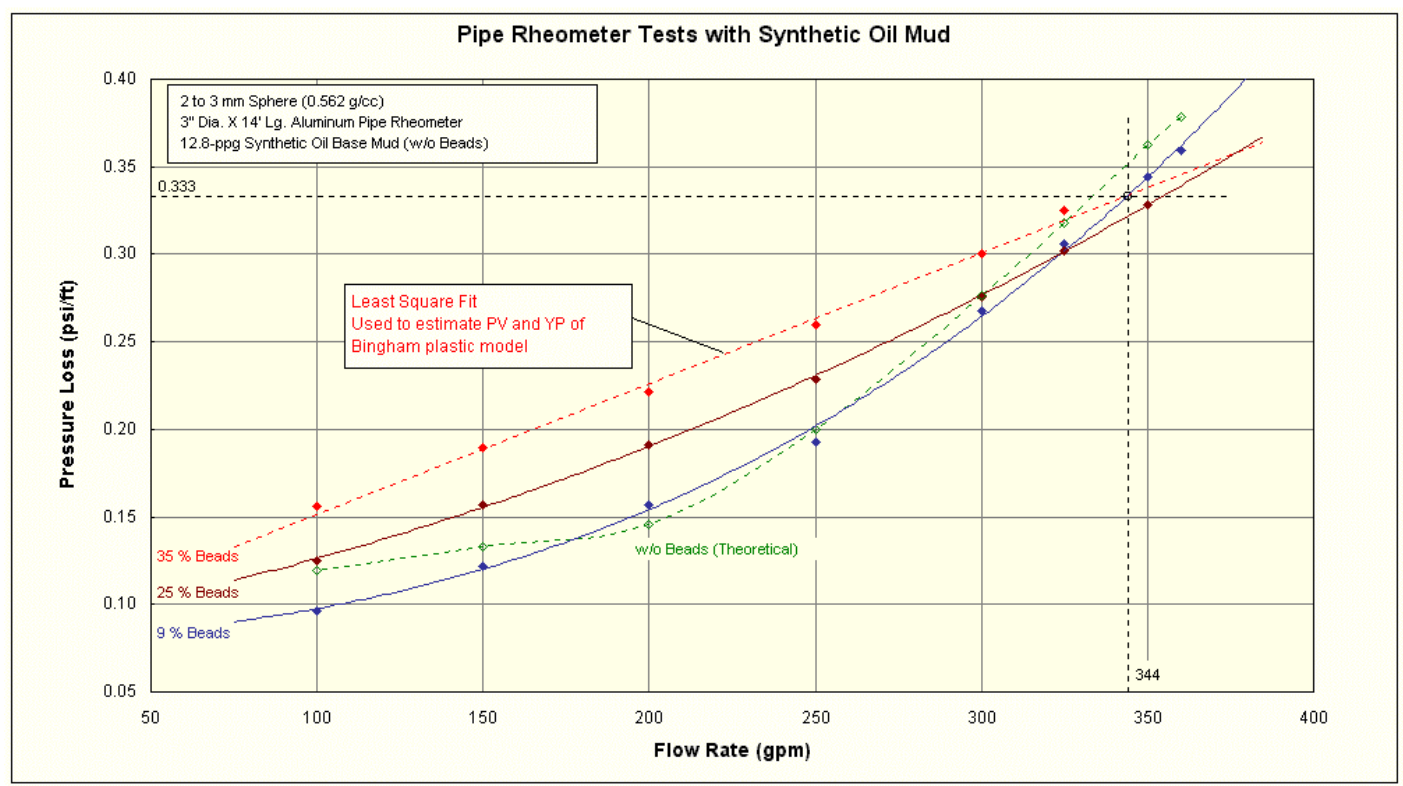

Figure 23. Pipe Rheometer Test (12.8-ppg Synthetic Oil Muds) 
At $100 \mathrm{gpm}$, the pressure drop with $35 \%$ spheres is $0.155 \mathrm{psi} / \mathrm{ft}$ compared to $0.095 \mathrm{psi} / \mathrm{ft}$ with no spheres - a $63 \%$ increase. A $0.155-\mathrm{psi} / \mathrm{ft}$ pressure drop corresponds to a 930-psi pressure drop in a 6000-ft flowline.

As flow rate is increased, the curves move closer together because mud containing $9 \%$ spheres transitions into turbulent flow. At $344 \mathrm{gpm}$, pressure drops with $9 \%$ spheres and $35 \%$ spheres are equal at $0.333 \mathrm{psi} / \mathrm{ft}$, showing that the spheres do not affect pressure drop at this high flow rate. This pressure drop corresponds to 2000-psi pressure drop in a 6000-ft flowline.

These tests show that spheres added to mud hinder the fluid's transition from laminar to turbulent flow and result in much smaller pressure drops than originally anticipated by most engineers.

\subsection{PRESSURE-DROP EXTRAPOLATIONS (WATERBASE MUD)}

Pressure drops for 10.8-ppg waterbase mud (25\% spheres) in the 3 -inch diameter pipe rheometer were extrapolated to 4 to 6 inch pipes using the least-squares fit curve in Figure 23 and the Bingham friction loss equations (Eqs. 4-3 to 4-9) as shown in Figure 24.

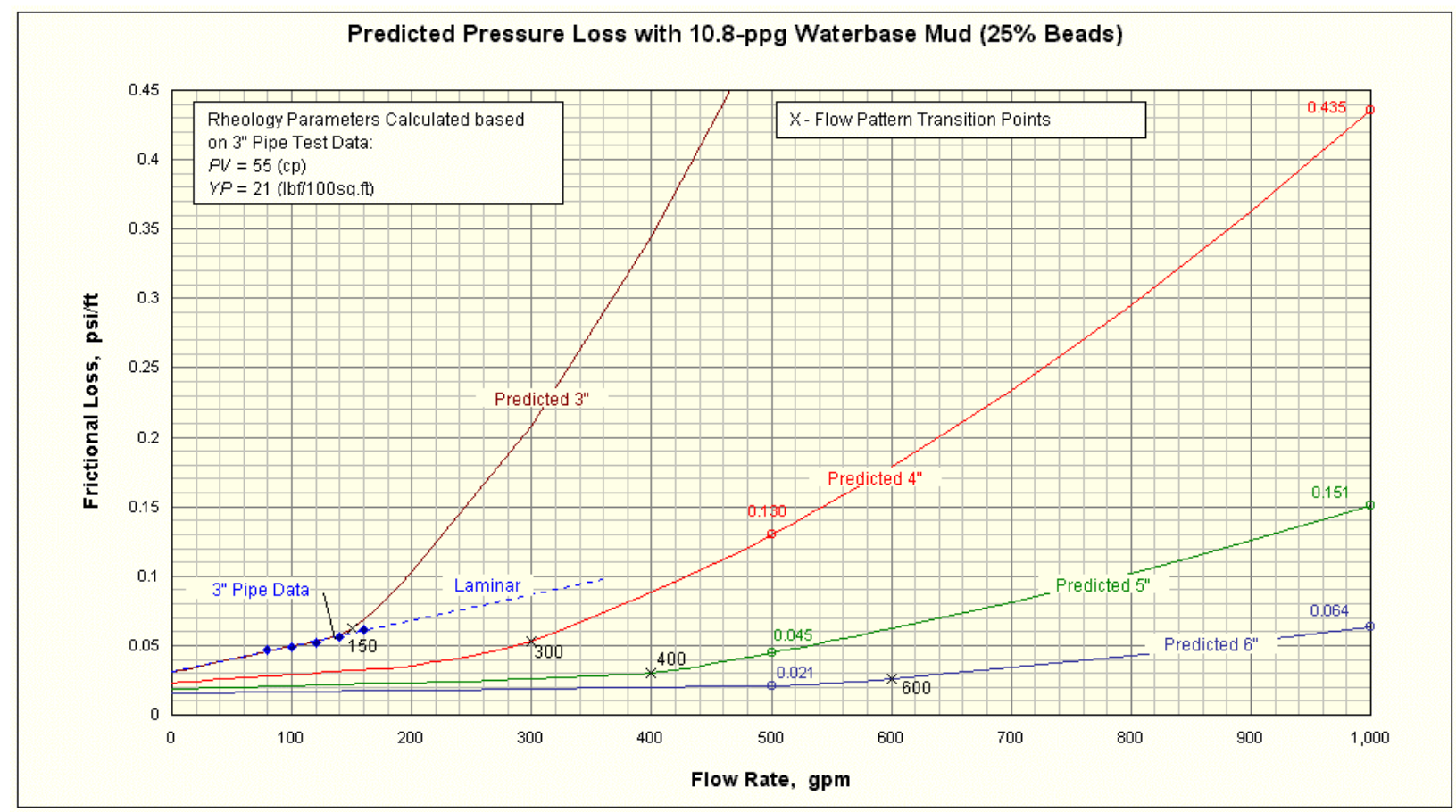

Figure 24. Predicted Pressure Drops with 10.8-ppg Waterbase Mud (25\% Spheres) 
Flow rates on the order of $1000 \mathrm{gpm}$ will be required in the sphere mixture flowlines. This $1000 \mathrm{gpm}$ flow can go through one flowline, or $500 \mathrm{gpm}$ can be pumped through each of two parallel flowlines. Predicted pressure drops for these cases are shown in Table 2.

\section{Table 2. Predicted Pressure Drops with 10.8-ppg Waterbase Mud (25\% Spheres)}

\begin{tabular}{|c|c|c|c|c|c|}
\hline $\begin{array}{c}\text { Number } \\
\text { Flowlines }\end{array}$ & $\begin{array}{c}\text { Flowline } \\
\text { Diameter } \\
\text { (inches) }\end{array}$ & $\begin{array}{c}\text { Flow } \\
\text { Rate } \\
(\mathrm{gpm})\end{array}$ & $\begin{array}{c}\text { Total } \\
\text { Flow } \\
(\mathrm{gpm})\end{array}$ & $\begin{array}{c}\text { Pressure } \\
\text { Drop } \\
(\mathrm{ps} / \mathrm{ft})\end{array}$ & $\begin{array}{c}\text { Pressure Drop } \\
6000 \mathrm{ft} \\
(\mathrm{psi})\end{array}$ \\
\hline 1 & 4 & 1000 & 1000 & 0.440 & 2640 \\
\hline 1 & 5 & 1000 & 1000 & 0.151 & 906 \\
\hline 1 & 6 & 1000 & 1000 & 0.064 & 384 \\
\hline \multicolumn{5}{|l}{} \\
\hline 2 & 4 & 500 & 1000 & 0.130 & 780 \\
\hline 2 & 5 & 500 & 1000 & 0.045 & 270 \\
\hline 2 & 6 & 500 & 1000 & 0.021 & 126 \\
\hline
\end{tabular}

Table 2 shows that pressure drops in a 6000-ft water depth can be kept below 1000 psi with this 10.8-ppg waterbase mud by using single 5- or 6 -inch flowlines or two 4-inch flowlines.

The 10.8-ppg oilfield waterbase mud used in these tests had very low viscosity, so sphere flotation velocities with $3 \mathrm{M}$ and Balmoral spheres were excessive (i.e., 7.9 and $15.4 \mathrm{ft} / \mathrm{min}$, respectively, as shown in Chapter 4 - Sphere Flotation Tests). As a result, viscosifiers such as bentonite or polymer would have to be added to this field mud to reduce sphere flotation velocity to less than $2 \mathrm{ft} / \mathrm{min}$. Pressure drop tests described below with synthetic oil mud, which had much high viscosity and low sphere flotation velocities (i.e., less than $1 . \mathrm{ft} / \mathrm{min}$ ), showed that this can be done while still keeping pressure drops within acceptable limits.

\subsection{PRESSURE-DROP EXTRAPOLATIONS (SYNTHETIC OIL MUD)}

Data recorded in the 3-inch pipe rheometer were used to extrapolate pressure drops for 12.8-ppg synthetic oil mud (35\% spheres) in 4- to 6-inch flowlines as shown in Figure 25 and Table 3 . The least-squares fit curve in Figure 23 and Bingham friction loss equations (Eqs. 4-3 to 4-9) were used to make these calculations. 


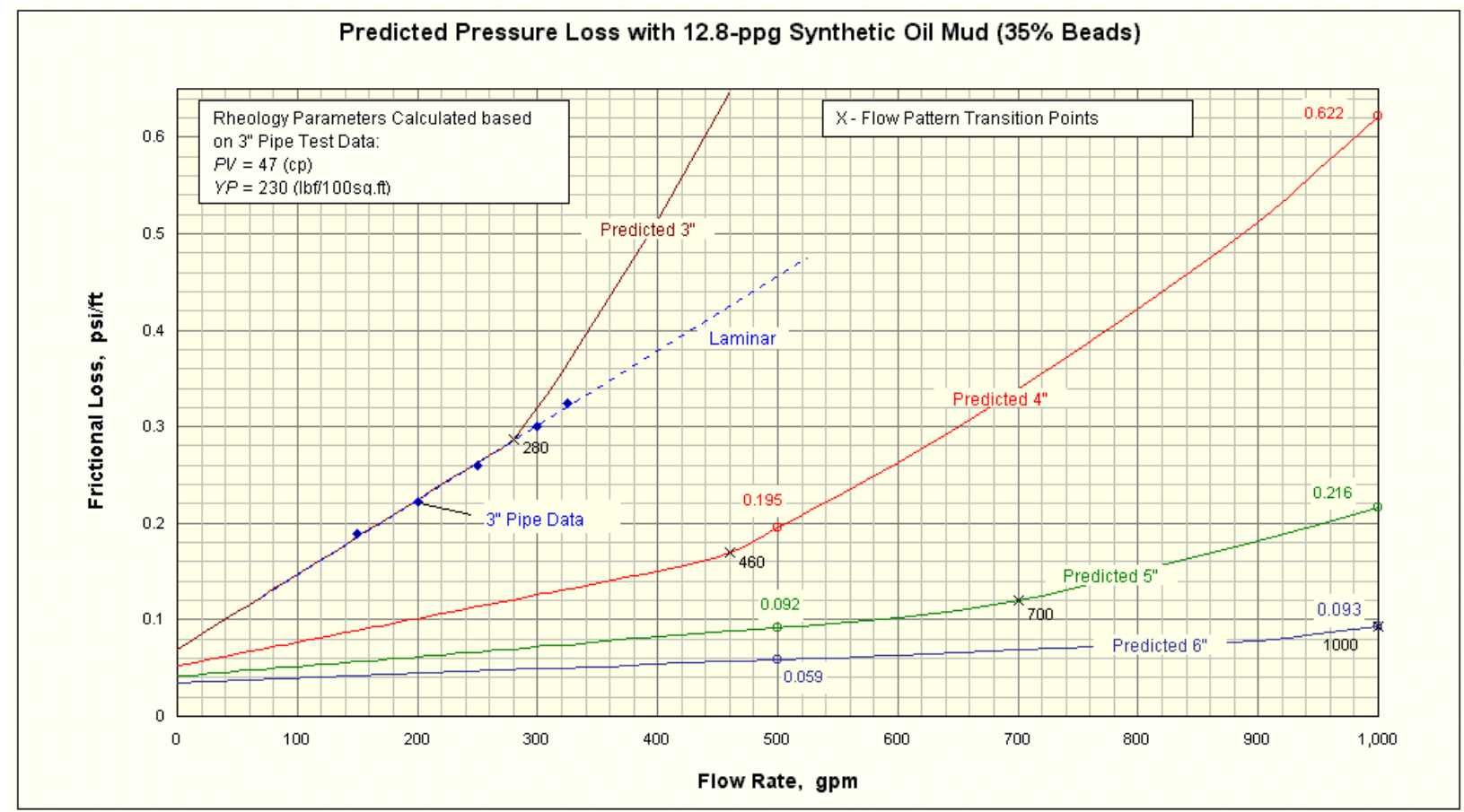

Figure 25. Predicted Pressure Drops with 12.8-ppg Synthetic Oil Mud (35\% Spheres)

Table 3. Predicted Pressure Drops with 12.8-ppg Synthetic Oil Mud (35\% Spheres)

\begin{tabular}{|c|c|c|c|c|c|}
\hline $\begin{array}{c}\text { Number } \\
\text { Flowlines }\end{array}$ & $\begin{array}{c}\text { Flowline } \\
\text { Diameter } \\
\text { (inches) }\end{array}$ & $\begin{array}{c}\text { Flow } \\
\text { Rate } \\
(\mathrm{gpm})\end{array}$ & $\begin{array}{c}\text { Total } \\
\text { Flow } \\
(\mathrm{gpm})\end{array}$ & $\begin{array}{c}\text { Pressure } \\
\text { Drop } \\
(\mathrm{psi} / \mathrm{ft})\end{array}$ & $\begin{array}{c}\text { Pressure Drop } \\
6000 \mathrm{ft} \\
(\mathrm{psi})\end{array}$ \\
\hline 1 & 4 & 1000 & 1000 & 0.625 & 3750 \\
\hline 1 & 5 & 1000 & 1000 & 0.217 & 1302 \\
\hline 1 & 6 & 1000 & 1000 & 0.093 & 558 \\
\hline \multicolumn{5}{|l|}{} \\
\hline 2 & 4 & 500 & 1000 & 0.196 & 1176 \\
\hline 2 & 5 & 500 & 1000 & 0.092 & 552 \\
\hline & 6 & 500 & 1000 & 0.059 & 354 \\
\hline
\end{tabular}

Table 3 shows that pressure drops with 12.8-ppg synthetic oil mud are greater than with 10.8-ppg waterbase mud, but are still without acceptable limits.

With $1000 \mathrm{gpm}$ total flow, a single 5-inch flowline would have a 1302-psi pressure drop, whereas two 4-inch flowlines with $500 \mathrm{gpm}$ flow each would have 1176psi pressure drops, both of which are within acceptable limits. 
This 12.8-ppg synthetic oil mud limits sphere flotation velocity to less than 1 $\mathrm{ft} / \mathrm{min}$ and has acceptable pressure drops, so it is an ideal mud for sphere-based DGD drilling.

\subsection{HIGHER SPHERE CONCENTRATIONS}

Tests were conducted with 25 to $35 \%$ sphere concentrations. These tests show that frictional pressure drops may be 20 to $30 \%$ higher with $50 \%$ sphere concentrations in laminar flow, but are only marginally higher in turbulent flow.

\subsection{U-TUBE EFFECT}

In addition to the friction losses calculated above, there is a u-tube effect that produces additional pressure that must also be overcome by the sphere mixture mud pump. This u-tube pressure is due to the mud in the riser being heavier than the sphere mixture being pumped down the flowline:

This u-tube $P_{u}$ pressure equals:

$$
P_{u}=0.052 \times \text { mud weight }(p p g) \times \text { riser length }(f t)
$$

For example, if mud in the riser weighs $3 \mathrm{ppg}$ more than the sphere mixture in the flowline, u-tube pressure $\mathrm{P}_{\mathrm{u}}$ in a 6000 -ft riser will equal:

$$
P_{u}=0.052 \times 3 \times 6000=936 p s i
$$

This u-tube pressure must be added to the frictional pressure drop to determine the sphere mixture pump pressure. For example, if frictional losses with waterbase mud are 1000 psi, total pump pressure will be 1936 psi $(1000+936$ psi) for the above example.

This analysis shows that spheres can be pumped with conventional oilfield mud pumps capable of pressures up to 5000 psi. 


\subsection{CONCLUSIONS}

1. At low flow rates, addition of 25 to $35 \%$ spheres approximately doubles the pressure drop in flowlines since pressure drops with laminar flow are controlled by mud viscosity.

2. As flow rates are increased, mud without spheres transitions into turbulent flow sooner where pressure drop is controlled by density of the mud. Pressure drop increases rapidly with increased flow rate.

3. Spheres maintain muds in laminar flow at higher flow rates. As a result, at high flow rates, pressure drops with spheres can be lower than without.

4. At $170 \mathrm{gpm}$, pressure drop in a 3-inch pipe with 10.8-ppg waterbase mud with and without spheres (25\%) was $0.064 \mathrm{psi} / \mathrm{ft}$, corresponding to a pressure drop of only $384 \mathrm{psi}$ in a $6000-\mathrm{ft}$ flowline to the seafloor.

5. At $350 \mathrm{gpm}$, pressure drop in a 3-inch pipe with 12.8-ppg synthetic oil mud was $0.353 \mathrm{psi} / \mathrm{ft}$ with and without spheres (35\%), corresponding to a pressure drop of $2118 \mathrm{psi}$ in a 6000 -ft flowline to the seafloor.

6. Pressure drop data recorded in a 3-inch pipe rheometer were used to extrapolate pressure drops in 4- to 6-inch flowlines. Extrapolations showed that with $1000 \mathrm{gpm}$ flow, friction pressure losses in flowlines can be kept below 1300 psi with waterbase or synthetic oil field muds using single 5- or 6 -inch flowlines or two parallel 4-inch flowlines.

7. In addition to friction losses, u-tubing due to heavier mud weight in the riser than in the flowline can create pressure differentials of up to $1000 \mathrm{psi}$.

8. Pressure required to pump spheres down a flowline equals friction pressure drop plus u-tube pressure, and will range from 1500 to $2500 \mathrm{psi}$, well within the capability of oilfield mud pumps which operate at pressures up to 5000 psi.

9. Doubling the size of a flowline reduces pressure drop by $89.4 \%$, so flowlines should be made as large as possible, or multiple flowlines should be used. 
10. Although pressure drops were not measured for larger Balmoral spheres (11 to $13 \mathrm{~mm}$ ), pressure drops with these spheres should not be significantly increased due to their large size.

11. Many engineers assumed that pressure drops with the sphere/mud mixture would be excessive and prevent commercialization of this DGD system. These tests clearly demonstrated that this is not the case. 


\section{Sphere Flotation Tests}

\subsection{TEST PROCEDURES}

Sphere flotation tests were conducted in a 10 -ft vertical plastic cylinder filled with water and mud (Figure 26) to determine if flotation velocities (i.e., speed of separation of the spheres from the mud) are excessive.

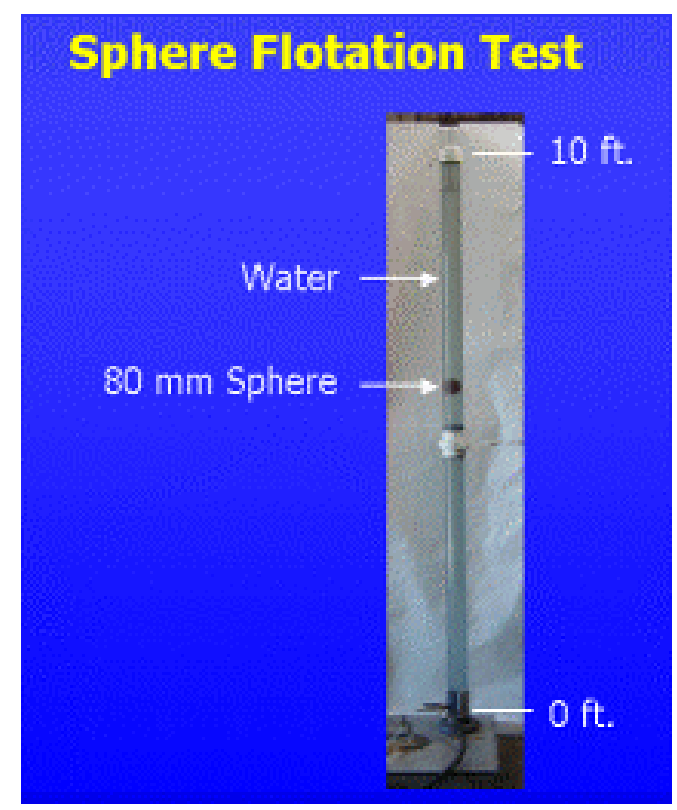

Figure 26. Sphere Flotation Test Apparatus

The spheres were released at the bottom of the cylinder and the time measured for the spheres to float to the top of the cylinder.

\subsection{MUDS TESTED}

DOE funds were used to conduct shale shaker and hydrocyclones sphere separation tests with oilfield waterbase and synthetic muds provided by Halliburton (Table 4). Sphere flotation velocities are shown in the table for comparison to mud properties. 
Table 4. Test Mud Properties

\begin{tabular}{|lcccrr|}
\hline Type & Weight & PV & YP & \multicolumn{2}{c|}{ Flotation Velocity (fpm) } \\
\hline & (ppg) & (cp) & (lbf/100 sq ft) & $3 \mathrm{M}$ & Balmoral \\
\hline Water & 8.33 & 1 & 0 & 22.10 & 46.5 \\
Polymer & 8.34 & 19 & 49 & 0.00 & 0.0 \\
Waterbase $^{1}$ & 10.8 & 17 & 21 & 7.87 & 15.4 \\
WB \& Polymer & 9.9 & 15 & 32 & 0.50 & 3.0 \\
WB \& Polymer & 10.8 & 23 & 31 & 0.67 & 10.0 \\
WB \& Polymer $^{2}$ & 12.0 & 29 & 21 & 0.75 & 17.1 \\
Synthetic Oil $^{2}$ & 12.8 & 112 & 96 & 0.05 & 0.2 \\
\hline
\end{tabular}

WB $=$ Waterbase Mud (Bentonite)

1. Mud used with DRC Shaker Tests (Chapter 6) and Flowline Pressure Drop Tests (Chapter 3) 2.Mud used with Varco Shaker Tests (Chapter 5) and Flowline Pressure Drop Tests (Chapter 3)

Table 5 shows six-speed viscometer data and Power Law model constants for the muds listed in Table 4.

Table 5. Six-Speed Viscometer Data

\begin{tabular}{|c|c|c|c|c|c|c|}
\hline Speed & $\begin{array}{c}8.34 \mathrm{ppg} \\
\text { Polymer }\end{array}$ & $\begin{array}{c}9.9 \mathrm{ppg} \\
\text { WE \& Polymer }\end{array}$ & $\begin{array}{c}10.8 \mathrm{ppg} \\
\text { Waterbase }^{1}\end{array}$ & $\begin{array}{c}10.8 \mathrm{ppg} \\
\text { WB \& Polymer }\end{array}$ & $\begin{array}{c}12.0 \mathrm{ppg} \\
\text { WB \& Polymer }\end{array}$ & $\begin{array}{c}12.8 \mathrm{ppg} \\
\text { Swnthetic Oil }\end{array}$ \\
\hline 600 & 87 & 62 & 55 & 77 & 79 & 320 \\
\hline 300 & 68 & 47 & 38 & 54 & 50 & 208 \\
\hline 200 & 59 & 41 & 31 & 44 & 39 & 160 \\
\hline 100 & 48 & 33 & 24 & 31 & 25 & 108 \\
\hline 60 & 42 & 29 & 20 & 24 & 19 & 82 \\
\hline 30 & 36 & 25 & 15 & 18 & 13 & 57 \\
\hline 6 & 24 & 16 & 9 & 8 & 7 & 26 \\
\hline 3 & 20 & 14 & 8 & 6 & 5 & 20 \\
\hline$n$ & 0.42 & 0.47 & 0.59 & 0.52 & 0.69 & 0.65 \\
\hline$K$ & 3.85 & 1.98 & 0.83 & 2.12 & 0.61 & 3.48 \\
\hline$T_{0}$ & 13.55 & 10.26 & 6.01 & 1.15 & 3.66 & 10.71 \\
\hline
\end{tabular}

WB $=$ Waterbase Mud (Bentonite) $\quad K=\mathrm{lbf} \mathrm{s}^{\mathrm{n}} / 100 \mathrm{ft}^{2} \quad T_{0}=\mathrm{lbf} / 100 \mathrm{ft}^{2}$

1 Mud used with DRC Shaker Tests and Flowline Pressure Drop Tests

2 Mud used with Varco Shaker Tests and Flowline Pressure Drop Tests 
The waterbase and synthetic oil muds used in the tests were Halliburton rental muds, so they are representative of muds used on offshore wells. The polymer mud was a special laboratory mud provided by Halliburton.

Sphere flotation tests were conducted in these muds because it is important to maintain flotation velocities of the spheres under about $1 \mathrm{ft} / \mathrm{min}$ in the riser so that they will not quickly float to the top of the riser when the well is shut in (e.g., connections, tripping, etc.).

DOE-funded tests showed that shale shakers and hydrocyclones can effectively remove spheres from 10.8-ppg waterbase and 12.8-ppg synthetic oil muds tested (see Chapters 5 and 6).

\subsection{FLOTATION TEST RESULTS}

Tests were conducted with $3 \mathrm{M}$ composite spheres ( 2 to $3 \mathrm{~mm} ; 0.56 \mathrm{SG}$ ) and Balmoral composite spheres ( 11 to $13 \mathrm{~mm} ; 0.51 \mathrm{SG}$ ) developed during the Phase I project. Sphere flotation velocities are shown in Figure 27 and Table 6.

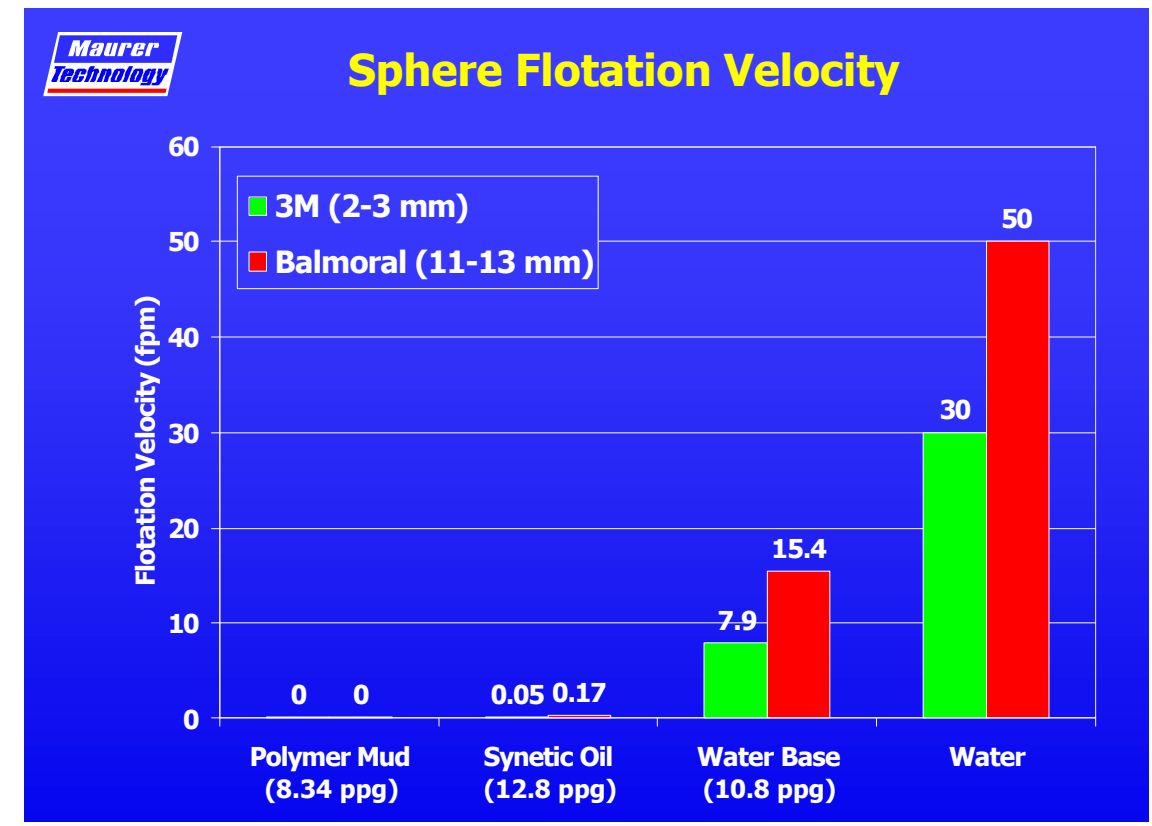

Figure 27. Sphere Flotation Velocities 
Table 6. Sphere Flotation Velocity Tests

\begin{tabular}{|c|c|c|c|c|c|c|c|c|c|}
\hline \multicolumn{4}{|c|}{ SPHERE } & \multicolumn{6}{|c|}{$\begin{array}{l}\text { FLOTATION VELOCITY } \\
\text { Theoretical }\end{array}$} \\
\hline Manufacturer & Density & Diameter & Type & Weight & Stokes & Moore & Chien & Tes & \\
\hline & $(\mathrm{g} / \mathrm{cc})$ & $(\mathrm{mm})$ & & (ppg) & & $(\mathrm{ft} / \mathrm{min})$ & & $(\mathrm{t} / \mathrm{min})$ & $(\mathrm{ft} / \mathrm{hr})$ \\
\hline $3 \mathrm{M}$ & 0.562 & 2.5 & $\begin{array}{l}\text { Water } \\
\text { Polymer } \\
\text { Waterbase } \\
\text { Synthetic Oil }\end{array}$ & $\begin{array}{l}8.34 \\
8.34 \\
10.8 \\
12.8\end{array}$ & $\begin{array}{c}31.12 \\
4.2 \\
10.1 \\
3.6\end{array}$ & $\begin{array}{l}19.49 \\
0.012 \\
0.124 \\
0.087\end{array}$ & $\begin{array}{l}17.38 \\
0.352 \\
1.82 \\
0.67\end{array}$ & $\begin{array}{c}22.1 \\
0 \\
7.87 \\
0.048\end{array}$ & $\begin{array}{c}1326 \\
0 \\
472 \\
2.88\end{array}$ \\
\hline Balmoral & 0.51 & 12 & $\begin{array}{l}\text { Water } \\
\text { Polymer } \\
\text { Waterbase } \\
\text { Synthetic Oil }\end{array}$ & $\begin{array}{l}8.34 \\
8.34 \\
10.8 \\
12.8 \\
\end{array}$ & $\begin{array}{c}1.45 \\
43.3 \\
68 \\
38 \\
\end{array}$ & $\begin{array}{c}0.74 \\
0.3 \\
3.1 \\
2.12 \\
\end{array}$ & $\begin{array}{l}0.69 \\
1.93 \\
9.67 \\
3.84 \\
\end{array}$ & $\begin{array}{c}46.5 \\
0 \\
15.4 \\
0.17 \\
\end{array}$ & $\begin{array}{c}2790 \\
0 \\
924 \\
10.2 \\
\end{array}$ \\
\hline
\end{tabular}

Table 6 shows that sphere flotation velocities are excessive with water (i.e., the spheres separate too quickly from the mud), but are acceptable with oilfield polymer and synthetic oil muds.

Measured flotation rates velocities were compared to theoretical values calculated with a computer model developed on the Phase I JIP. Different flotation models are more accurate for different fluids because the physics of the flotation process change as flotation velocities change. Gel strength of the polymer mud suspends the spheres, so none of the flotation models are appropriate in this case. Theoretical gel strengths required to suspend the spheres were calculated using equations from Bourgoyne et al.

\subsubsection{Flotation Tests (Waterbase Mud + Polymer)}

Flotation velocity of $3 \mathrm{M}$ spheres was excessive $(7.87 \mathrm{ft} / \mathrm{min})$ in 10.8-ppg oilfield waterbase mud (no polymer), so the 8.34 -ppg polymer and the 10.8-ppg waterbase muds were mixed together and barite added to form a 10.8-ppg mud containing both bentonite and polymer. This approach was followed since earlier tests showed that polymer significantly reduces sphere flotation velocities by increasing the low-shear-rate viscosity of muds.

Figure 28 and Table 6 show that adding polymer to 10.8-ppg bentonite waterbase mud reduced flotation velocity of $3 \mathrm{M}$ spheres from 7.87 to $0.67 \mathrm{ft} / \mathrm{min}$ and increased pressure drop from 0.057 to $0.095 \mathrm{psi} / \mathrm{ft}$, both within acceptable limits. 


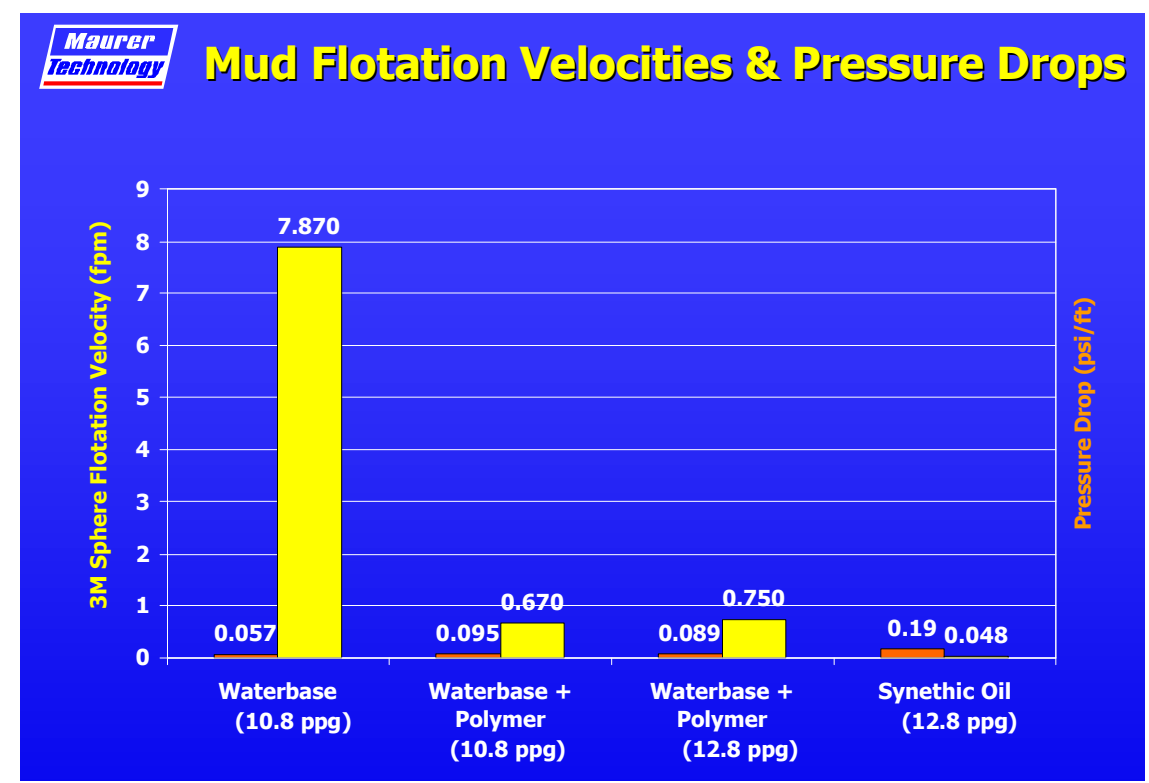

Figure 28. Effect of Polymer on Sphere Flotation Velocity

Barite was then added to the 10.8-ppg mud to increase density to $12.0 \mathrm{ppg}$. This change increased flotation velocity of the $3 \mathrm{M}$ spheres to $0.75 \mathrm{ft} / \mathrm{min}$ and reduced pressure drop to $0.089 \mathrm{psi} / \mathrm{ft}$, both acceptable values.

In both cases, pressure drops with waterbase muds containing polymer $(0.095$ and $0.089 \mathrm{psi} / \mathrm{ft}$, respectively) were about half that of 12.8 -ppg synthetic oil mud $(0.190$ $\mathrm{psi} / \mathrm{ft}$ ), showing that sphere flotation velocities with waterbase muds can be controlled with the addition of polymer while keeping pressure drops within acceptable limits.

\subsubsection{Flotation Tests (Water)}

Tests showed that flotation velocities of both $3 \mathrm{M}$ and Balmoral spheres were very high in water (22.1 and $46.5 \mathrm{ft} / \mathrm{min}$, respectively) due to the low viscosity of water and the fact that water has no gel strength. Flotation velocity should not exceed about 1 to 3 $\mathrm{ft} / \mathrm{min}$, if possible; otherwise, the spheres will float to the top of the riser and pile up there when circulation is stopped (e.g., during connections, trips or downtime).

\subsubsection{Flotation Tests (Polymer Mud)}

Tests conducted with an 8.34-ppg high-gel-strength polymer mud provided by Halliburton showed that this mud had sufficient gel strength to suspend $3 \mathrm{M}$ and Balmoral spheres indefinitely, so the flotation velocity was essentially zero (Figure 29). 

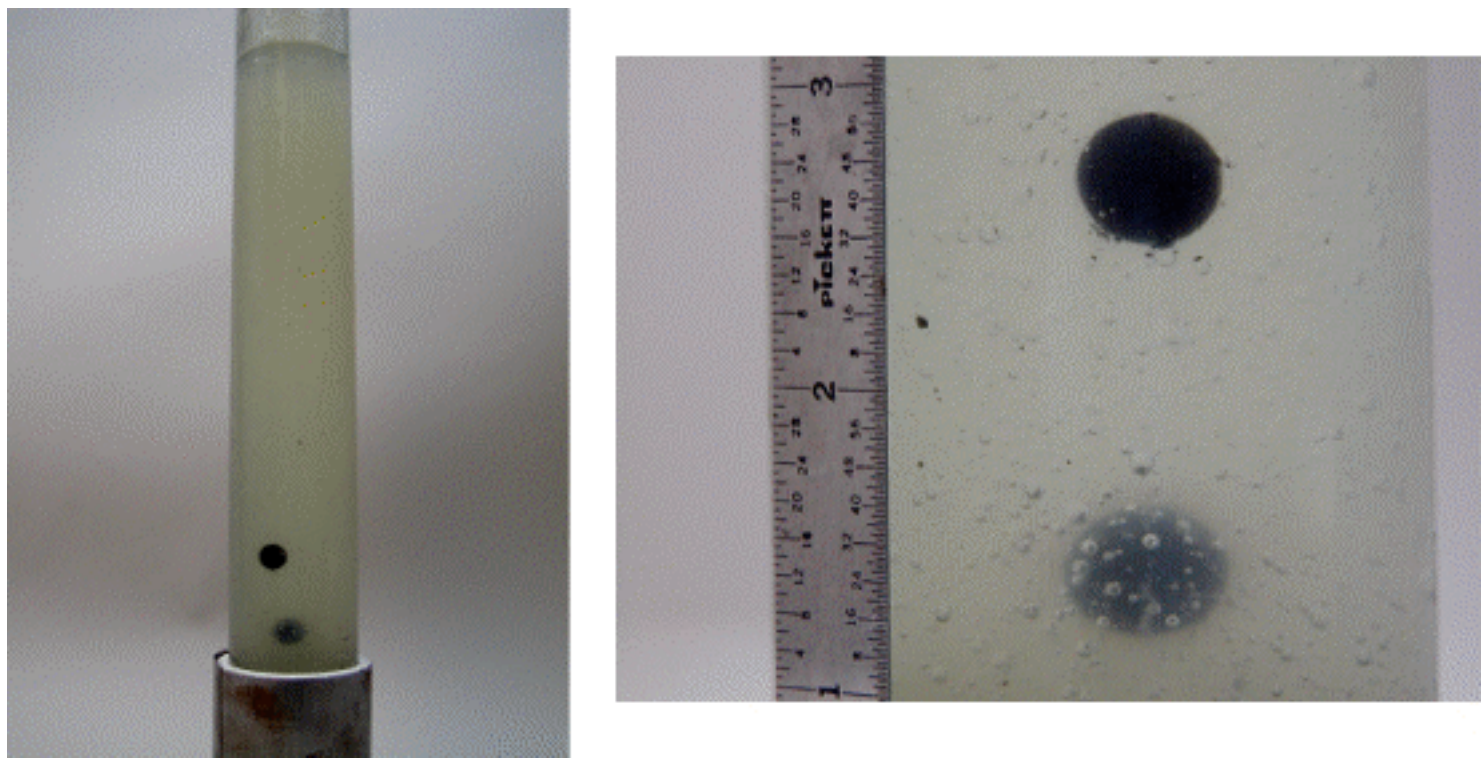

Figure 29. Balmoral Spheres Suspended in 8.34-ppg Polymer Mud

The 8.34-ppg polymer mud had excellent sphere suspension capabilities, but it did not perform well in shaker tests because most of this mud flowed over the 10- and 20-mesh screens due to high viscosity at low shear rates.

\subsubsection{Flotation Tests (Waterbase Mud)}

$3 \mathrm{M}$ spheres floated upward at $7.9 \mathrm{ft} / \mathrm{min}$ in 10.8-ppg waterbase mud (Figure 30 ). This 10.8-ppg waterbase mud supplied by Halliburton performed well in shaker and hydrocyclone tests.

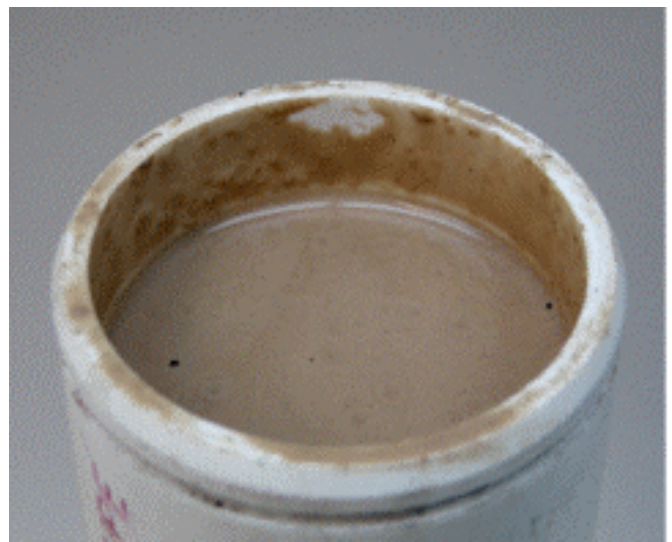

$t=0$

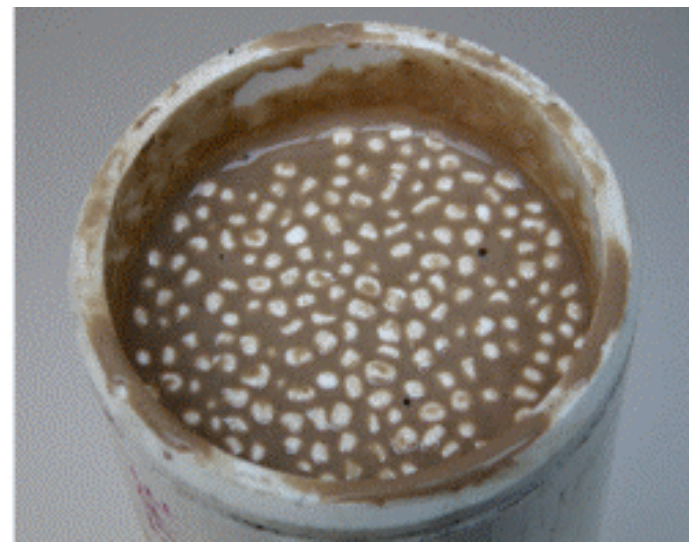

$t=21.6 \sec \left(34^{\prime \prime}\right)$

Figure 30. 3M Sphere Flotation in 10.8-ppg Waterbase Mud (7.87 ft/min) 
Balmoral spheres floated upward at $15.4 \mathrm{ft} / \mathrm{min}$ in the 10.8-ppg waterbase mud (Figure 31).

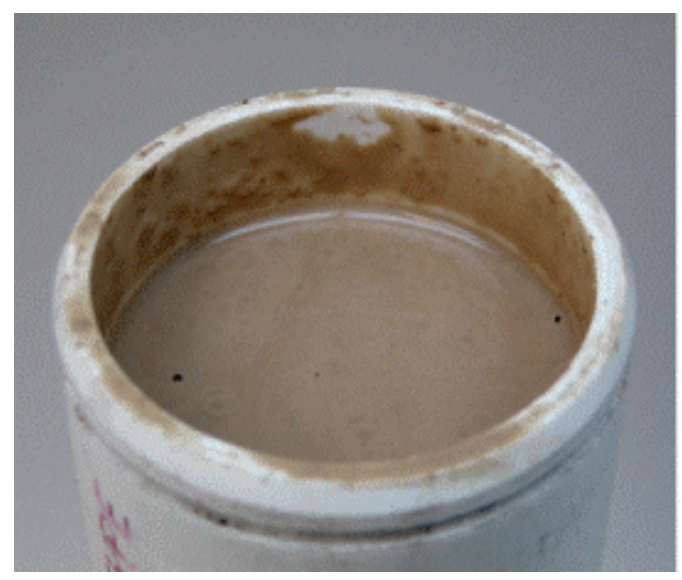

$$
t=0
$$

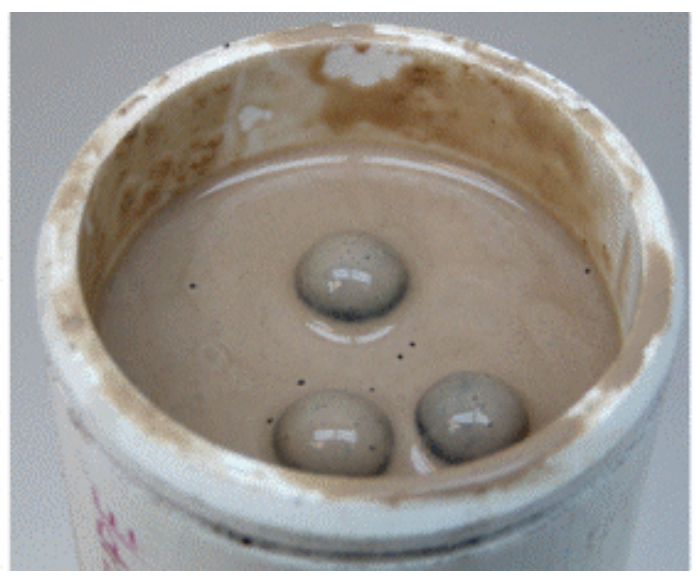

$t=21.8 \sec \left(67^{\prime \prime}\right)$

Figure 31. Balmoral Sphere Flotation in 10.8-ppg Waterbase mud (15.4 ft/min)

Flotation velocity was higher with Balmoral spheres due to their larger size and lower density. Tests with polymer mud showed that the flotation velocities of spheres in water can be brought to acceptable levels by adding polymer to the mud.

Although flotation velocities in oilfield waterbase mud were higher than desired, low flotation velocities with polymer and synthetic oil muds show that it should be possible to reduce flotation velocity in waterbase muds to acceptable levels by the addition of polymer or other viscosifers to the mud.

\subsubsection{Flotation Tests (Synthetic Oil Mud)}

$3 \mathrm{M}$ spheres floated upward at only $0.048 \mathrm{ft} / \mathrm{min}(2.9 \mathrm{ft} / \mathrm{hr})$ in 12.8-ppg synthetic oil mud from Halliburton's mud rental facility (Figure 32). 


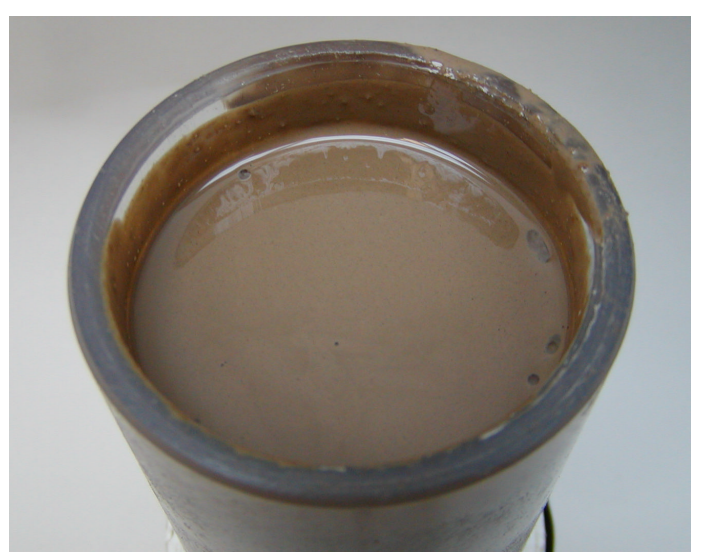

$t=0$

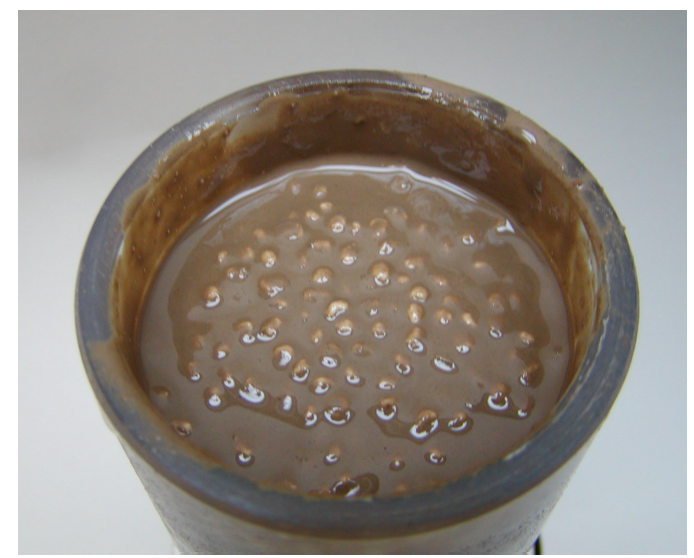

$t=24.7 \min \left(14^{\prime \prime}\right)$

Figure 32. 3M Sphere Flotation in 12.8-ppg Synthetic Oil Mud (0.048 ft/min)

This mud, which is representative of offshore synthetic oil muds, performed well in shaker and hydrocyclone tests. Balmoral spheres floated upward at $0.017 \mathrm{ft} / \mathrm{min}$ $(10.2 \mathrm{ft} / \mathrm{hr}$ ) in the same synthetic oil mud (Figure 33).

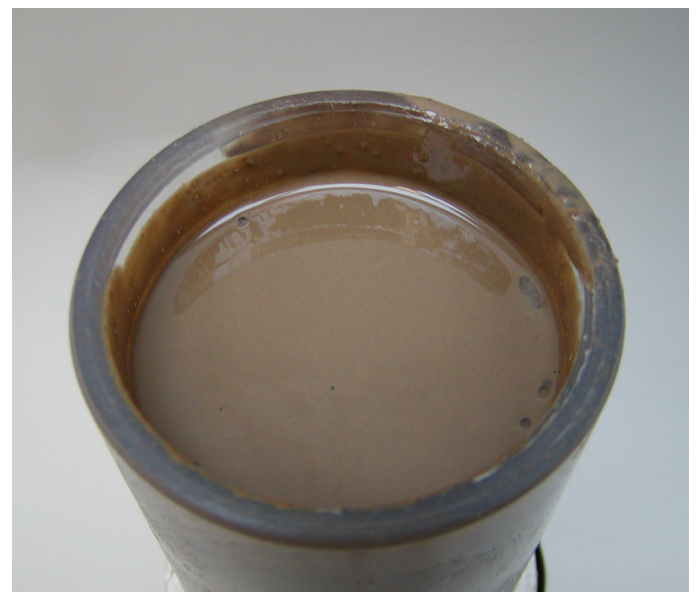

$t=0$

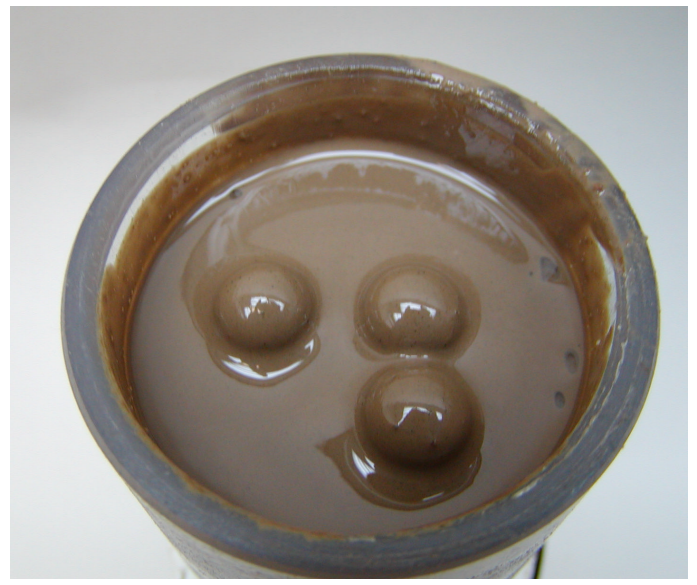

$t=24.9 \min (50 ")$

Figure 33. Balmoral Sphere Flotation in 12.8-ppg Synthetic Oil Mud (0.17 ft/min)

\subsection{CONCLUSIONS}

1. Flotation velocities of $3 \mathrm{M}$ and Balmoral spheres were excessive in water (22 and $46 \mathrm{ft} / \mathrm{min}$, respectively) due to water's low viscosity and lack of gel strength. 
2. $3 \mathrm{M}$ and Balmoral spheres were suspended indefinitely in 8.34-ppg polymer mud due to the high gel strength.

3. Flotation velocities of $3 \mathrm{M}$ and Balmoral spheres were very low (0.048 and $0.17 \mathrm{ft} / \mathrm{min}$, respectively) in 12.8-ppg synthetic oil mud.

4. Flotation velocities of $3 \mathrm{M}$ and Balmoral spheres were high in 10.8-ppg waterbase mud ( 7.87 and $15.4 \mathrm{ft} / \mathrm{min}$, respectively) due to the low viscosity and low gel strength of this mud.

5. Low flotation velocities of spheres in polymer and synthetic oil muds show that it should be possible to reduce flotation velocities in waterbase muds to acceptable levels by adding polymer or other viscosifiers.

6. These tests show that by proper mud design, controlling sphere flotation velocities to within acceptable levels should not be a major problem with oilfield muds. 


\section{Varco Shale Shaker Tests (Synthetic Oil Mud)}

\subsection{SHALE SHAKER TEST DESCRIPTION}

The ability to separate hollow spheres from mud at high flow rates (1000 to 2000 $\mathrm{gpm}$ ) is critical to the success of this DGD system. Tests were conducted at Varco as part of the DOE grant to determine if conventional oilfield shale shakers could be used to separate $3 \mathrm{M}$ spheres from DGD muds. Figure 34 shows a Varco King Cobra shaker used to separate $3 \mathrm{M}$ spheres from synthetic oil drilling mud at a feed rate of $720 \mathrm{gpm}$.

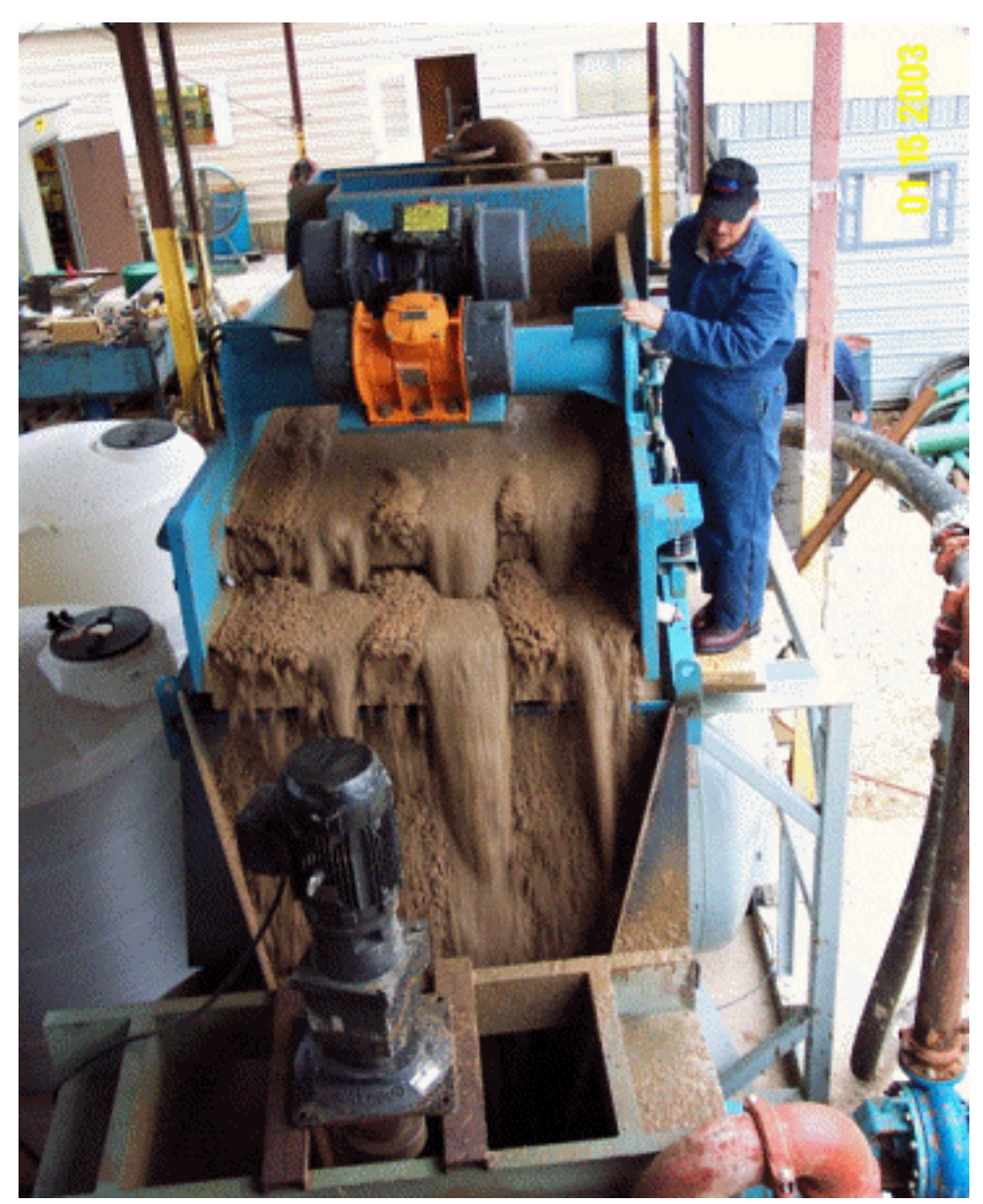

Figure 34. Varco King Cobra Shaker

Technical specifications for this shaker are summarized in Table 7. 
Table 7. Varco King Cobra Shale Shaker Specifications

\begin{tabular}{|l|l|}
\hline Model & King Cobra \\
\hline Vibration & Linear \\
\hline No. Screens & 4 \\
\hline Screen Angle & $0,+5^{\circ},+5^{\circ},+5^{\circ}$ \\
\hline Adjustable Angle & $-1^{\circ}$ to $+3^{\circ}$ \\
\hline Screen Area & $33.4 \mathrm{sq} \mathrm{ft}$ \\
\hline Screen Type & Pre-tensioned, Rigid Frame \\
\hline
\end{tabular}

Varco's shaker test stand (Figure 35) was used during these tests.

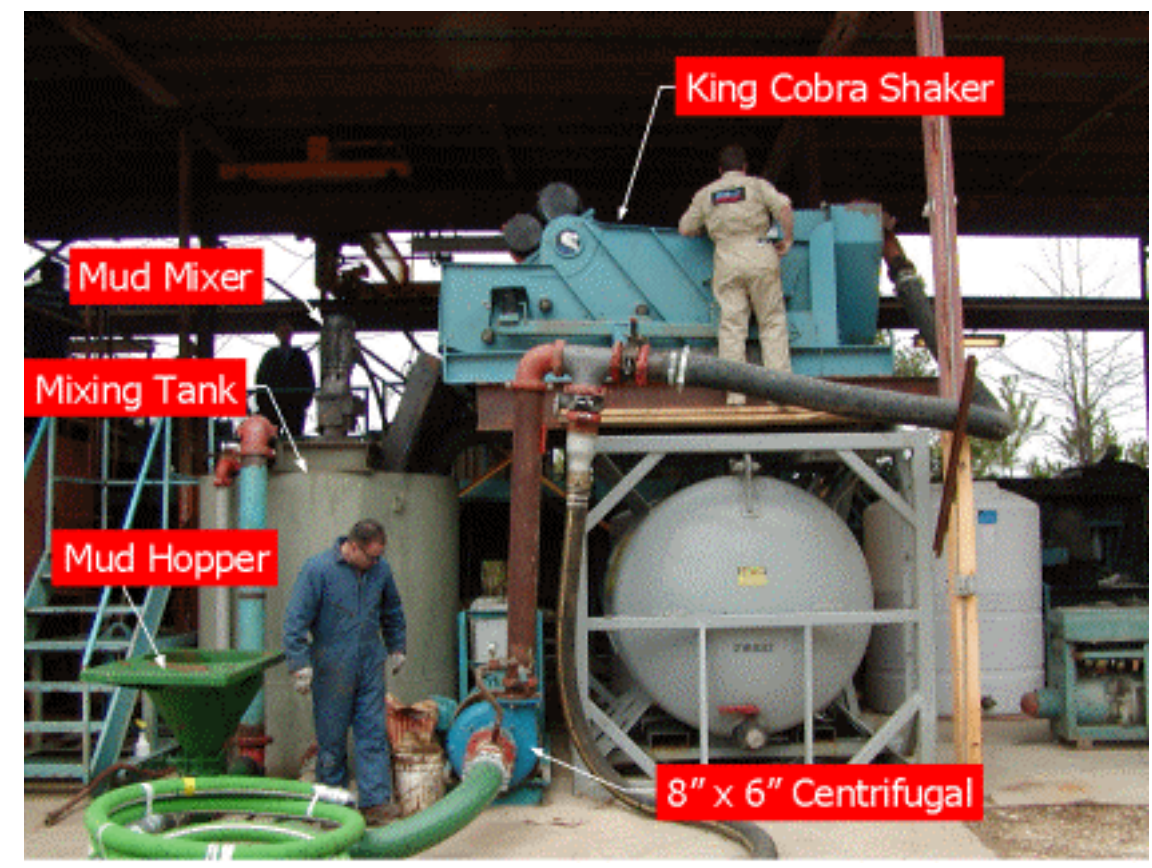

Figure 35. Varco Shaker Test Stand

An $8 \times 6$-inch magnum centrifugal pump was used to recirculate the sphere mixture from the cylindrical test tank to the shale shaker. An oilfield mud hopper was used to mix spheres into 12.8-ppg oilfield synthetic oil mud provided by Halliburton. A mud mixer on the cylindrical mixer tank kept the mud (25\% spheres) well mixed (Figure 36). 


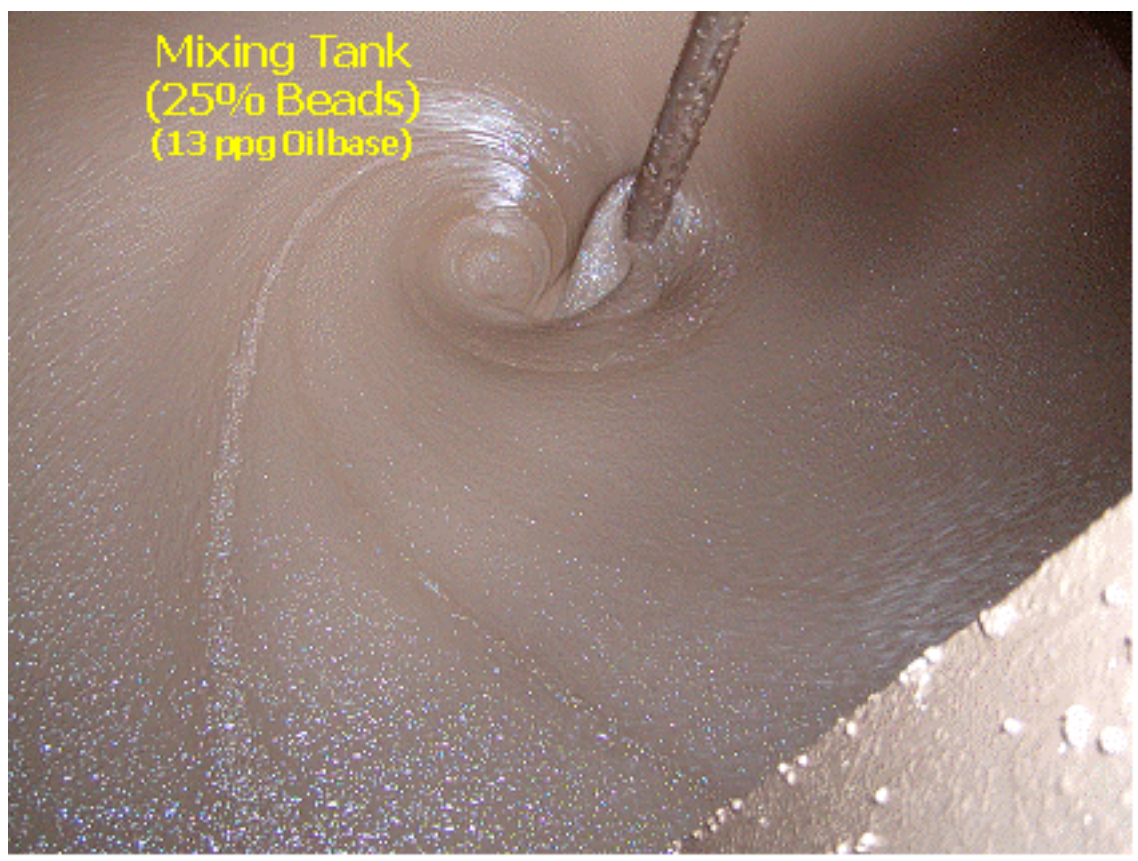

Figure 36. Mud with 25\% Spheres in Mixing Tank

The King Cobra shaker uses four screens. The first screen is oriented level to form a "mud pool" which is essential for good shaker performance. The other three screens are normally tilted at $5^{\circ}$ so that drill cuttings move upward as they move along the screen.

This shaker allows $\mathrm{a} \pm 3^{\circ}$ adjustment, so the shaker screen angle can be varied from 2 to $8^{\circ}$. Tests showed that the shaker did not perform as well at $2^{\circ}$ as at higher angles.

The $3 \mathrm{M}$ spheres tested have diameters of 2 to $3 \mathrm{~mm}$ (0.08 to $0.12 \mathrm{inch}$ ). Tenand 20-mesh screens were used during these tests. $100 \%$ of the spheres are removed by these screens since the screen openings $(0.075$ and 0.034 inch, respectively) are smaller than the diameter of the spheres.

\subsection{TEST RESULTS (10-MESH SCREEN)}

Performance with a 10-mesh screen is shown in Figure 37 and Table 8. 


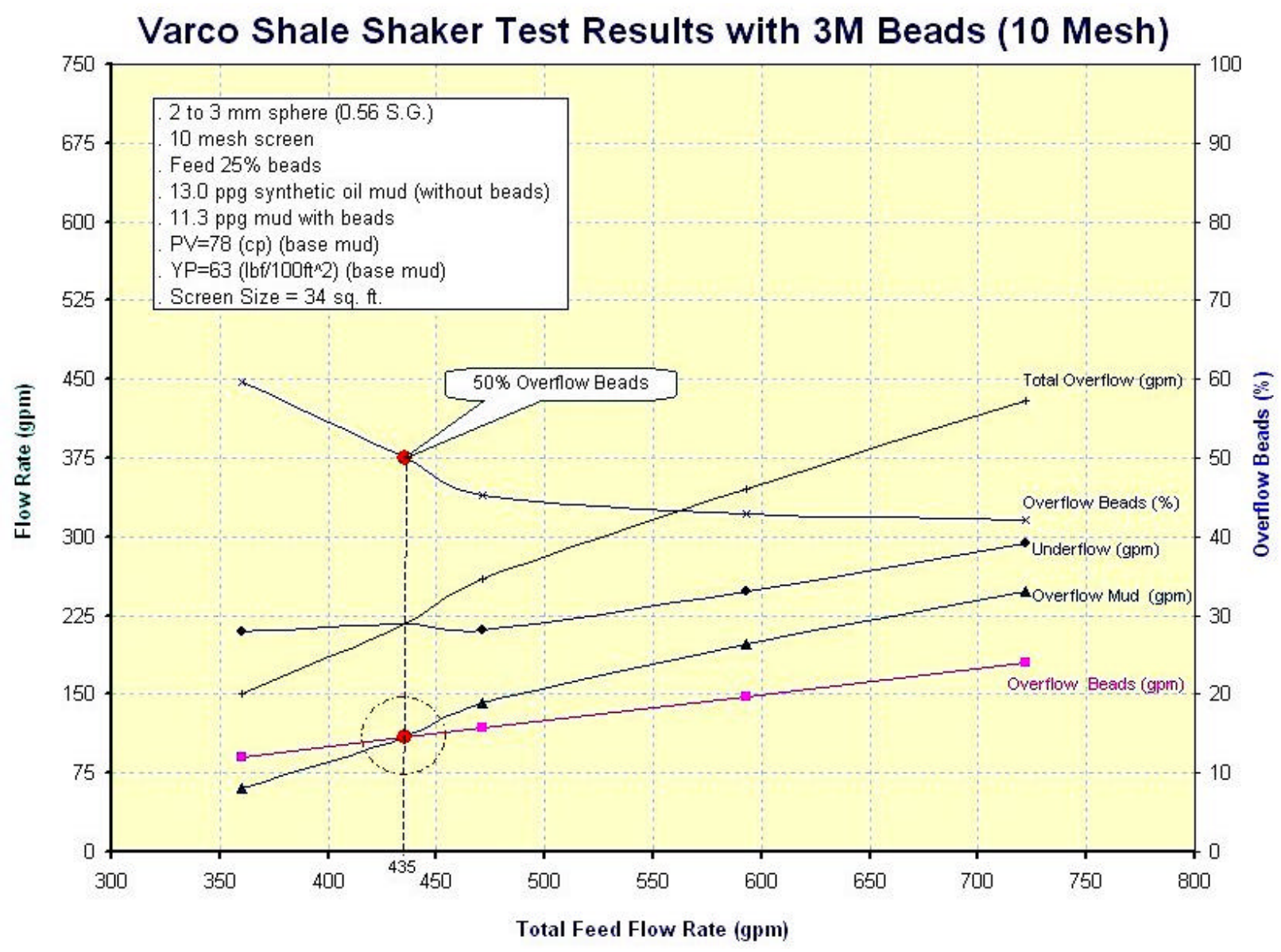

Figure 37. Varco Shaker Tests (10 mesh)

Table 8. Varco Shaker Tests (10 mesh)

VARCO Shaker Test Results (10 Mesh, 13 ppg Synthetic Oil, 25\% 3M Spheres)

\begin{tabular}{|c|c|c|c|c|c|c|c|c|c|c|c|}
\hline \multirow{3}{*}{$\begin{array}{c}\text { Test } \\
\text { No. }\end{array}$} & \multicolumn{4}{|c|}{ Feed } & \multicolumn{4}{|c|}{ Overflow } & \multicolumn{3}{|c|}{ Underflow } \\
\hline & \multirow{2}{*}{$\begin{array}{l}\text { Total } \\
(\mathrm{gpm}) \\
\end{array}$} & \multirow{2}{*}{$\begin{array}{c}\text { Mud } \\
\text { (gpm) }\end{array}$} & \multicolumn{2}{|c|}{ Beads } & \multirow{2}{*}{$\begin{array}{c}\text { Total } \\
\text { (gpm) }\end{array}$} & \multirow{2}{*}{$\begin{array}{c}\text { Mud } \\
\text { (gpm) }\end{array}$} & \multicolumn{2}{|c|}{ Beads } & \multirow{2}{*}{$\begin{array}{c}\text { Total } \\
\text { (gpm) }\end{array}$} & \multirow{2}{*}{$\begin{array}{c}\text { Mud } \\
\text { (gpm) }\end{array}$} & \multirow{2}{*}{$\begin{array}{c}\text { Beads } \\
\text { (gpm) }\end{array}$} \\
\hline & & & (gpm) & (vol.\%) & & & (gpm) & (vol.\%) & & & \\
\hline 1 & 257 & 193 & 64 & 25 & 101 & 37 & 64 & 63.4 & 156 & 156 & 0 \\
\hline 2 & 360 & 270 & 90 & 25 & 151 & 61 & 90 & 59.6 & 209 & 209 & 0 \\
\hline 3 & 435 & 326 & 109 & 25 & 218 & 109 & 109 & 50.0 & 217 & 217 & 0 \\
\hline 4 & 471 & 353 & 118 & 25 & 260 & 142 & 118 & 45.4 & 211 & 211 & 0 \\
\hline 5 & 593 & 445 & 148 & 25 & 345 & 197 & 148 & 42.9 & 248 & 248 & 0 \\
\hline 6 & 722 & 542 & 181 & 25 & 429 & 248 & 181 & 42.2 & 293 & 293 & 0 \\
\hline
\end{tabular}

Table 8 shows that total overflow increased from 101 to $429 \mathrm{gpm}$ and the percentage of beads in the overflow decreased from 63.4 to $42.2 \%$ as the feed rate was increased from 257 to $722 \mathrm{gpm}$. 
At all flow rates, all $3 \mathrm{M}$ ( 2 to $3 \mathrm{~mm}$ ) beads came across the top of the screen, showing that shakers equipped with 10-mesh screens can effectively separate $3 \mathrm{M}$ beads from the mud.

With a feed rate of $300 \mathrm{gpm}$ across a 10-mesh screen, only wetted beads came over the top of the shaker while $100 \%$ of the liquid mud not used to wet the spheres flowed through the screen (Figures 38 and 39). With this feed rate, $75 \mathrm{gpm}$ of beads $(100 \%)$ plus $45 \mathrm{gpm}$ of liquid mud (wetting bead surface) flowed over the screen, and $180 \mathrm{gpm}$ of liquid mud flowed through the screen.

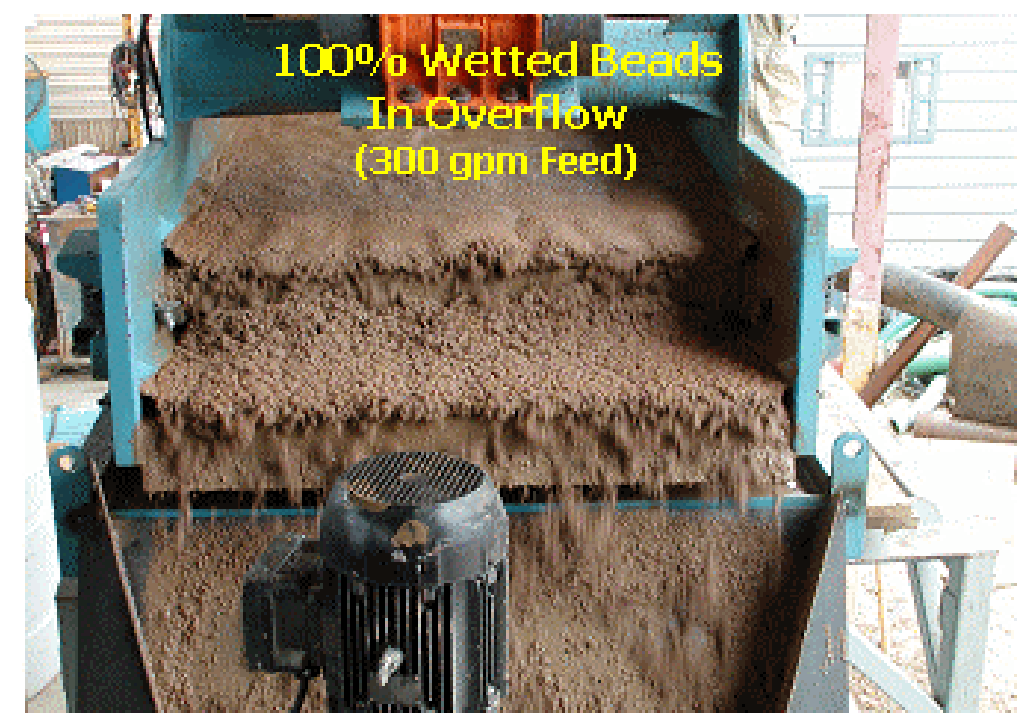

Figure 38. Wetted Beads in 10-mesh Overflow (300 gpm feed)

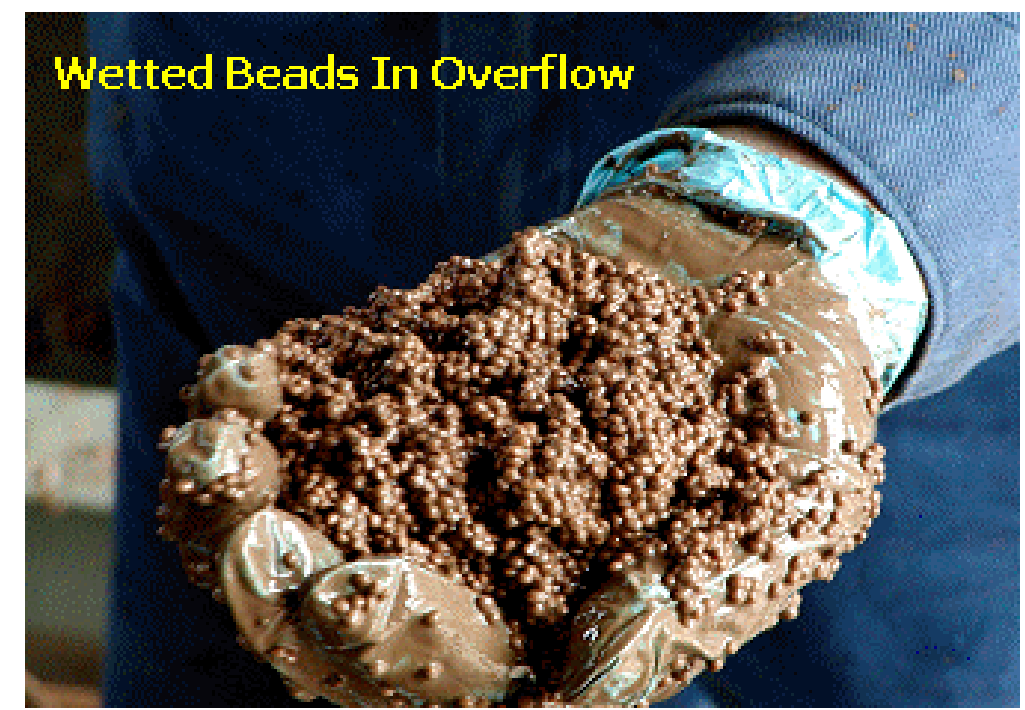

Figure 39. Wetted Beads in 10-Mesh Overflow (300 gpm feed) 
With $430 \mathrm{gpm}$ feed, a $50 \%$ bead mixture comes over the shaker $(107.5 \mathrm{gpm}$ beads; $107.5 \mathrm{gpm}$ mud), which is the ideal mixture to pump to the bottom of the riser, and $215 \mathrm{gpm}$ flows through the screen (Figure 40).

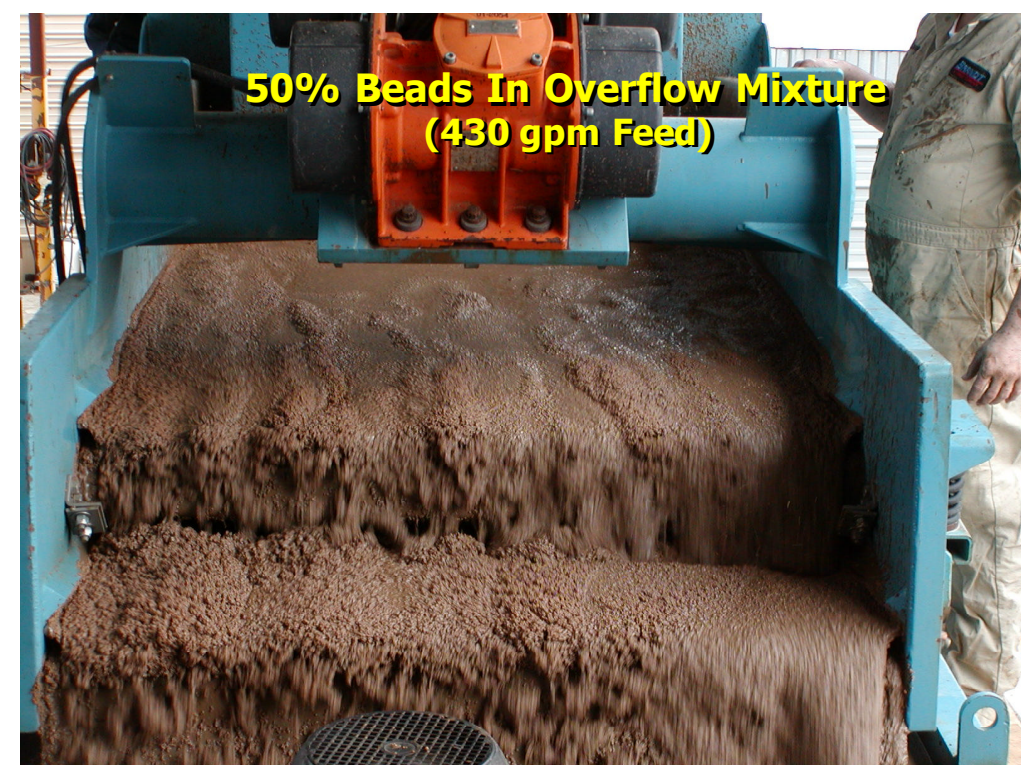

Figure $40.50 \%$ Beads in Overflow (430 gpm feed)

With $720 \mathrm{gpm}$ feed, bead concentration in the overflow decreased to $40 \%$, with $450 \mathrm{gpm}$ of the feed (63\%) passing over the screen and $270 \mathrm{gpm}$ of liquid mud (37\%) flowing through the screen (Figure 41).

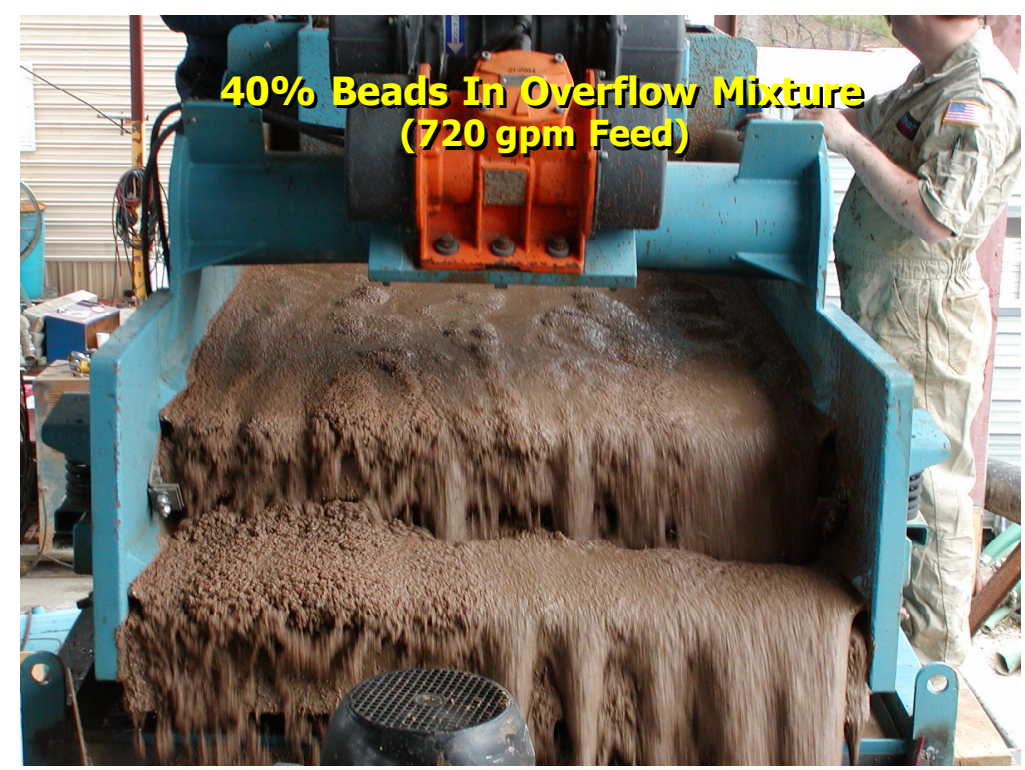

Figure $41.40 \%$ Beads in Overflow (720 gpm feed) 


\subsection{TEST RESULTS (20-MESH SCREEN)}

Test results with a 20-mesh screen were similar to those with a 10-mesh screen, except that there was slightly more flow through a 10-mesh screen (Figure 42 and Table 9).

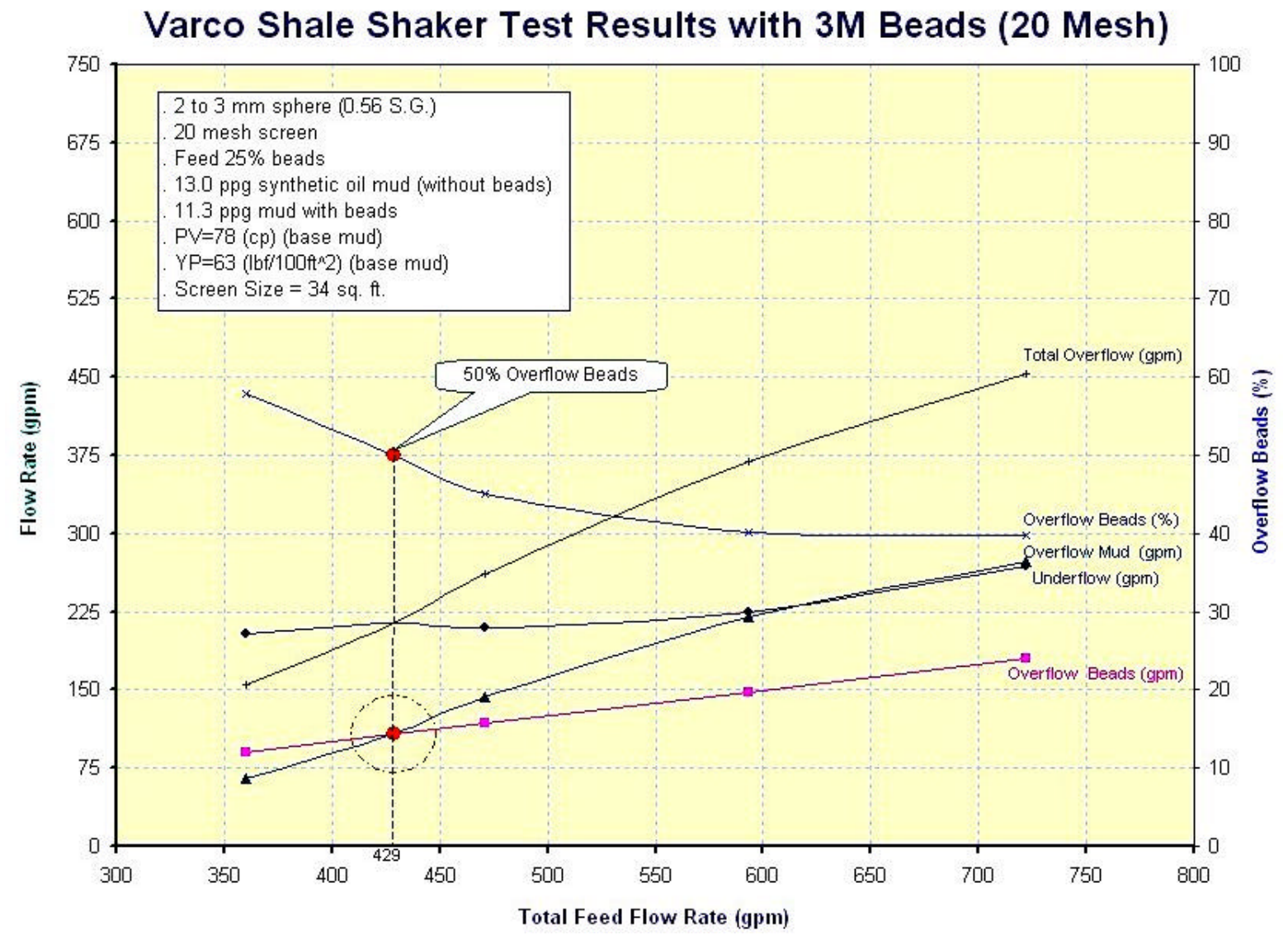

Figure 42. Varco Shaker Test (20 mesh)

Table 9. Varco Shaker Test (20 mesh)

VARCO Shaker Test Results (20 Mesh, 13 ppg Synthetic Oil, 25\% 3M Spheres)

\begin{tabular}{|c|c|c|c|c|c|c|c|c|c|c|c|}
\hline \multirow{3}{*}{$\begin{array}{l}\text { Test } \\
\text { No. }\end{array}$} & \multicolumn{4}{|c|}{ Feed } & \multicolumn{4}{|c|}{ Overflow } & \multicolumn{3}{|c|}{ Underflow } \\
\hline & \multirow{2}{*}{$\begin{array}{l}\text { Total } \\
\text { (gpm) }\end{array}$} & \multirow{2}{*}{$\begin{array}{c}\text { Mud } \\
(\mathrm{gpm})\end{array}$} & \multicolumn{2}{|c|}{ Beads } & \multirow{2}{*}{$\begin{array}{c}\text { Total } \\
\text { (gpm) }\end{array}$} & \multirow{2}{*}{$\begin{array}{c}\text { Mud } \\
(g p m)\end{array}$} & \multicolumn{2}{|c|}{ Beads } & \multirow{2}{*}{$\begin{array}{c}\text { Total } \\
\text { (gpm) }\end{array}$} & \multirow{2}{*}{$\begin{array}{c}\text { Mud } \\
\text { (gpm) }\end{array}$} & \multirow{2}{*}{$\begin{array}{c}\text { Beads } \\
\text { (gpm) }\end{array}$} \\
\hline & & & (gpm) & (vol.\%) & & & (gpm) & (vol.\%) & & & \\
\hline 1 & 257 & 193 & 64 & 25 & 97 & 33 & 64 & 66.0 & 160 & 160 & 0 \\
\hline 2 & 360 & 270 & 90 & 25 & 156 & 66 & 90 & 57.7 & 204 & 204 & 0 \\
\hline 3 & 429 & 322 & 107 & 25 & 214 & 107 & 107 & 50.0 & 215 & 215 & 0 \\
\hline 4 & 471 & 353 & 118 & 25 & 261 & 143 & 118 & 45.2 & 210 & 210 & 0 \\
\hline 5 & 593 & 445 & 148 & 25 & 368 & 220 & 148 & 40.2 & 225 & 225 & 0 \\
\hline 6 & 722 & 542 & 181 & 25 & 454 & 273 & 181 & 39.9 & 268 & 268 & 0 \\
\hline
\end{tabular}


With $360 \mathrm{gpm}$ feed, $209 \mathrm{gpm}$ of mud flows through the 10-mesh screen compared to $204 \mathrm{gpm}$ through the 20-mesh screen (Figure 43).

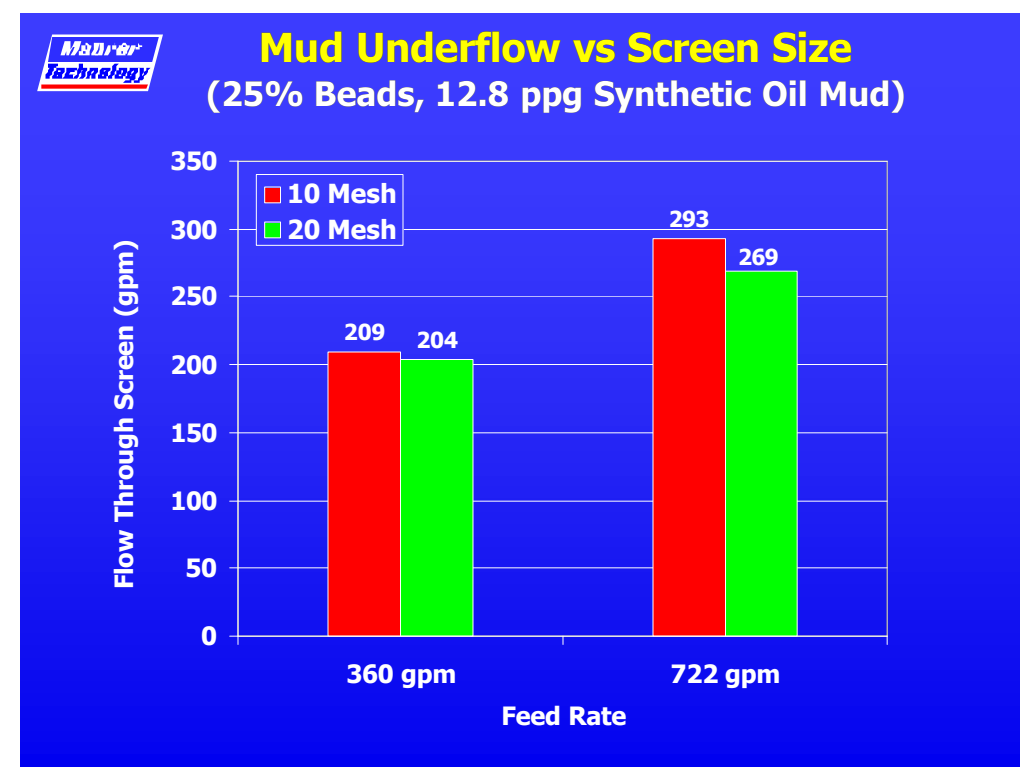

Figure 43. Mud Flow Through Screens

With $722 \mathrm{gpm}$ feed, $293 \mathrm{gpm}$ flows through a 10-mesh screen compared to 269 gpm through a 20-mesh screen. The similarity in flow rates shows that flow rate through 10-mesh and 20-mesh screens is controlled primarily by flow through the beads on top of the screens, not by the size of the openings in the screen.

These tests show that either 10- or 20-mesh screens can be used to remove all of the $3 \mathrm{M}$ spheres (2 to $3 \mathrm{~mm}$ ) from the mud. 10-mesh screens allow slightly more flow, whereas 20-mesh screens will provide allowance for more sphere wear before the spheres will be worn small enough to pass through the screen. Since these flow rates are similar, 20-mesh screens are therefore preferred.

\subsection{CONCLUSIONS}

1. A Varco King Cobra shaker was used to separate spheres from 13.0-ppg synthetic oil rates mud containing $25 \% 3 \mathrm{M}$ spheres at flow rates up to $722 \mathrm{gpm}$.

2. No problems were encountered in mixing spheres into 13-ppg synthetic oil mud or in pumping the sphere mixture with an $8 \times 6$-inch centrifugal pump. 
3. All 3M spheres (2 to $3 \mathrm{~mm}$ ) were screened out of the mud with 10- and 20mesh screens since the openings in these screens are smaller than the sphere diameters.

4. Performance of the Varco shaker was nearly identical with 10- and 20-mesh screens, showing that flow rate through these screens is controlled by flow through the beads on the screen, not by the size of the openings in the screens.

5. When flow rate was increased from 257 to $722 \mathrm{gpm}$, flow across a 10-mesh screen increased from 101 to $429 \mathrm{gpm}$, and sphere concentration in the overflow decreased from 63.4 to $42.2 \%$.

6. With $257 \mathrm{gpm}$ flow, only wetted spheres came across the top of the screen and all of the liquid mud flowed through the screen.

7. As flow rate was increased, more liquid mud flowed across the screen along with the spheres, reducing sphere concentration in the overflow from 63.4 to $42.2 \%$.

8. 10- and 20-mesh screens allowed high flow rates through the screens, making them ideal for use with this DGD system.

9. Based on results of these DOE-funded tests, Varco solids-control experts were $100 \%$ confident that they could develop a reliable sphere separation system for this DGD system using only shale shakers to separate spheres from the mud.

10. These DOE yard tests were very important in demonstrating the viability of this hollow sphere DGD system. 


\section{DRC Shale Shaker Tests (Waterbase Mud)}

\subsection{TEST DESCRIPTION}

Shaker tests were conducted at MTl's Drilling Research Center (DRC) with an oilfield waterbase mud provided by Halliburton using the National Oilwell T180 Shale Shaker shown in Figure 44.

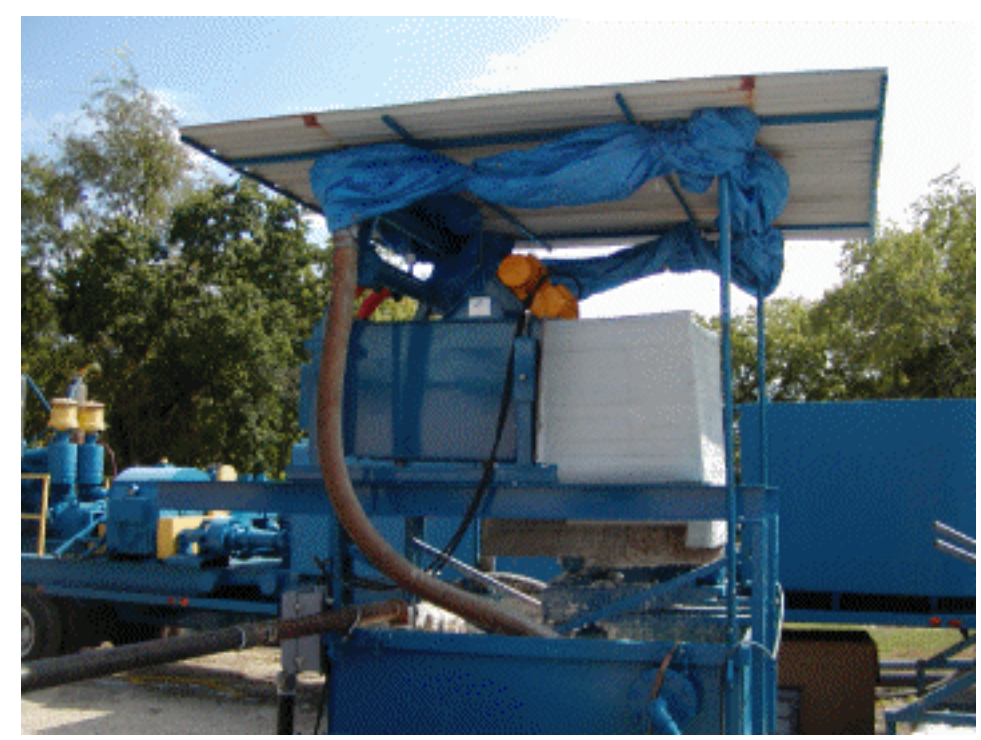

Figure 44. DRC Shaker Test Stand

Characteristics of the National Oilwell T180 shale shaker are shown in Table 10.

Table 10. National Oilwell T180 Shaker

$\begin{array}{ll}\text { Size } & 62 " \text { L x 43" W x 45" H } \\ \text { Type } & \text { Tandem Deck } \\ \text { Dry Weight } & 450 \mathrm{lb}[204 \mathrm{~kg}] \\ \text { Deck Angle } & +4^{\circ} \text { to }-2^{\circ} \\ \text { Vibration } & \text { Linear Motion } \\ \text { G Force } & \text { Up to } 4 \text { G Maximum } \\ \text { Number of Screens } & 2 \\ \text { Screen Area } & 18 \mathrm{ft}^{2}\left[1.7 \mathrm{~m}^{2}\right] \\ \text { Screen Type } & \text { Pre-tensioned Panel }\end{array}$


Tests were conducted with 2- to 20-mesh screens (Figure 45) at flow rates of 30 to $250 \mathrm{gpm}$.
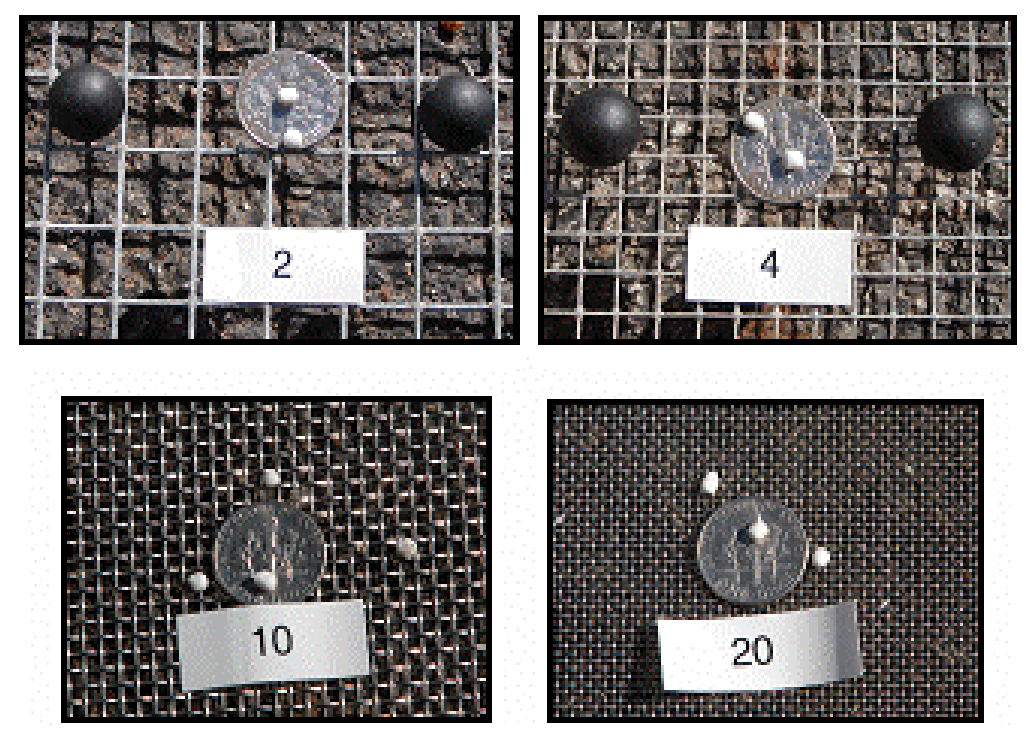

Figure 45. Shaker Screens Tested

The size of the screen openings and sphere diameters are compared in Table 11.

\section{Table 11. Screen Sizes}

\begin{tabular}{|c|c|c|c|c|}
\hline \multirow{2}{*}{ Mesh Size } & $\begin{array}{c}\text { Opening Size } \\
\text { (in.) }\end{array}$ & \multicolumn{2}{|c|}{ Sphere Diameter (in.) } & Screen Open \\
\cline { 5 - 5 } & 3M & Balmoral & & Area $\left(\mathrm{in}^{2}\right)$ \\
\hline 2 & 0.463 & & & 85.7 \\
\hline 4 & 0.206 & & & 67.9 \\
\hline 8 & 0.097 & \multirow{5}{*}{0.08 to 0.12} & \multirow{2}{*}{0.43 to 0.50} & 60.2 \\
\hline 10 & 0.075 & & & 56.3 \\
\hline 20 & 0.034 & & & 46.2 \\
\hline 100 & 0.0055 & & & 30.3 \\
\hline
\end{tabular}

Table 11 shows that $3 \mathrm{M}$ spheres will pass through the openings in an 8-mesh screen but not a 10-mesh screen. Balmoral spheres will pass through the openings in a 2-mesh screen, but not a 4-mesh screen.

Flow areas of 4- and 10-mesh screens are large compared to 100-mesh screens often used on rigs, so shakers with these larger screens can handle very high mud flow rates. 
A series of tests was conducted at the DRC with a 10.4-ppg oilfield waterbase mud provided by Halliburton. This mud was from Halliburton's rental facility, so it is representative of waterbase muds used on offshore wells. These tests were conducted with $35 \%$ by volume $3 \mathrm{M}$ spheres ( 2 to $3 \mathrm{~mm}$; $0.56 \mathrm{SG}$ ). The objective of these tests was to determine if $3 \mathrm{M}$ and Balmoral spheres could be removed effectively from DGD muds using conventional oilfield shale spheres.

\subsection{SPHERE SEPARATION TESTS (VARIABLE SCREEN SIZE)}

With the sphere-based DGD system, all spheres must be removed in the screen overflow because no spheres can be pumped down the drillpipe to the drill bit. This dictates the use of 10 -mesh $(0.075$-inch openings) or higher screens since the $3 \mathrm{M}$ spheres have diameters of 2 to $3 \mathrm{~mm}$ (0.08 to 0.12 inch). Figure 46 and Table 12 show how sphere separation varies with flow rate and mesh size.

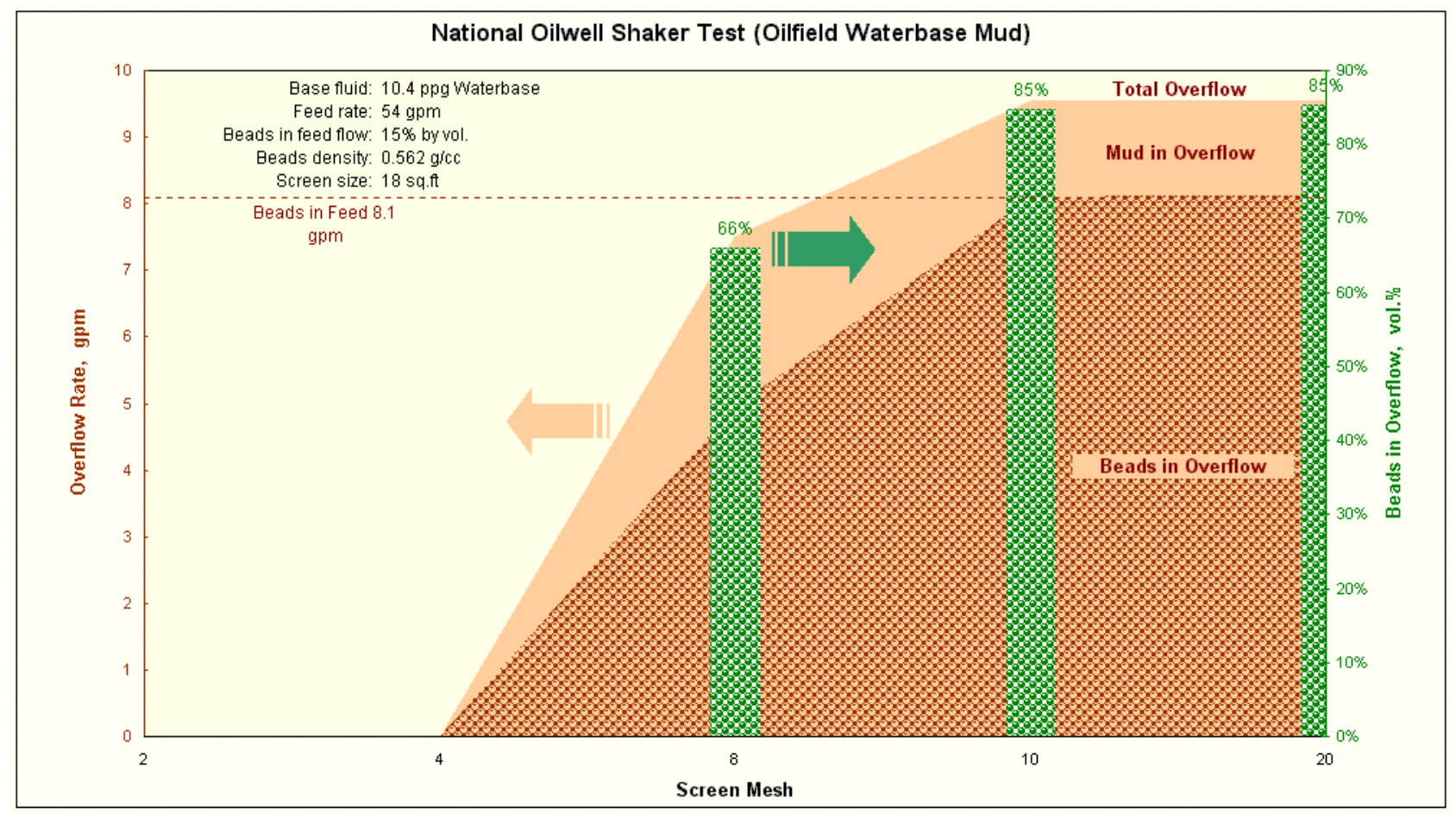

Figure 46. Effect of Screen Size on Sphere Separation 
Table 12. National Oilwell Shaker Tests

National Oilwell Shaker Tests (10.4 ppg Waterbase Mud)

\begin{tabular}{|c|c|c|c|c|c|c|c|c|c|c|c|c|}
\hline \multirow{3}{*}{$\begin{array}{c}\text { Screen } \\
\text { Mesh }\end{array}$} & \multicolumn{4}{|c|}{ Feed } & \multicolumn{4}{|c|}{ Overflow } & \multicolumn{4}{|c|}{ Underflow } \\
\hline & \multirow{2}{*}{$\begin{array}{l}\text { Total } \\
\text { (gpm) }\end{array}$} & \multirow{2}{*}{$\begin{array}{c}\begin{array}{l}\text { Mud } \\
\text { (gpm) }\end{array} \\
\end{array}$} & \multicolumn{2}{|c|}{ 3M Beads } & \multirow{2}{*}{$\begin{array}{r}\text { Total } \\
\text { (gpm) }\end{array}$} & \multirow{2}{*}{$\begin{array}{c}\text { Mud } \\
\text { (gpm) }\end{array}$} & \multicolumn{2}{|c|}{ 3M Beads } & \multirow{2}{*}{$\begin{array}{l}\text { Total } \\
\text { (gpm) }\end{array}$} & \multirow{2}{*}{$\begin{array}{c}\text { Mud } \\
(\mathrm{gpm}) \\
\end{array}$} & \multicolumn{2}{|c|}{ 3M Beads } \\
\hline & & & (gpm) & (vol.\%) & & & (gpm) & (vol.\%) & & & (gpm) & (vol.\%) \\
\hline 2 & 54 & 45.9 & 8.1 & 15 & 0 & 0 & 0 & 0 & 54 & 45.9 & 8.1 & 15.0 \\
\hline 4 & 54 & 45.9 & 8.1 & 15 & 0 & 0 & 0 & 0 & 54 & 45.9 & 8.1 & 15.0 \\
\hline 8 & 54 & 45.9 & 8.1 & 15 & 7.60 & 2.6 & 5.0 & 65.8 & 46.4 & 43.3 & 3.1 & 6.7 \\
\hline 10 & 54 & 45.9 & 8.1 & 15 & 9.55 & 1.45 & 8.1 & 84.8 & 44.5 & 44.5 & 0 & 0.0 \\
\hline 20 & 54 & 45.9 & 8.1 & 15 & 9.54 & 1.44 & 8.1 & 84.9 & 44.5 & 44.5 & 0 & 0.0 \\
\hline
\end{tabular}

Figure 47 shows that all the mud and $3 \mathrm{M}$ beads flowed through the 2 and 4-mesh screens and that all of the $3 \mathrm{M}$ beads flowed over the 10 and 20 -mesh screens. These tests were very successful, showing that the shakers could effectively separate $3 \mathrm{M}$ beads from mud at high flow rates.

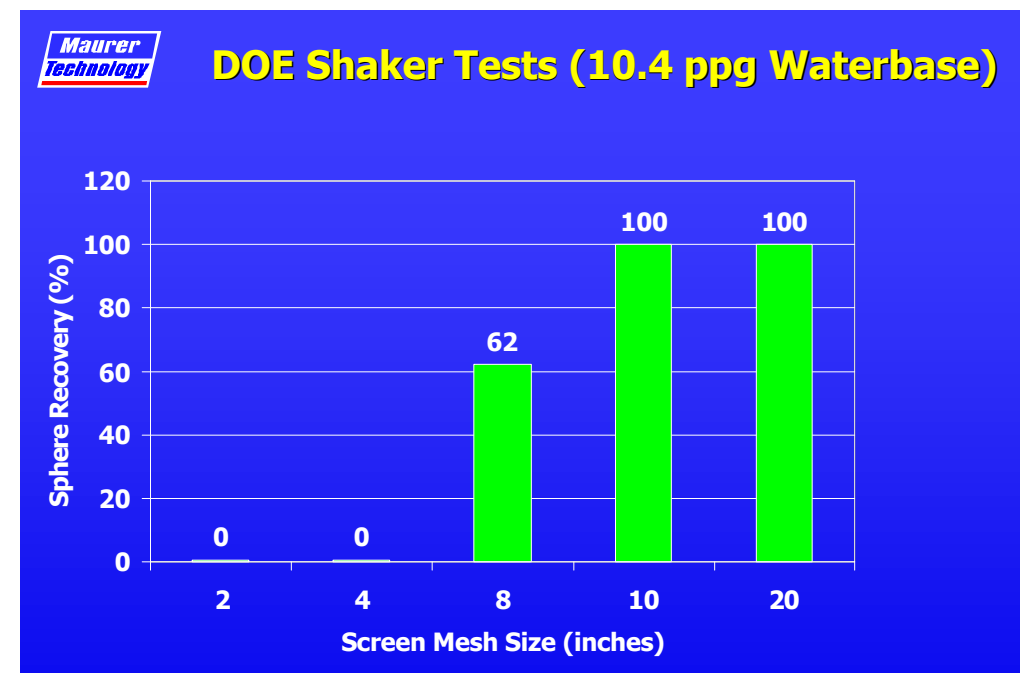

Figure 47. Shaker Sphere Recovery Tests (10.4-ppg Waterbase Mud)

Figure 48 shows that with $54 \mathrm{gpm}$ flow to the shaker, $44.5 \mathrm{gpm}(82 \%)$ of the waterbase bentonite mud flow went through the screen. This is very important because with the polymer mud tested earlier, most of the mud flowed over the screen due to its high viscosity at low shear rates. 


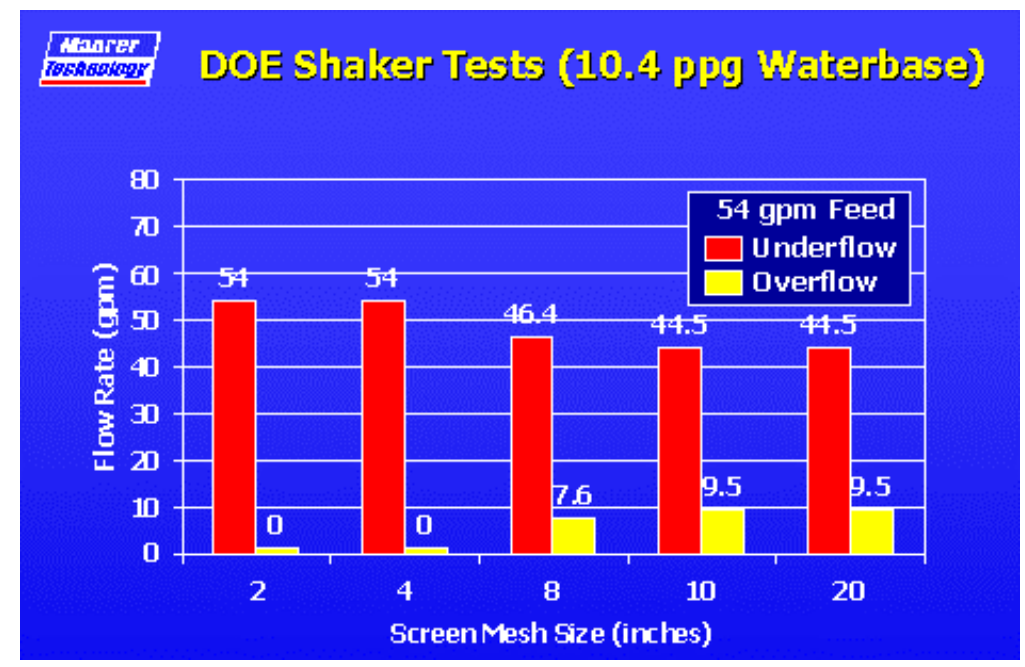

Figure 48. Shaker Flow Rate Tests (10.4-ppg Waterbase Mud)

These results demonstrate that the shakers can be used effectively with oilfield waterbase DGD muds.

With $54 \mathrm{gpm}$ flow (45.9 gpm mud, $8.1 \mathrm{gpm}$ beads) across a 4-mesh screen, all of the oilfield waterbase mud (35\% spheres) passed through the screen with no overflow (Figure 49).

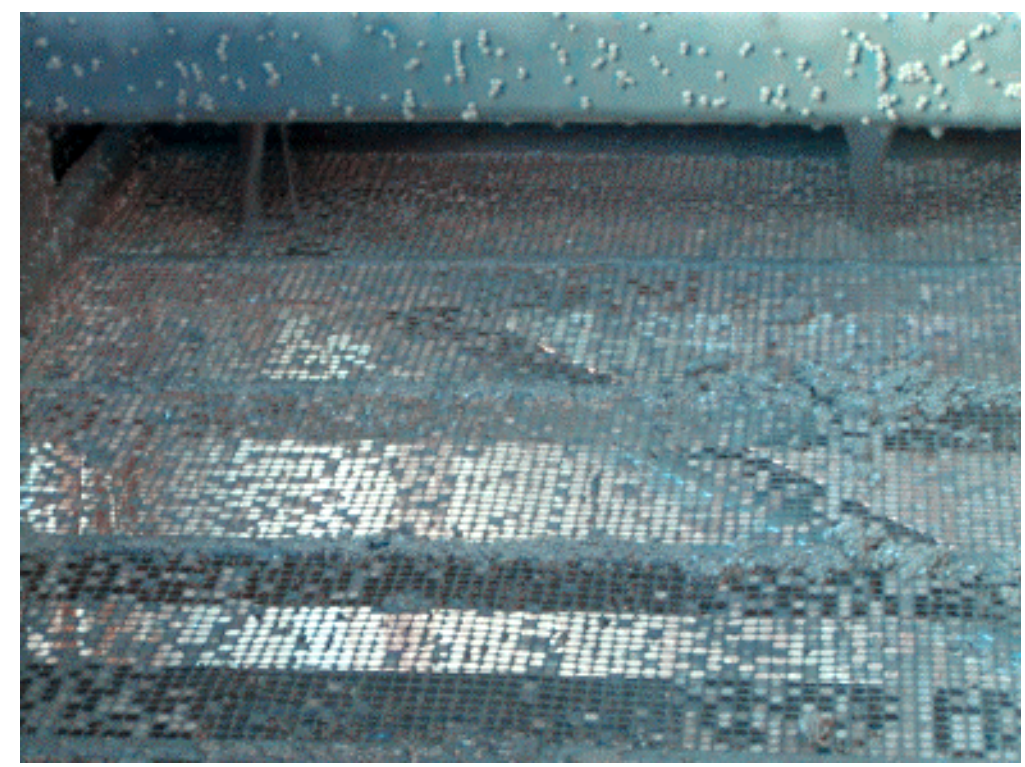

Figure 49. 4-Mesh Shaker Test (3M Spheres, Waterbase Mud)

With $54 \mathrm{gpm}$ flow across an 8-mesh screen, $46.4 \mathrm{gpm}$ (43.3 gpm mud; $3.1 \mathrm{gpm}$ beads) flowed through the screen and $7.6 \mathrm{gpm}$ ( $2.6 \mathrm{gpm}$ mud; $5.0 \mathrm{gpm}$ beads) flowed over the screen. This corresponds to sphere concentrations of $65.8 \%$ across the screen and $6.7 \%$ through the screen. 
With $54 \mathrm{gpm}$ flow across a 10-mesh screen (Figures 50 and 51 ), $44.5 \mathrm{gpm}$ of liquid mud (no spheres) flowed through the screen and $9.55 \mathrm{gpm}$ (1.45 gpm mud; 8.1 gpm beads) flowed over the screen. This corresponds to sphere concentrations of $84.8 \%$ across the screen and $0 \%$ through the screen. With a 10-mesh screen, only spheres came across the top of the screen while some liquid mud flowed through the screen.

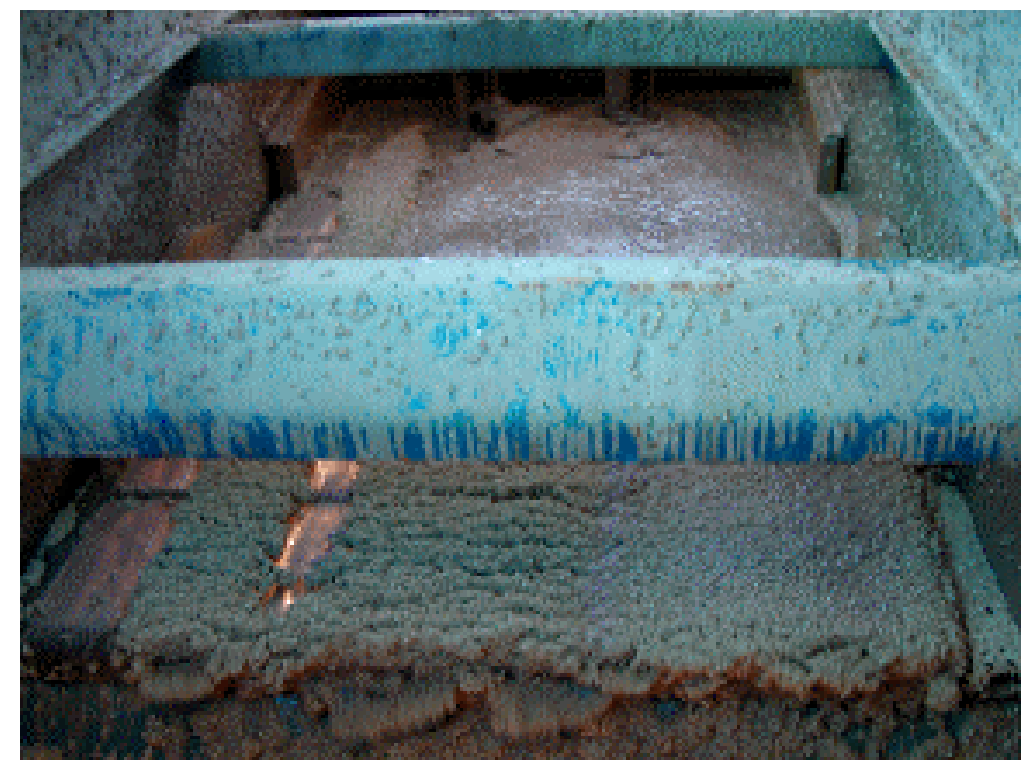

Figure 50. 10-Mesh Screen Overflow (3M Spheres, Waterbase Mud)

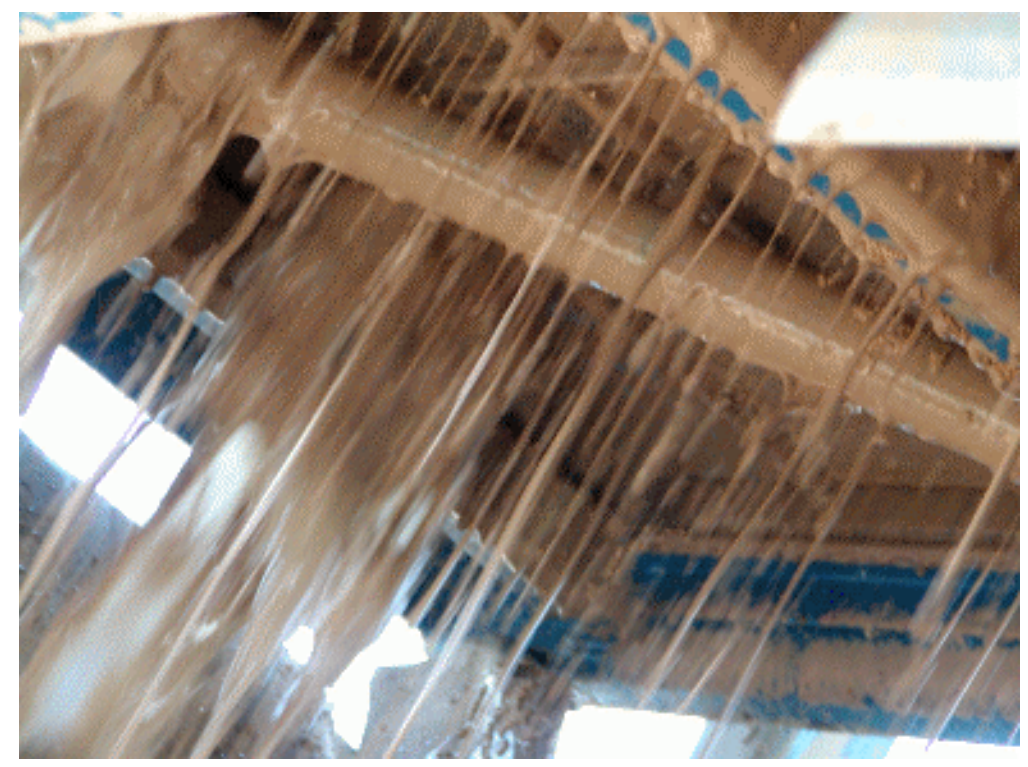

Figure 51. 10-Mesh Screen Underflow (3M Spheres, Waterbase Mud) 
With $54 \mathrm{gpm}$ flow, the performance with the 20-mesh screen was identical to the 10-mesh screen. With both 10 and 20-mesh, flow through the screen was controlled by flow through the beads on the screen, not by the size of the openings in the screen.

Liquid flow rate through 10 - and 20-mesh screens was very high with oilfield waterbase mud compared to more viscous polymer mud tested earlier on the Phase I project. This indicates that screens could be used as the primary sphere separation system with this oilfield mud.

\subsection{CUTTINGS SEPARATION TESTS}

Small pebbles were mixed into the mud at $3 \%$ by volume with $15 \% 3 \mathrm{M}$ spheres to determine if the shaker could separate these simulated cuttings from the spheres. Figure 52 shows the apparatus used to put the pebbles into the mud flow and Figure 53 shows some of the pebbles used.

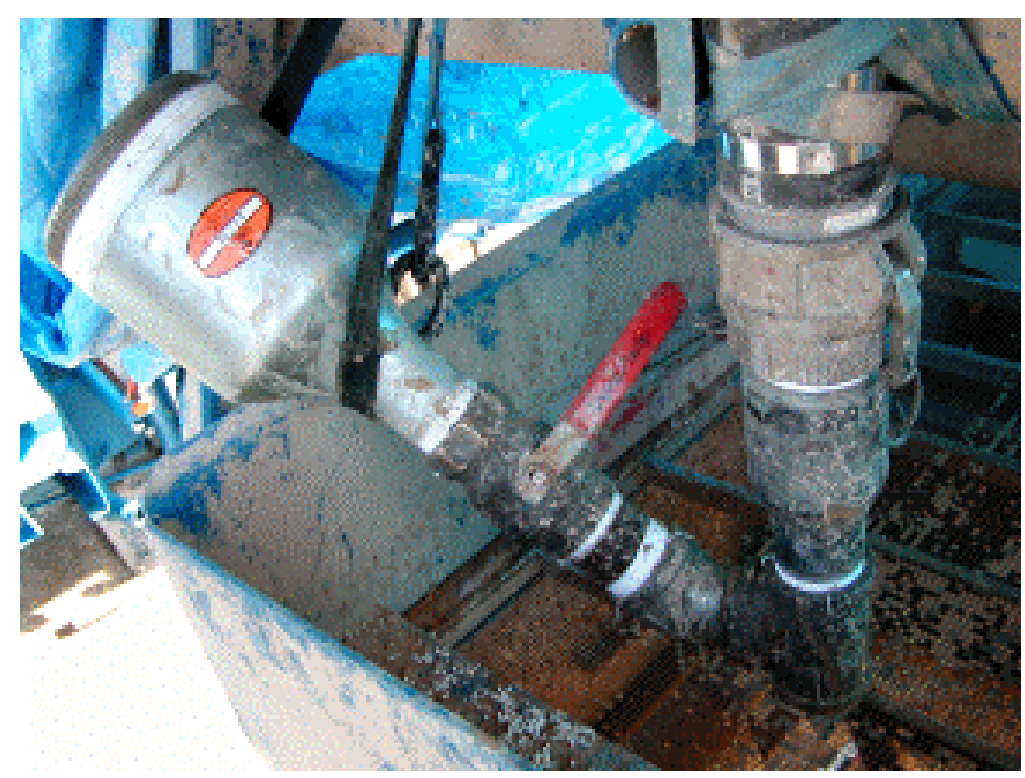

Figure 52. Apparatus for Putting Pebbles Into Mud 


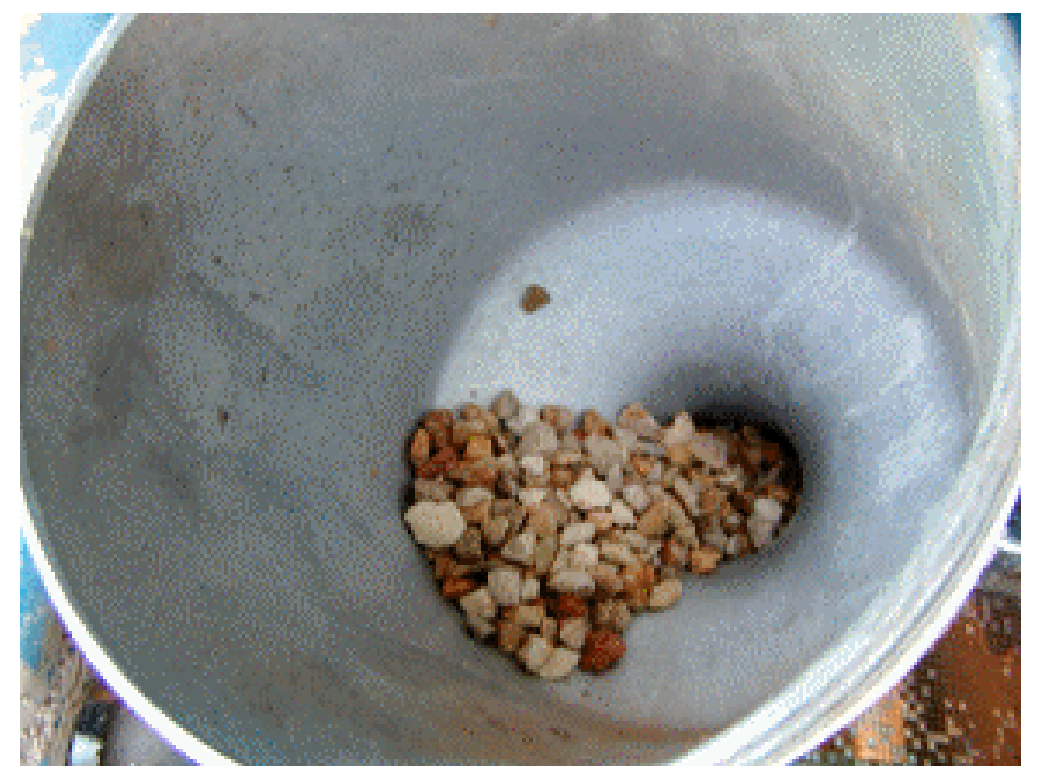

Figure 53. Pebbles Used to Simulate Cuttings in the Mud

With a 4-mesh screen, all of the spheres and mud passed through the screen and all of the pebbles came across the top of the screen in the overflow (Figure 54).

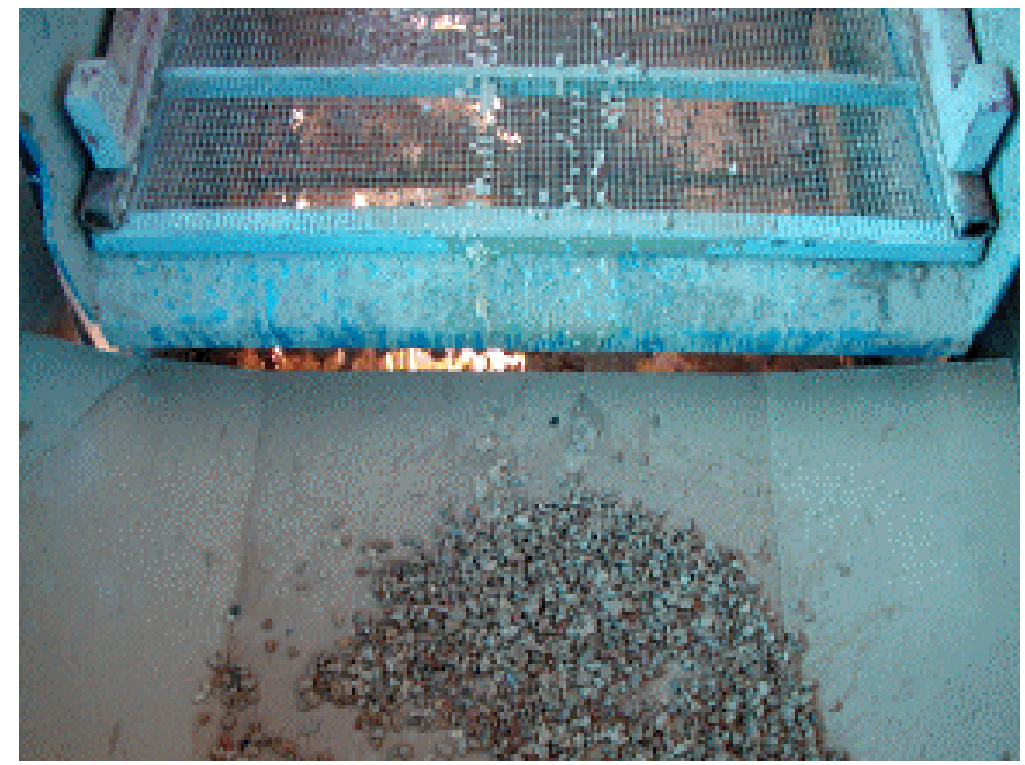

Figure 54. Pebbles Removed by 4-Mesh Screen

These tests show that a 4-mesh screen should effectively remove all cuttings larger than 4-mesh from the mud/sphere mixture while allowing all of the 3M spheres to flow through. Then, a 10-mesh screen on the next shaker will remove all of the spheres from the mud. 


\subsection{SEPARATION WITH FLOW RATE}

A series of tests was conducted to determine the effect of flow rate on sphere separation (Figure 55, Table 13).

\section{National Oilwell Shale Shaker Test Results with 3M Beads}

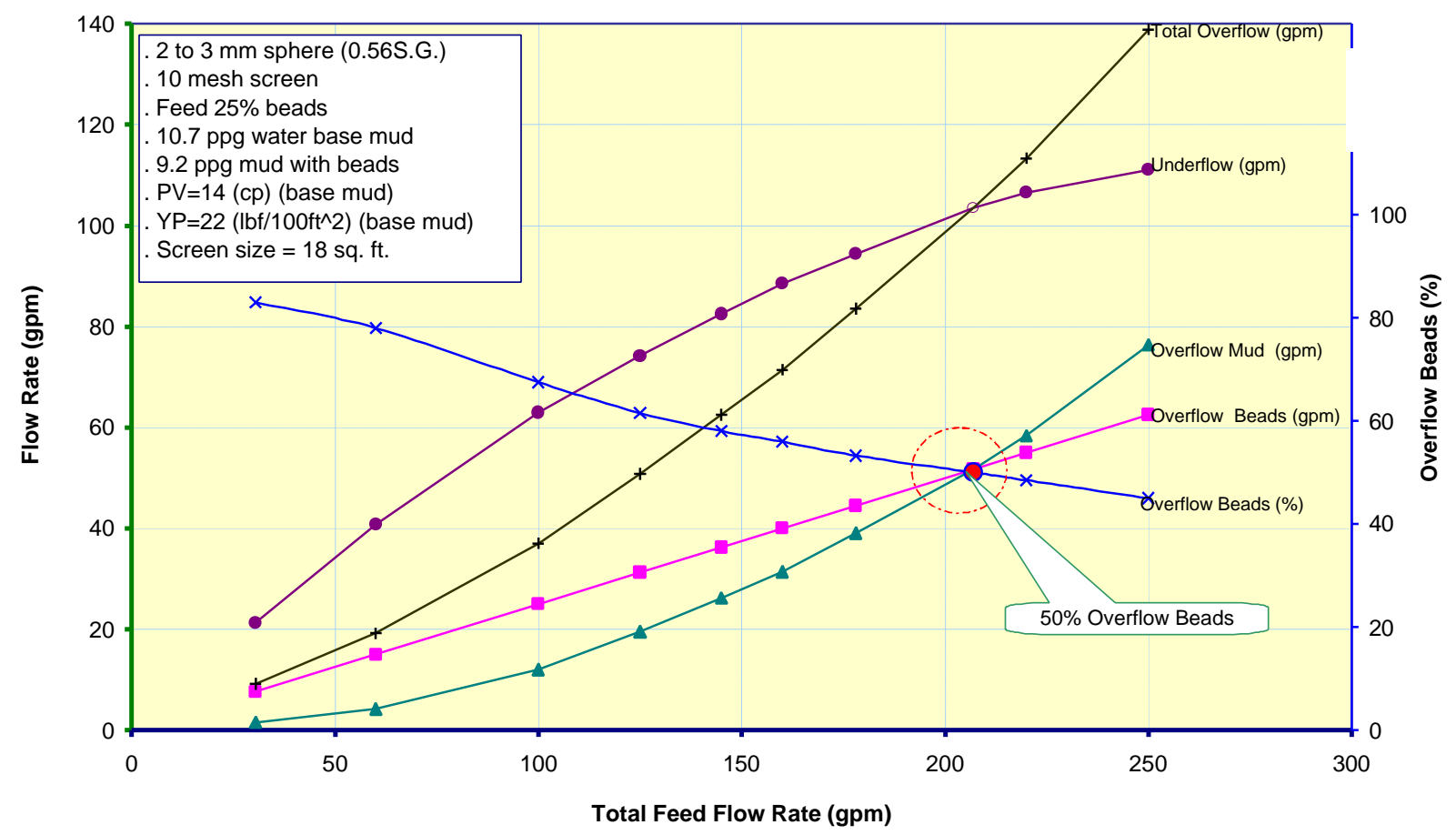

Figure 55. Effect of Flow Rate on Shaker Performance

Table 13. National Oilwell Shaker Tests

National Oilwell Shaker Tests (10.4 ppg Waterbase Mud, 3M Beads, 10 Screen Mesh)

\begin{tabular}{|c|c|c|c|c|c|c|c|c|c|c|c|}
\hline \multicolumn{4}{|c|}{ Feed } & \multicolumn{4}{|c|}{ Overflow } & \multicolumn{4}{|c|}{ Underflow } \\
\hline \multirow{2}{*}{$\begin{array}{l}\text { Total } \\
\text { (gpm) }\end{array}$} & \multirow{2}{*}{$\begin{array}{c}\text { Mud } \\
\text { (gpm) }\end{array}$} & \multicolumn{2}{|c|}{ Beads } & \multirow{2}{*}{$\begin{array}{l}\text { Total } \\
\text { (gpm) }\end{array}$} & \multirow{2}{*}{$\begin{array}{l}\text { Mud } \\
\text { (gpm) }\end{array}$} & \multicolumn{2}{|c|}{ Beads } & \multirow{2}{*}{$\begin{array}{l}\text { Total } \\
\text { (gpm) }\end{array}$} & \multirow{2}{*}{$\begin{array}{c}\text { Mud } \\
\text { (gpm) }\end{array}$} & \multicolumn{2}{|c|}{ Beads } \\
\hline & & (gpm) & (vol.\%) & & & $(\mathrm{gpm})$ & (vol.\%) & & & (gpm) & (vol.\%) \\
\hline 30.5 & 22.9 & 7.6 & 25 & 9.2 & 1.6 & 7.6 & 83.0 & 21.3 & 21.3 & 0 & 0 \\
\hline 60 & 45.0 & 15.0 & 25 & 19.2 & 4.2 & 15.0 & 78.0 & 40.8 & 40.8 & 0 & 0 \\
\hline 100 & 75.0 & 25.0 & 25 & 37.0 & 12.0 & 25.0 & 67.5 & 63.0 & 63.0 & 0 & 0 \\
\hline 125 & 93.8 & 31.3 & 25 & 50.8 & 19.6 & 31.3 & 61.5 & 74.2 & 74.2 & 0 & 0 \\
\hline 145 & 108.8 & 36.3 & 25 & 62.5 & 26.3 & 36.3 & 58.0 & 82.5 & 82.5 & 0 & 0 \\
\hline 160 & 120.0 & 40.0 & 25 & 71.4 & 31.4 & 40.0 & 56.0 & 88.6 & 88.6 & 0 & 0 \\
\hline 178 & 133.5 & 44.5 & 25 & 83.6 & 39.1 & 44.5 & 53.3 & 94.4 & 94.4 & 0 & 0 \\
\hline 207 & 155.3 & 51.8 & 25 & 103.5 & 51.8 & 51.8 & 50.0 & 103.5 & 103.5 & 0 & 0 \\
\hline 220 & 165.0 & 55.0 & 25 & 113.4 & 58.4 & 55.0 & 48.5 & 106.6 & 106.6 & 0 & 0 \\
\hline 250 & 187.5 & 62.5 & 25 & 138.9 & 76.4 & 62.5 & 45.0 & 111.1 & 111.1 & 0 & 0 \\
\hline
\end{tabular}


With $30.5 \mathrm{gpm}$ feed flow (25\% sphere), $21.3 \mathrm{gpm}$ of liquid mud flows through the 10-mesh screen while only $9.2 \mathrm{gpm}$ wetted beads (7.6 gpm beads $+1.6 \mathrm{gpm}$ mud) came over the top of the screen in the overflow. This corresponds to $83 \%$ beads in the overflow.

As the flow rate is increased, more of the liquid mud flows across the screen in the overflow, thus decreasing the percentage of beads in the overflow from $83 \%$ to $45 \%$ as the flow rate is increased from 30.5 to $250 \mathrm{gpm}$.

With a feed flow rate of $210 \mathrm{gpm}$, there are $50 \%$ spheres in the overflow, which is an ideal mixture for pumping to the bottom of the riser at the seafloor for re-injection into the riser.

\subsection{SHAKER SIZE TESTS}

The small National Oilwell T180 shaker used in the DRC tests has a surface area of $18 \mathrm{ft}^{2}$ compared to $34.4 \mathrm{ft}^{2}$ for the Varco King Cobra shaker used with the oilbase mud tests (see Chapter 5). The amount of flow that a shaker can handle is proportional to its surface area. This indicates that increasing the area of the National Oilwell shaker from 18 to $34.4 \mathrm{ft}^{2}$ would have allowed it to operate with $50 \%$ sphere overflow at a flow rate of:

$$
\text { Flow Rate }=\frac{34.4 \times 210}{18}=401 \mathrm{gpm}
$$

Varco is building a larger King Cobra shaker with larger screen area which should handle even higher flow rates.

This analysis shows that two or three of these large shakers with 10-mesh screens should handle 1000 to $2000 \mathrm{gpm}$ flow rates required with this hollow sphere DGD system. 


\subsection{CONCLUSIONS}

1. These sphere separation tests were very successful, showing that a National Oilwell shale shaker should be able to remove 3M spheres from oilfield waterbase muds at high rates needed with this DGD system.

2. All of the mud and $3 \mathrm{M}$ spheres (2 to $4 \mathrm{~mm}$ ) flowed through the 2- and 4mesh screens.

3. All of the 3M spheres flowed over (were separated out by) the 10- and 20mesh screens.

4. With $54 \mathrm{gpm}$ flow, only wetted beads came across the 10- and 20-mesh screens, with all of the liquid mud flowing through the screen.

5. As the flow rate was increased from 30.5 to $250 \mathrm{gpm}$, mud in the overflow with a 10-mesh screen increased from 1.6 to $76.4 \mathrm{gpm}$, and the bead concentration in the overflow decreased from 83 to $45 \%$.

6. With $210 \mathrm{gpm}$ flow, bead concentration in the overflow was $50 \%$, the ideal ratio for pumping to the seafloor and re-injecting into the bottom of the riser.

These DOE-funded tests were very important because without them, the feasibility of using shale shakers to separate the $3 \mathrm{M}$ and Balmoral spheres from oilfield waterbase and oilbase muds would not have been demonstrated. 


\section{Varco Hydrocyclone Tests}

\subsection{INTRODUCTION}

At the end of the Phase I DGD joint-industry project, there were still unanswered questions about whether lightweight spheres ( $3 \mathrm{M}$ and Balmoral) could be removed from oilfield muds (waterbase and oilbase) at high flow rates (800 to $1600 \mathrm{gpm}$ ) as would be needed with this oilfield DGD system. Tests were run to determine if this could be successfully accomplished with large 12-inch hydrocyclones.

\subsection{TEST PROCEDURE}

Halliburton supplied two waterbase muds (10.0 and $11.4 \mathrm{ppg}$ ) and a diesel oilbase (NAF) mud (12.8 ppg) for these tests. Figure 56 shows the tank in which the muds were delivered. The 11.4-ppg waterbase mud used in the first test was diluted to $10 \mathrm{ppg}$ for the second test.

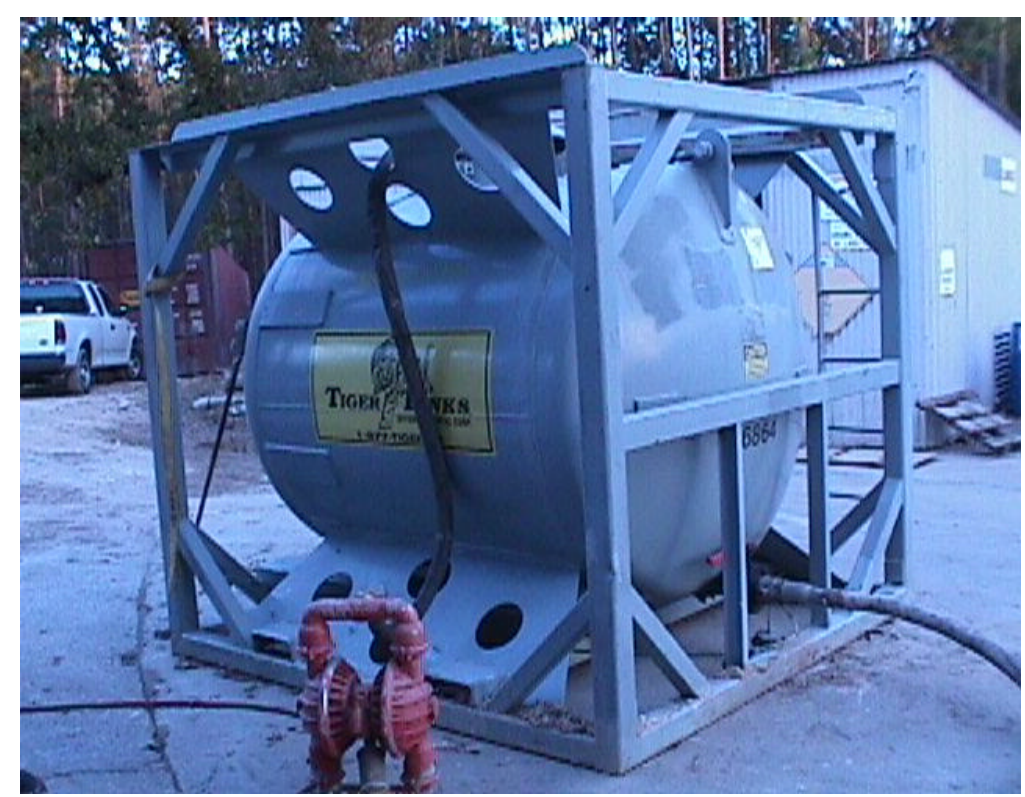

Figure 56. Tank for Shipping Mud

Varco transferred $15 \mathrm{bbl}$ of the mud to the test loop shown in Figure 57. 


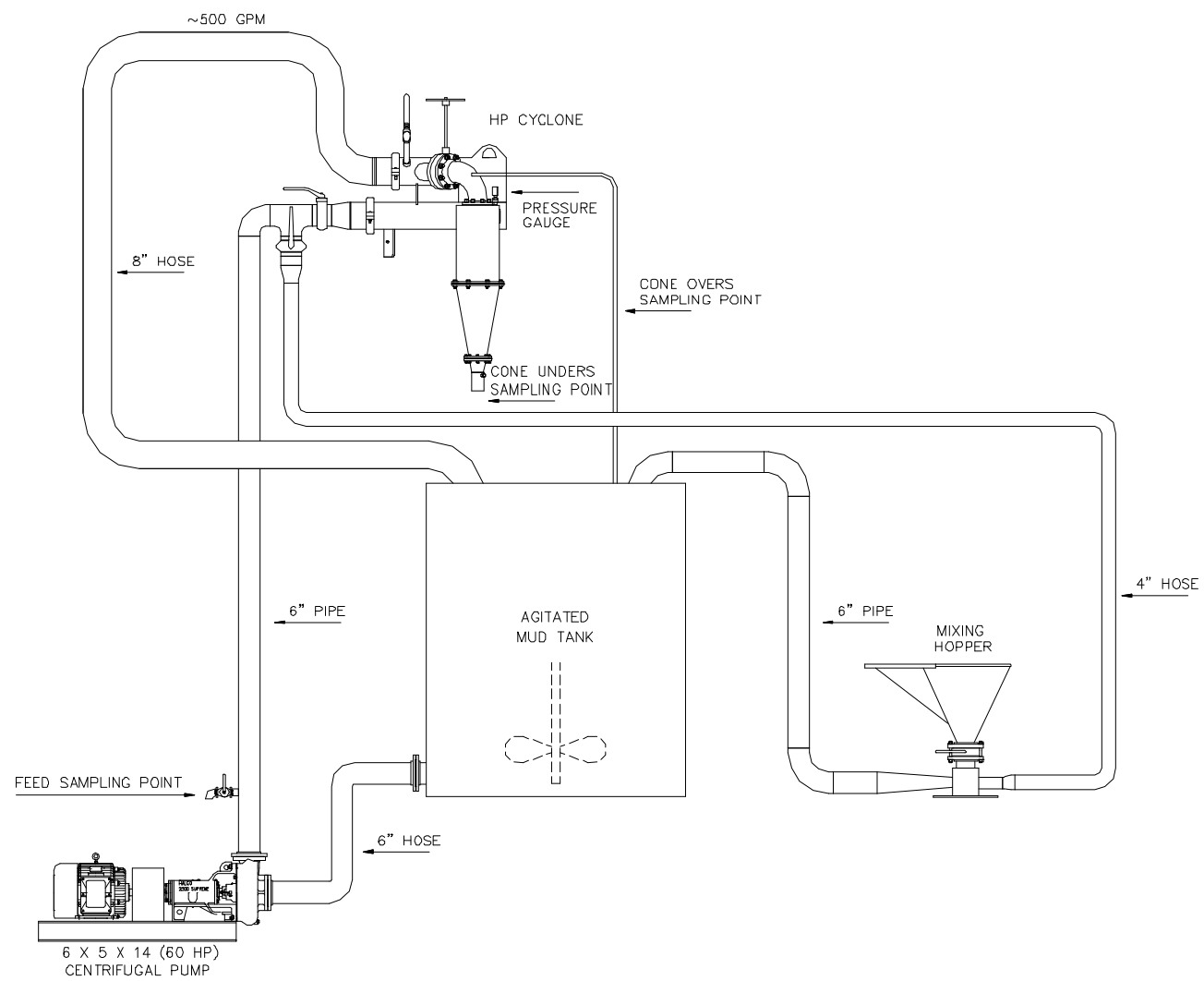

Figure 57. Schematic of Hydrocyclone Flow Loop

Mud in the flow loop tank is mixed using a conventional mud mixer (Figure 58) on top of the mud mixing tank (Figure 59). This mixer keeps the spheres and drill cuttings suspended in the mud.

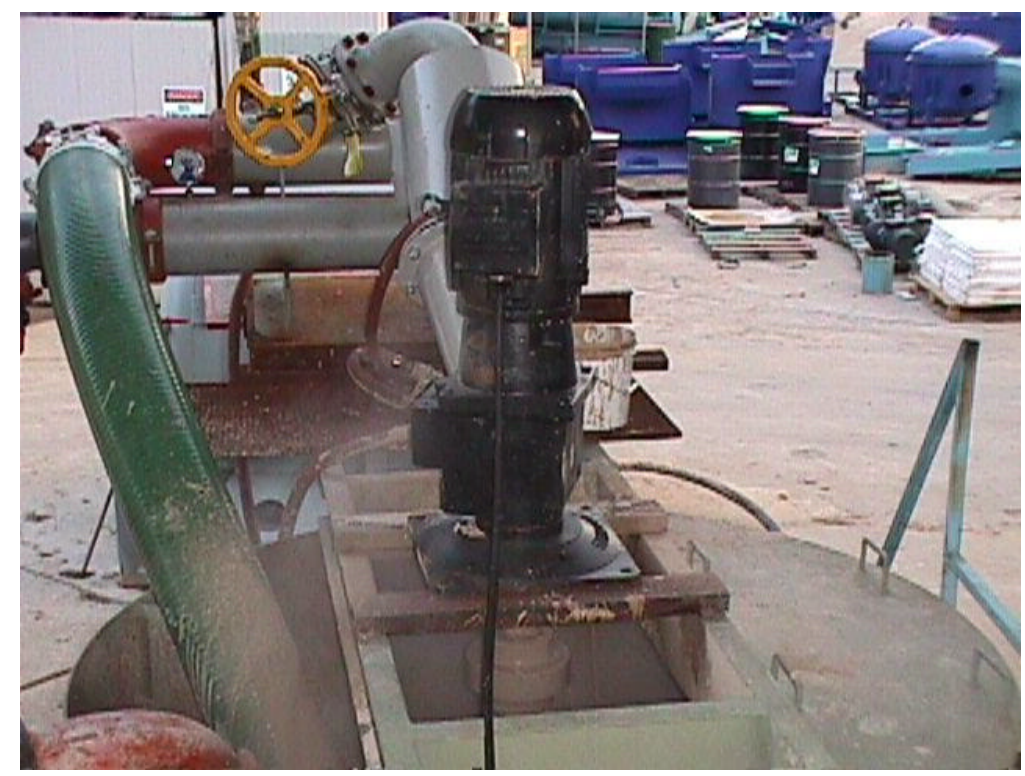

Figure 58. Flow Loop Mud Mixer 


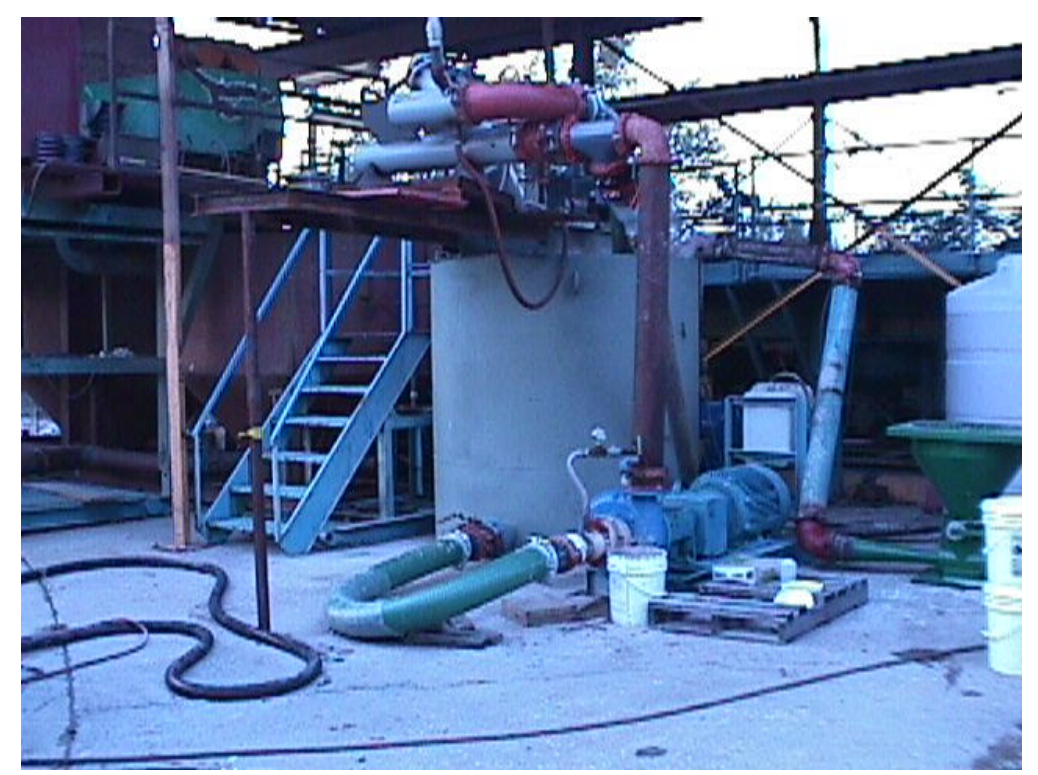

Figure 59. Mud Mixing Tank

A centrifugal pump on the mixing tank was used to pump fluid from the flow loop tank to the 12-inch Varco hydrocyclone (Figure 60).

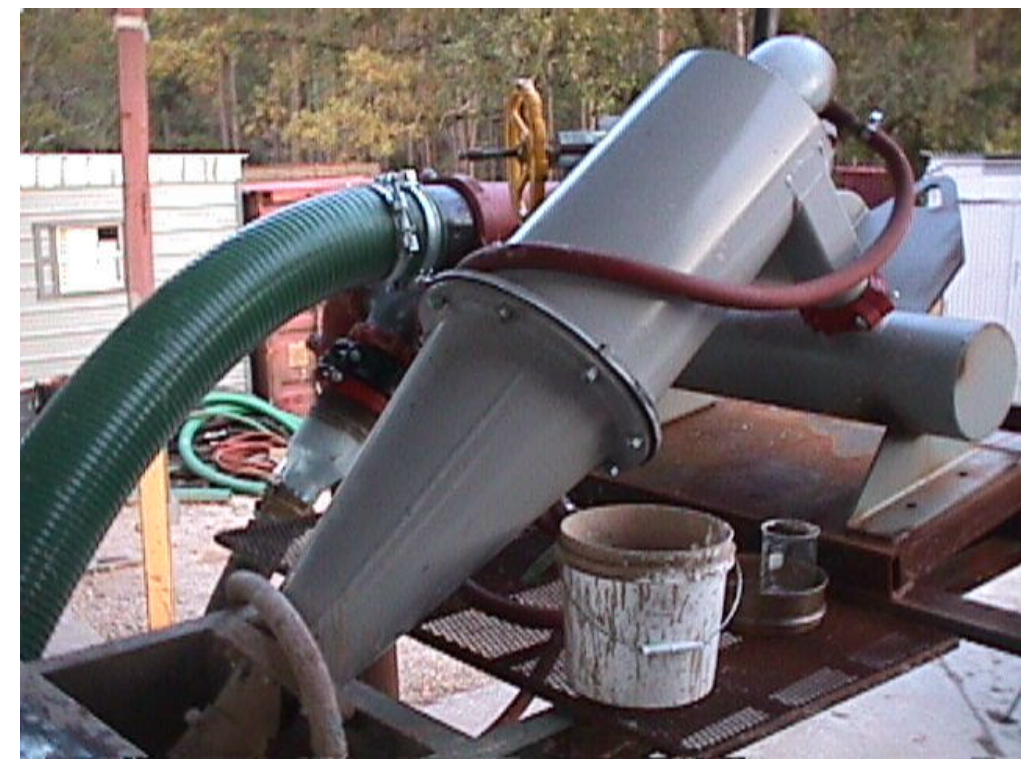

Figure 60. 12-in. Varco Hydrocyclone

A small ball valve was used at the "feed sampling point" shown in the flow-loop schematic in Figure 57. A mud hopper (Figure 61) was used to mix spheres into the mud. 


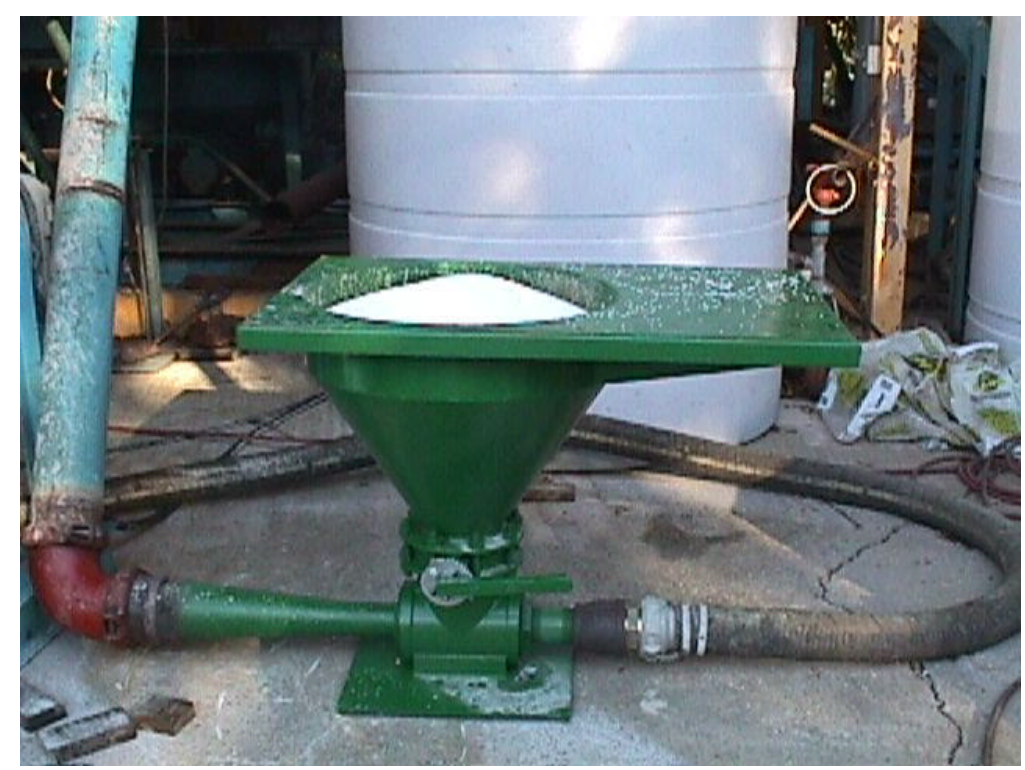

Figure 61. Sphere Mixing Hopper

Hydrocyclone under- and over-flows were mixed back together in the mud mixing tank and continually recirculated for 8 hours to study sphere degradation. A gate valve (Figure 62) was used to adjust backpressure on the hydrocyclone overflow to alter the performance of the cone. The gate valve allows making small changes to optimize hydrocyclone performance. However, larger changes require major modifications to the hydrocyclone configuration.

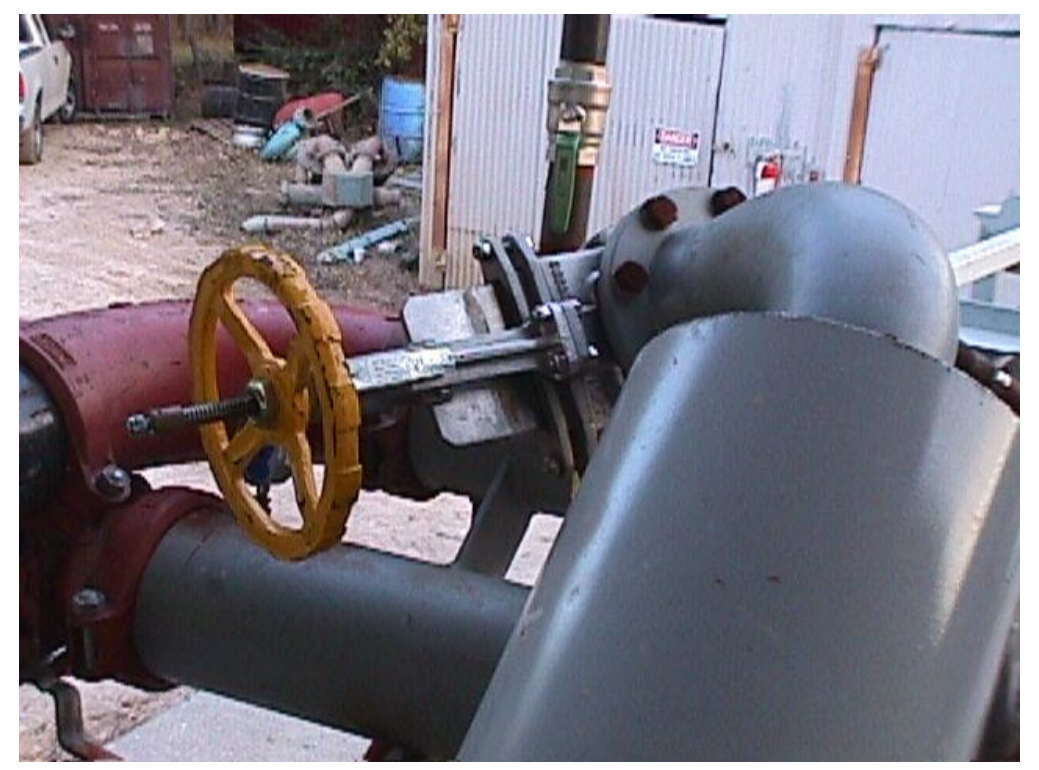

Figure 62. Adjustment Gate Valve

A small line transporting fluid from the hydrocyclone overflow was used to take samples for the test since the majority of the fluid exits the overflow. The underflow was 
sampled directly from the bottom of the cone. Calculations showed that when drilling a $171 / 2$-inch hole at $150 \mathrm{ft} / \mathrm{hr}$ with $1000 \mathrm{gpm}$ flow rate, there will be $3.12 \%$ by volume drill cuttings in the mud (Table 14).

Table 14. Theoretical Well Conditions

\begin{tabular}{|l|c|}
\hline Parameter & Value \\
\hline Hole Size & $17.5 \mathrm{in}$. \\
\hline Cuttings Specific Gravity & $2.6 \mathrm{~g} / \mathrm{cc}$ \\
\hline ROP & $150 \mathrm{ft} / \mathrm{hr}$ \\
\hline Flow Rate & $1000 \mathrm{gpm}$ \\
\hline Cuttings \% by volume in base mud & $3.12 \%$ \\
\hline Cuttings & $0.74 \mathrm{bbl} / \mathrm{min}$ \\
\hline Cuttings & $676.5 \mathrm{lb} / \mathrm{min}$ \\
\hline Cuttings lb/bbl in mud volume & 28.4 \\
\hline Base Fluid Density & $8.33 \mathrm{lb} / \mathrm{gal}$ \\
\hline
\end{tabular}

Sand and gravel were added to the mud to simulate $3 \%$ drill cuttings. Then $20 \%$ by volume of $3 \mathrm{M}$ spheres ( $\mathrm{SG}=0.56 ; 2$ to $3 \mathrm{~mm}$ ) were mixed into the mud and this sphere mixture was then circulated through the hydrocyclone.

Mud samples were taken at the start of the test, every 2 hours during the test, and at the end of the test from the feed, overflow, and underflow (Figure 63).

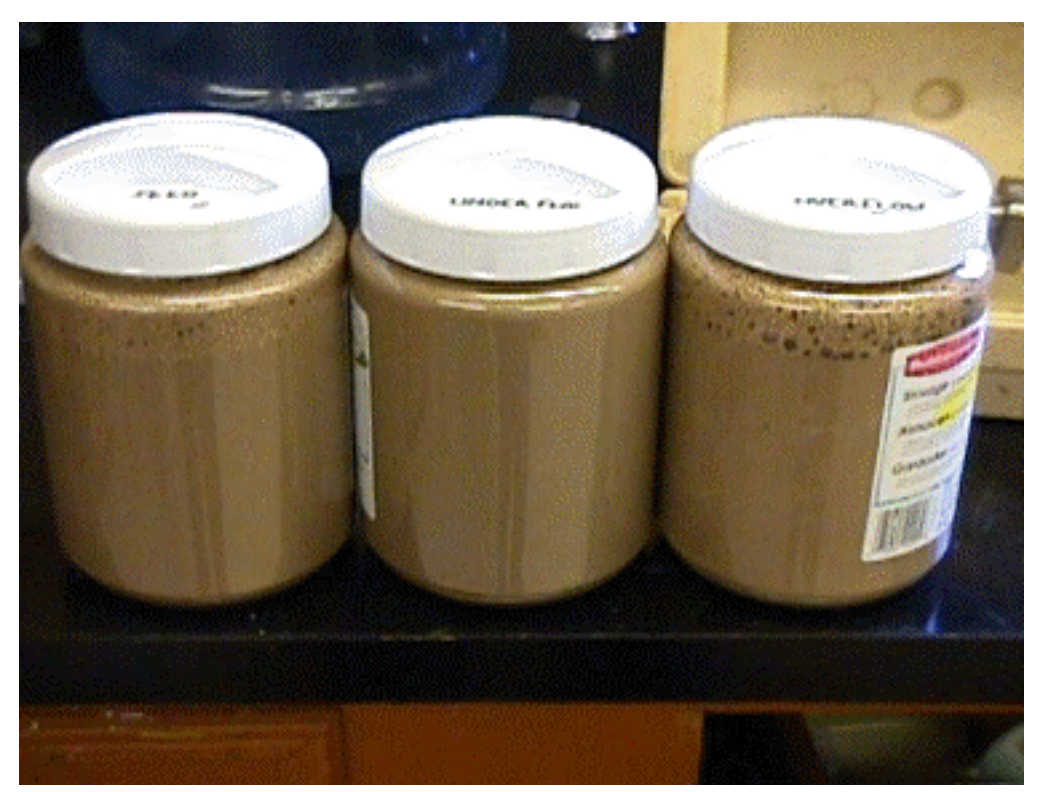

Figure 63. Samples for Post-Test Evaluation 
All samples were weighed to determine mud weight at each collection point and efficiency of the hydrocyclone at separating drill cuttings and spheres from the mud. Every other sample set was kept for post-test evaluation (one-half gallon for Halliburton and one pint for $3 \mathrm{M}$ ). A scale was used to weigh the half-gallon samples to determine mud weights (Figure 64).

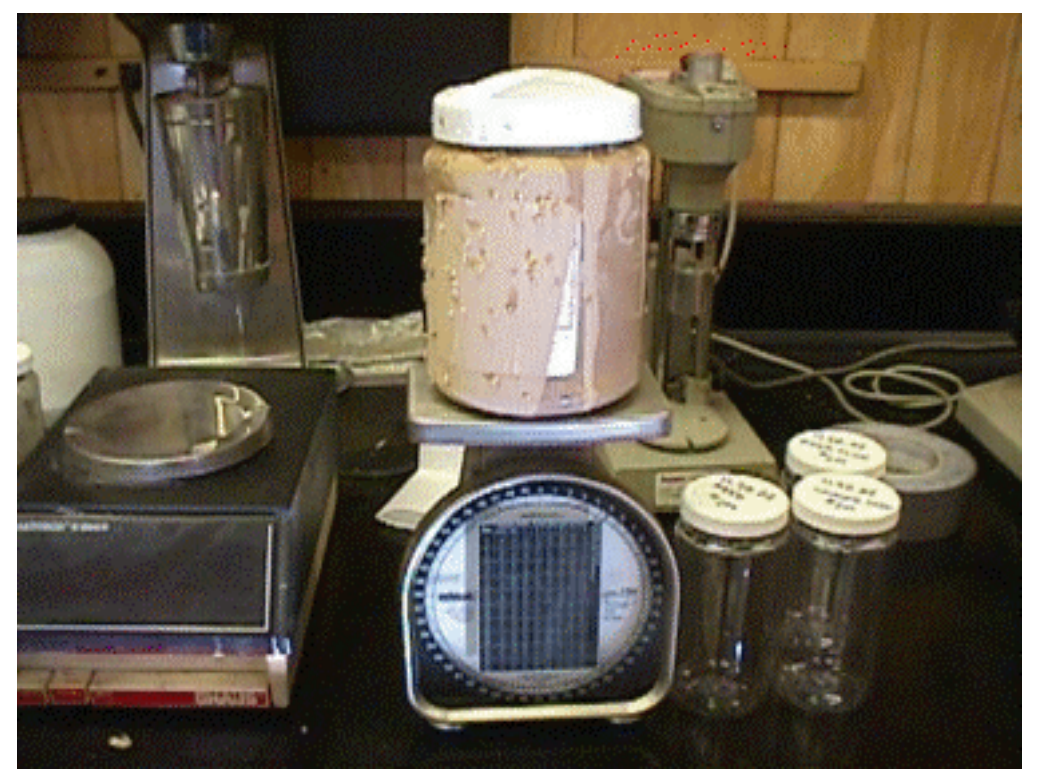

Figure 64. Weighing Half-Gallon Sample

Properties of the different feed muds are shown in Table 15.

Table 15. Feed Mud Properties

\begin{tabular}{|c|c|c|c|c|c|c|c|}
\hline $\begin{array}{c}\text { Test } \\
\text { No. }\end{array}$ & Mud Type & $\begin{array}{c}\text { Base Mud } \\
\text { Weight } \\
(\mathrm{lb} / \mathrm{gal})\end{array}$ & $\begin{array}{c}\text { Final Mud } \\
\text { Weight } \\
(\mathrm{lb} / \mathrm{gal})\end{array}$ & $\begin{array}{c}\text { Test } \\
\text { Length } \\
(\mathrm{hr})\end{array}$ & $\begin{array}{c}\text { Base Mud } \\
\text { Volume (bbl) }\end{array}$ & $\begin{array}{c}\text { Bead } \\
\text { Loading \% } \\
\text { by Volume }\end{array}$ & $\begin{array}{c}\text { Cuttings \% } \\
\text { by Volume }\end{array}$ \\
\hline 1 & Water & 11.4 & 10.34 & 8.5 & 15.0 & 20 & 3 \\
\hline 2 & Water & 10.0 & 9.39 & 8 & 15.0 & 20 & 3 \\
\hline 3 & Oilbase & 12.8 & 11.43 & 8.5 & 13.84 & 20 & 3 \\
\hline
\end{tabular}

\subsection{TEST RESULTS}

Tests were conducted with two waterbase muds (10.0 and $11.4 \mathrm{ppg}$ ) and one synthetic oil mud (12.8 ppg), each containing $20 \%$ beads and $3 \%$ drill solids. Table 16 shows results of the hydrocyclone tests with waterbase and synthetic muds. Figure 65 shows typical results with the 12-inch Varco hydrocyclone. 
Table 16. Varco Hydrocyclone Test Results (20\% Spheres, $3 \%$ Solids)

\begin{tabular}{|c|c|c|c|c|c|c|c|c|c|c|c|c|c|c|c|}
\hline \multirow{3}{*}{$\begin{array}{l}\text { Test } \\
\text { No. }\end{array}$} & \multicolumn{2}{|c|}{ Base Mud } & \multicolumn{4}{|c|}{ Feed } & \multicolumn{5}{|c|}{ Overflow } & \multicolumn{4}{|c|}{ Underflow } \\
\hline & Type & Weight & Total & Mud & Beads & Cuttings & Total & Mud & Bea & & Cuttings & Total & Mud & Beads & Cuttings \\
\hline & & (ppg) & (gpm) & (gpm) & (gpm) & (gpm) & (gpm) & (gpm) & (vol.\%) & (gpm) & (gpm) & (gpm) & (gpm) & (gpm) & \\
\hline 1 & Waterbase & 11.4 & 500 & 385 & 100 & 15 & 480 & 380 & 100 & 20.8 & 0 & 20 & 5 & 0 & 15 \\
\hline 2 & Waterbase & 10.0 & 500 & 385 & 100 & 15 & 481 & 381 & 100 & 20.8 & 0 & 19 & 4 & 0 & 15 \\
\hline 3 & Synthetic Oil & 12.8 & 500 & 385 & 100 & 15 & 470 & 370 & 100 & 21.3 & 0 & 30 & 15 & 0 & 15 \\
\hline
\end{tabular}

500 GPM (Feed)

388 GPM Base Mud

100 GPM Beads

12 GPM Drill Solids

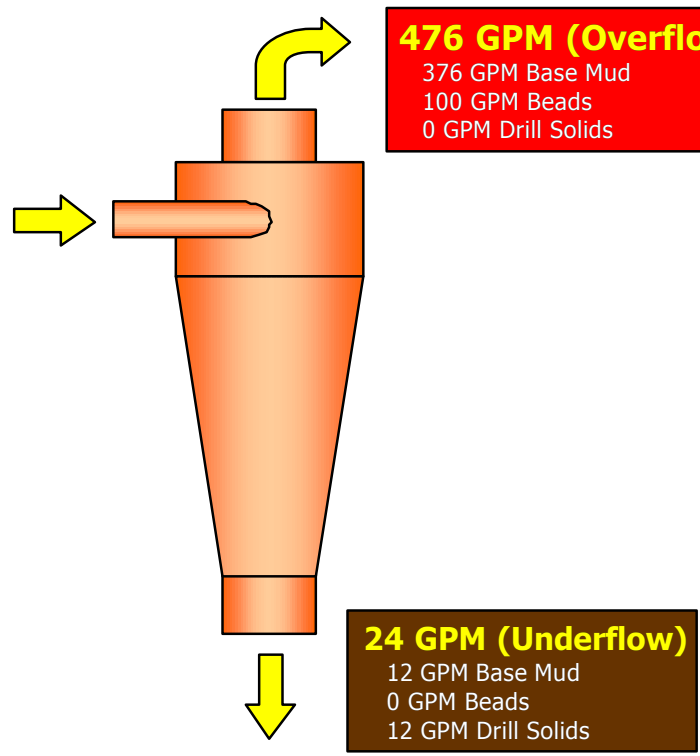

Figure 65. Typical Separation with 12-inch Varco Hydrocyclone

The 12-inch Varco hydrocyclone was very effective in all of the tests. $100 \%$ of the beads came out the top of the cone and all the cuttings (except for trace amounts) came out the bottom of the cone.

With $500 \mathrm{gpm}$ waterbase mud feed containing $20 \%$ beads (100 gpm) and $3 \%$ cuttings (15 gpm), $480 \mathrm{gpm}$ flow (380 gpm mud and $100 \mathrm{gpm}$ beads) came out the overflow while $20 \mathrm{gpm}$ (5 gpm mud and $15 \mathrm{gpm}$ cuttings) came out the underflow. The results were very similar with $500 \mathrm{gpm}$ synthetic oil mud feed $(100 \mathrm{gpm}$ beads and 15 gpm cuttings), with $470 \mathrm{gpm}$ overflow (370 gpm mud and $100 \mathrm{gpm}$ beads) and $30 \mathrm{gpm}$ underflow (15 gpm mud and $15 \mathrm{gpm}$ beads).

These tests showed that two to four 12-inch hydrocyclones could effectively separate spheres and drill cuttings at flow rates of 1000 to $2000 \mathrm{gpm}$ as required with this DGD system. Varco engineers indicated to project personnel that they were very pleased with these results and stated that the hydrocyclone performed much better than they expected. Based on their observations, they were $100 \%$ confident that a reliable 
sphere separation system could be designed for this DGD system using hydrocyclones and shale shakers.

\subsection{CONCLUSIONS}

1. In hydrocyclone separation tests, $100 \%$ of the beads came out as part of the 460 to $480 \mathrm{gpm}$ overflow. The $500 \mathrm{gpm}$ feed mud to the hydrocyclone consisted of $77 \%$ base mud, $20 \% 3 \mathrm{M}$ spheres, and $3 \%$ drill cuttings (sand and pebbles).

2. $100 \%$ of the simulated drill cuttings (sand and pebbles) came out the bottom of the cone in the 20 to $40 \mathrm{gpm}$ underflow.

3. No plugging problems were encountered with the 12-inch hydrocyclone.

4. Beads passed through the centrifugal pump and hydrocyclone over 800 times with no detectable breakage or wear. This corresponds to the number of circulations in 2 to 6 wells.

5. Waterbase and oilbase muds produced no chemical degradation of the $3 \mathrm{M}$ beads.

6. A 12-inch Varco hydrocyclone produced a $50 \%$ sphere mixture in the overflow at a feed rate of $430 \mathrm{gpm}$ with $20 \%$ spheres in the feed mixture.

7. Two to four hydrocyclones should handle the 1000 to $2000 \mathrm{gpm}$ flow rates required with this DGD system.

8. A 12-inch hydrocyclone should be a highly reliable option for removing spheres and drill solids from DGD muds. 


\section{Flow Loop Tests (Oilfield Waterbase Mud)}

\subsection{INTRODUCTION}

Phase I of the Hollow Sphere DGD joint-industry project was focused on testing individual components of the DGD system including: hollow spheres, low- and highpressure pumps, shale shakers, hydrocyclones, mud-mixing systems, mud rheometers, and flowmeters. The objective of this DOE follow-on project was to test the complete DGD system with oilfield muds in a flow loop to more clearly define feasibility of the system.

\subsection{DRC FLOW LOOP}

The DGD system was tested in the flow loop at MTI's Drilling Research Center (DRC) depicted in Figure 66.

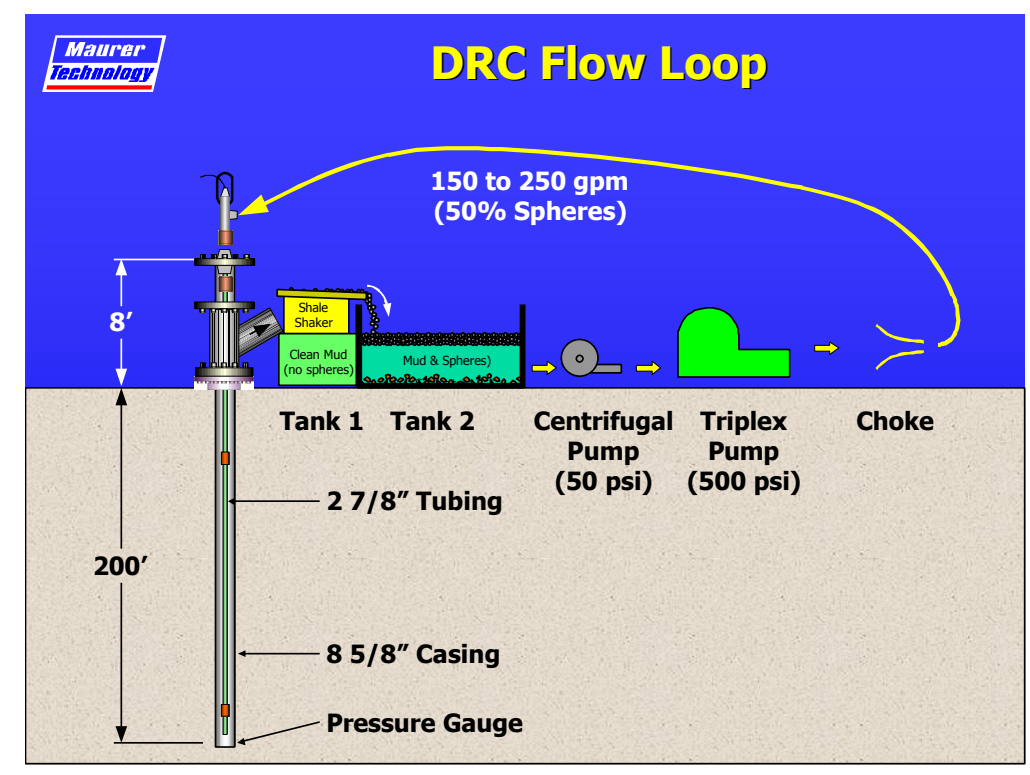

Figure 66. DRC Flow Loop

Mud containing up to $25 \%$ spheres was pumped to a 200 - $\mathrm{ft}$ test well using a 440 HP Ellis Williams triplex mud pump. The $200-\mathrm{ft}$ test well contained $8-5 / 8$ inch casing and 2-7/8 inch tubing (Figure 67). 


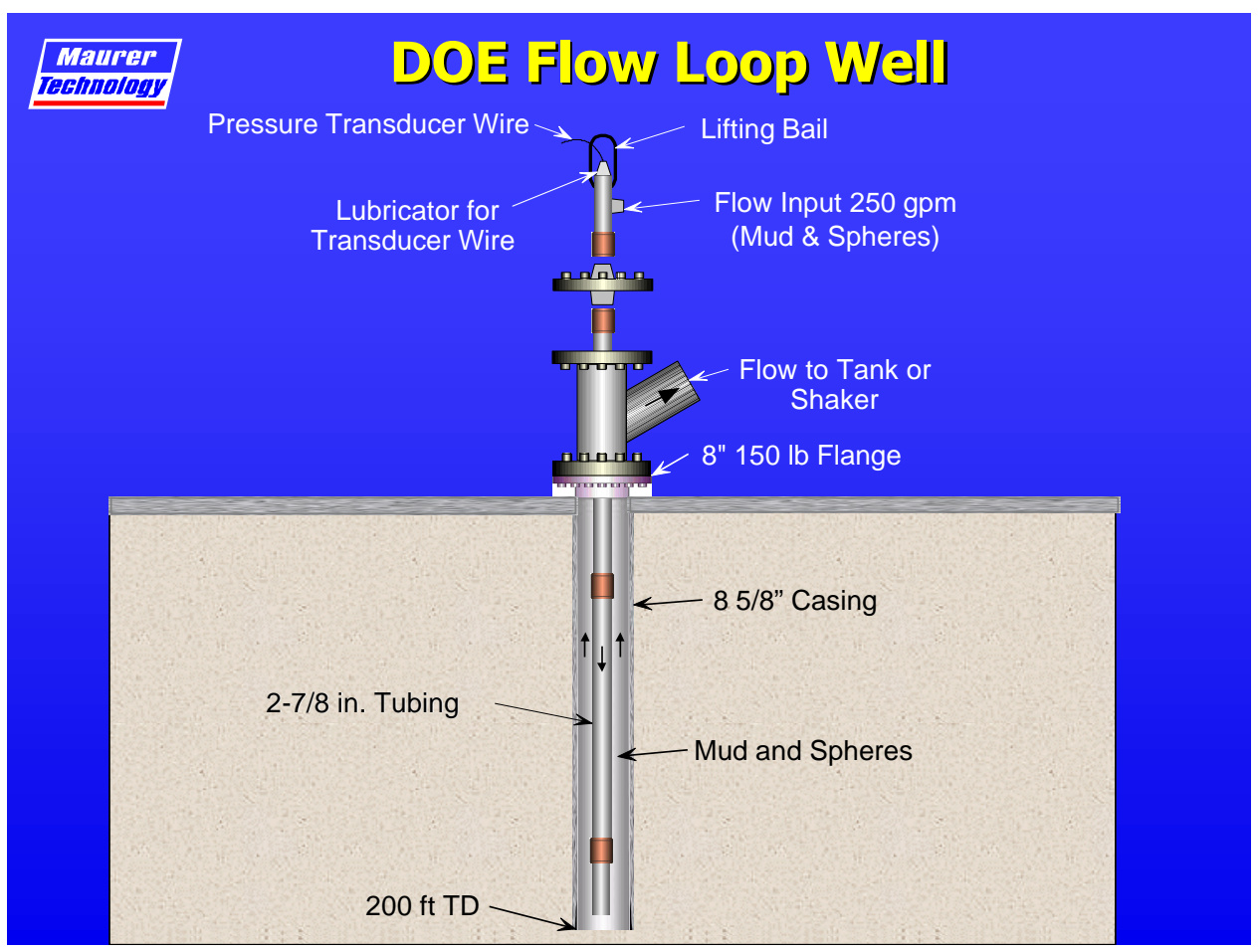

Figure 67. DOE Flow Loop Well

A choke was placed downside of the mud pump to create a 500-psi pressure drop on the triplex mud pump. Earlier tests showed that $25 \%$ spheres could be pumped at 1400 psi with the Ellis Williams mud pump, so higher pump pressures were not necessary for this test.

Although the test well is only $200 \mathrm{ft}$ deep, the flow loop contains all elements required with a deepwater DGD system, so it is an effective set-up for testing the entire system.

\subsection{TEST MUDS}

An 8.34-ppg polymer mud and 10.8-ppg waterbase (bentonite) mud described in Chapter 4 were mixed together to form a 9.9-ppg oilfield waterbase mud containing both bentonite and polymer ( $P V=15 \mathrm{cp}$ and $\left.\mathrm{YP}=32 \mathrm{lbf} / 100 \mathrm{ft}^{2}\right)$. Six speed viscometer data for this mud are given in Table 5 in Chapter 4. 


\subsection{TEST PROCEDURES}

$3 \mathrm{M}$ spheres (2 to $3 \mathrm{~mm}$ ) were mixed into oilfield waterbase mud (provided by Halliburton) in the DRC mixing tank shown in Figure 68.

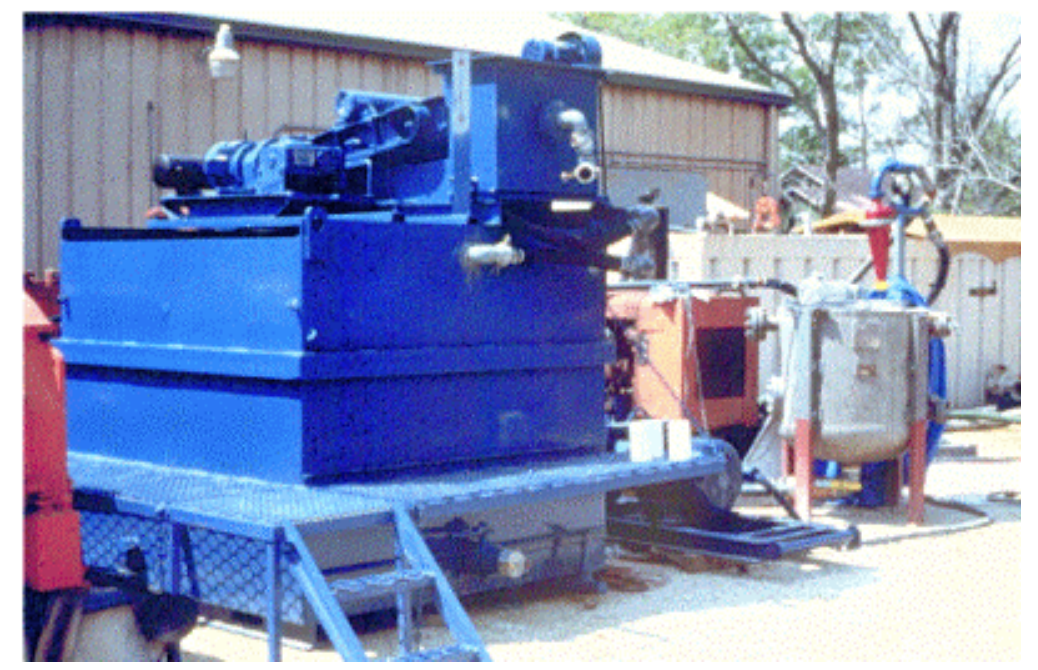

Figure 68. National Oilwell T180 Shale Shaker on Mixing Tank

A mud mixer and mud pumps were used to maintain $25 \% 3 \mathrm{M}$ spheres suspended in the mud (Figure 69).

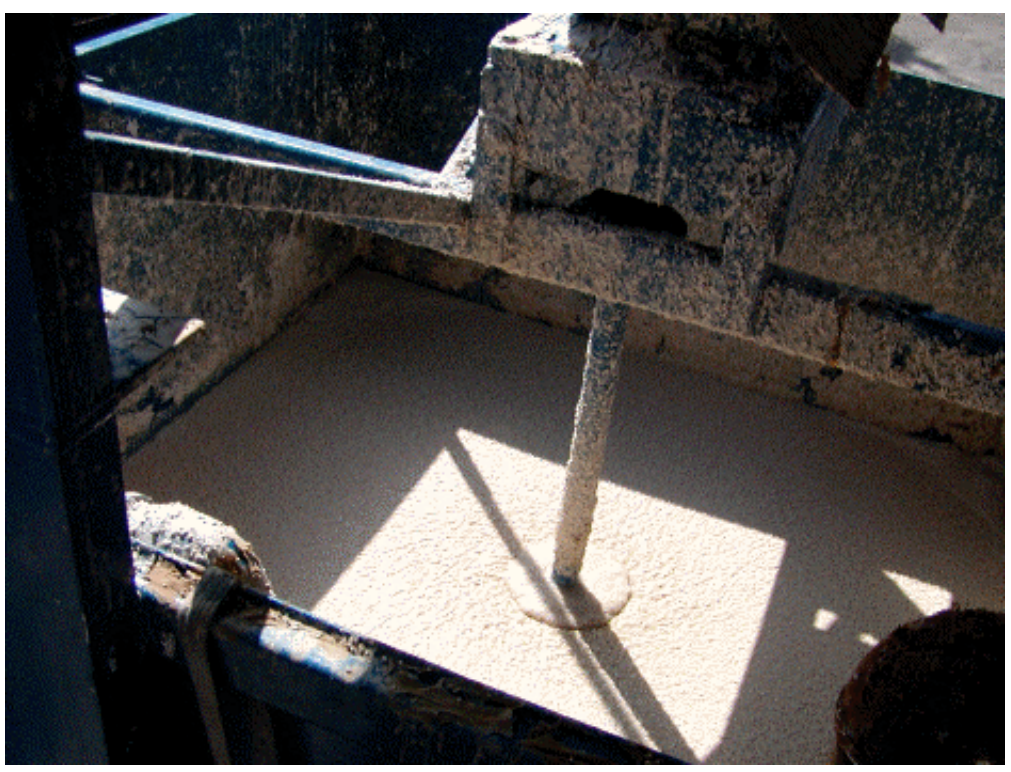

Figure 69. 25\% Spheres Mixed in Mud

A $6 \times 5$-inch 40-HP centrifugal pump (Figure 70) was used to pump 3M spheres to an Ellis Williams 440-HP triplex mud pump (Figure 71). 


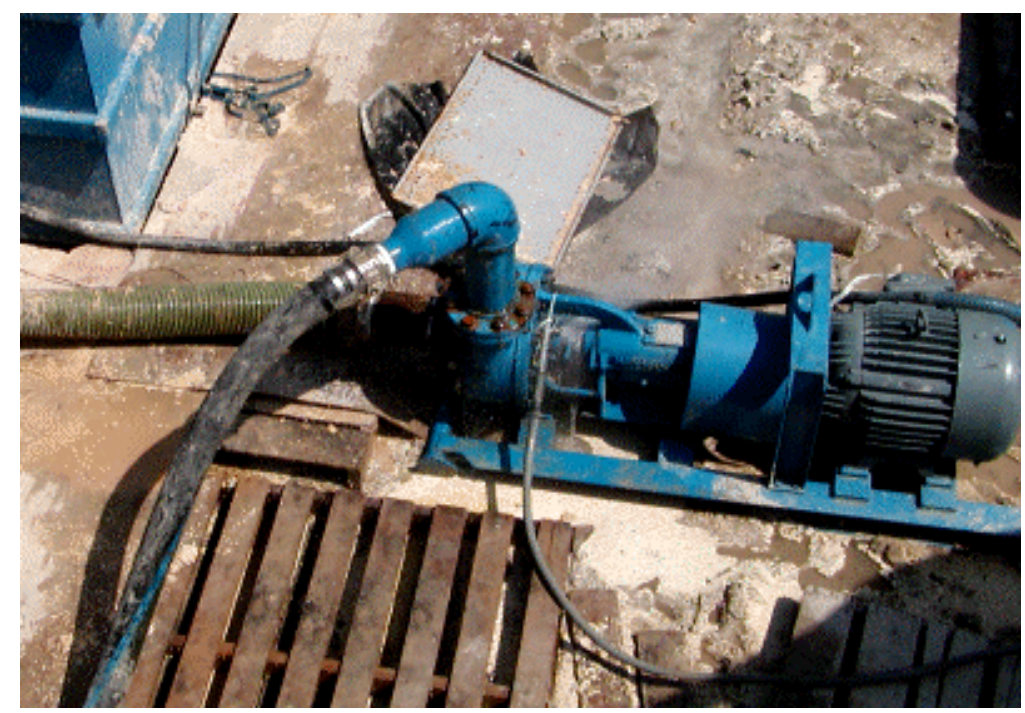

Figure 70. 40-HP Centrifugal Pump

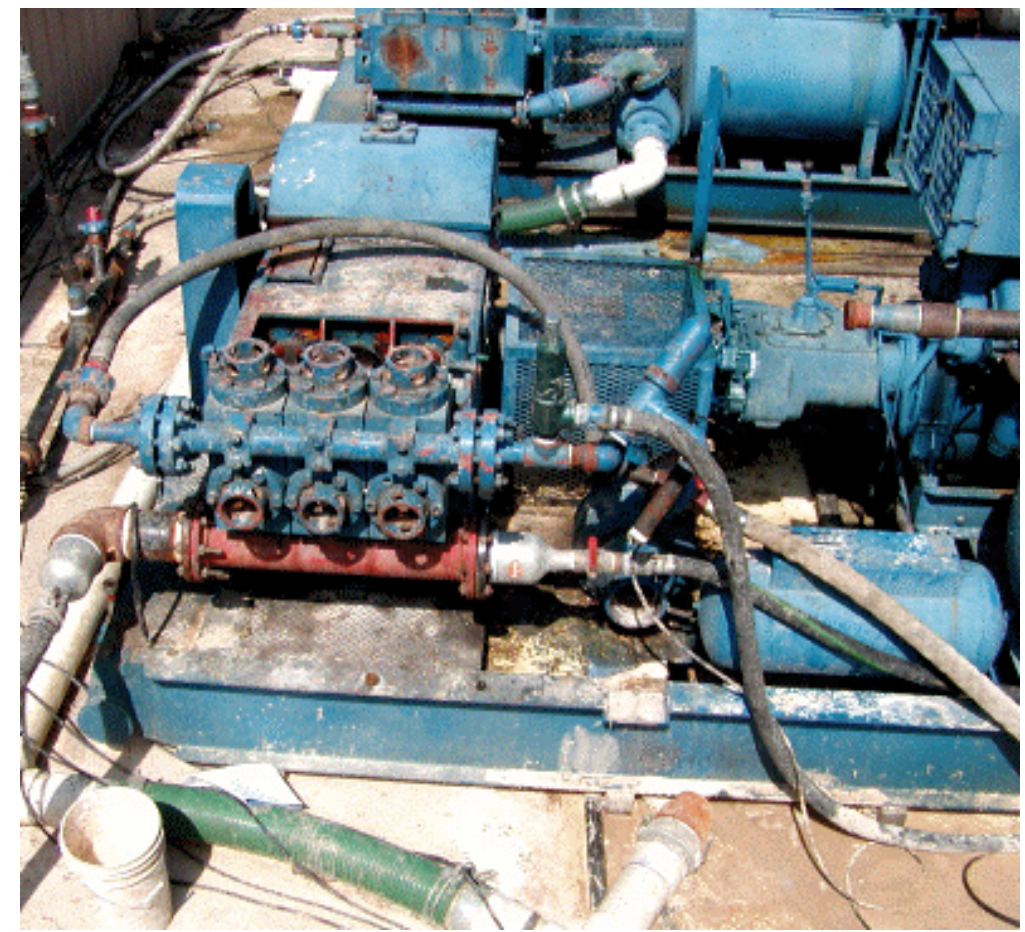

Figure 71. 440-HP Ellis Williams Pump

Spheres were pumped to the test well through a steel pipe and returned to the shale shaker and mud tank through a low-pressure hose (Figure 72). 


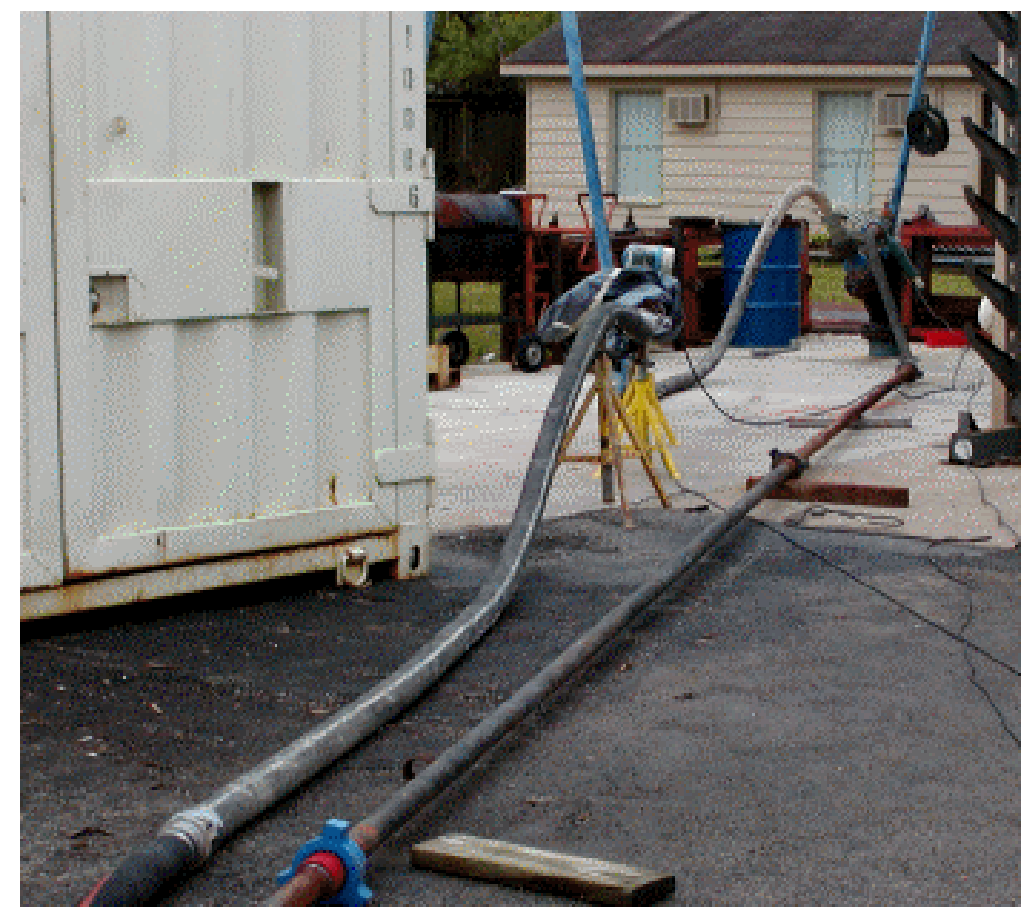

Figure 72. Steel Flowline to Wellhead and Hose Return

Multiple $2 \times 1$-inch swages were used downstream of the Ellis Williams triplex pump to create a 500-psi pressure drop (Figure 73).

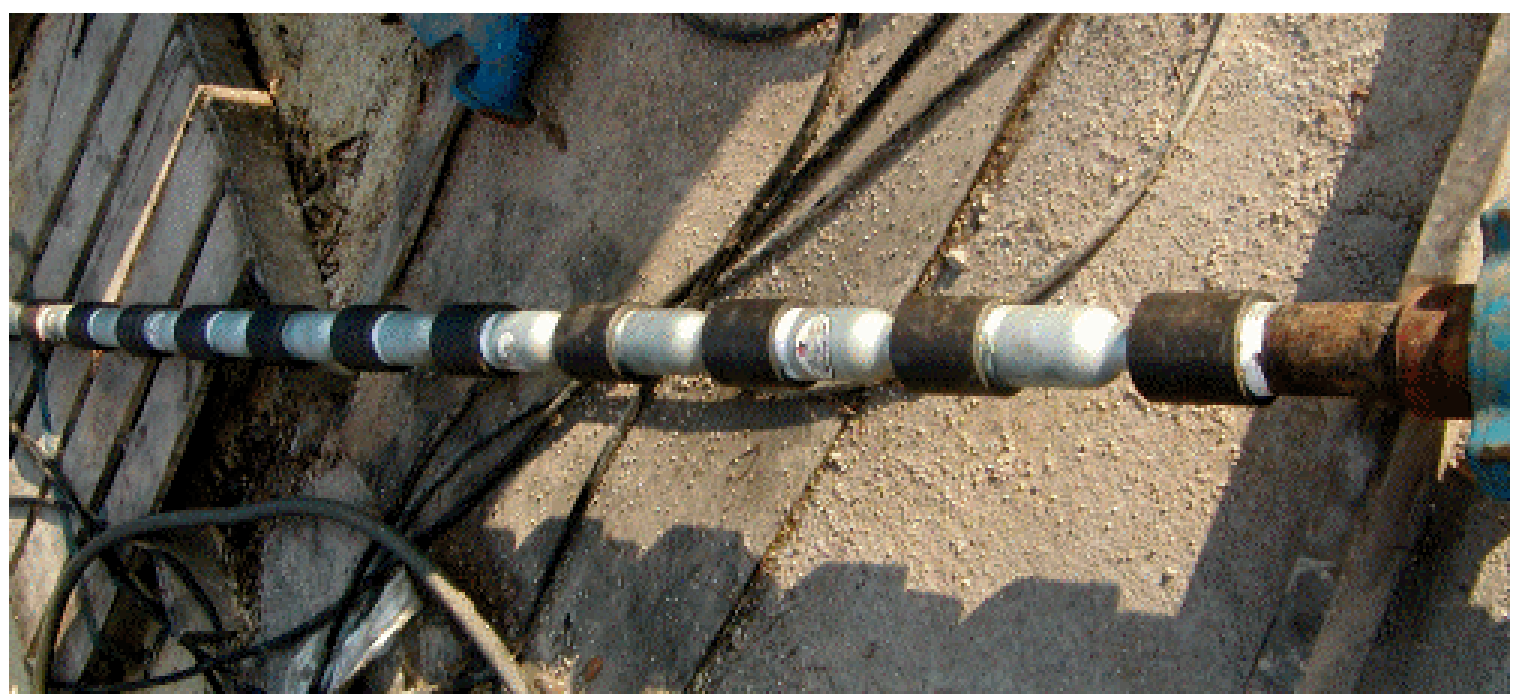

Figure 73. Multiple $2 \times 1$-inch Swages $(\Delta p=500 p s i)$ 
Mud with $25 \%$ spheres was pumped to the test well wellhead and to the bottom of the $200 \mathrm{ft}$ well in 2-7/8 inch tubing (Figure 74).

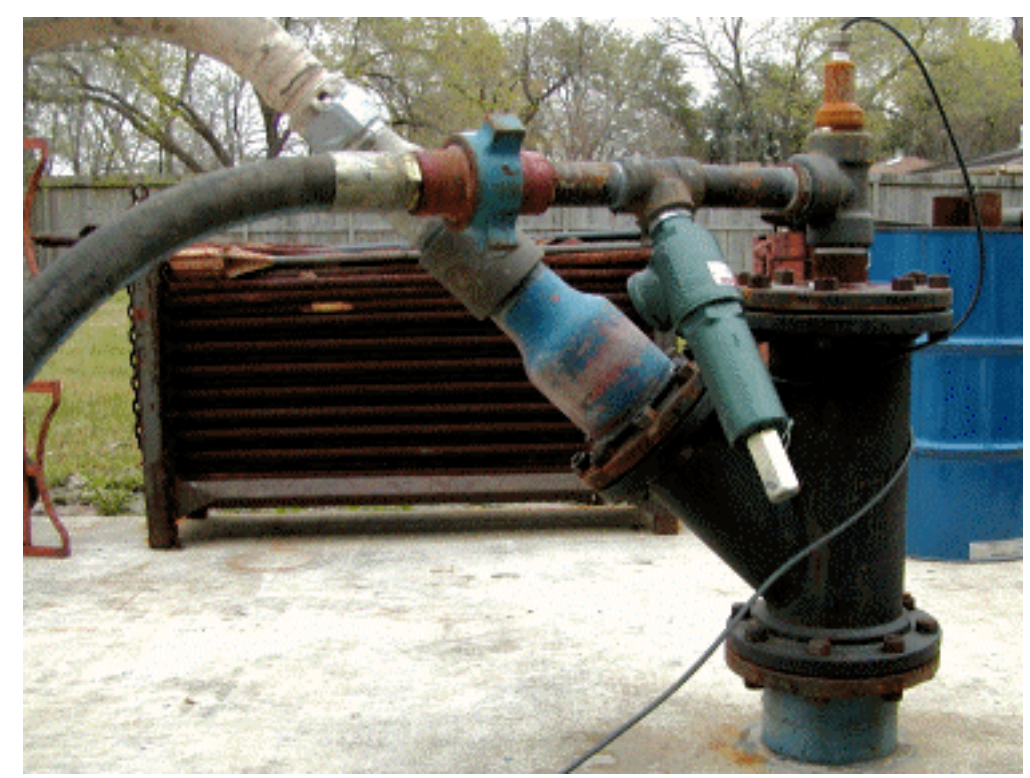

Figure 74. Test Wellhead Assembly

Spheres flowed up the annular space between the 2-7/8 inch tubing and 8-5/8 inch casing and back to the National Oilwell T180 shale shaker shown in Figure 68. The 10-mesh screen on the shale shaker removed $100 \%$ of the spheres in the overflow. The spheres were mixed back into the mud and recirculated to the test well. The well was circulated for 8 hours in this manner with no problems encountered with pumps or other equipment and with no noticeable degradation of the $3 \mathrm{M}$ spheres.

\subsection{TEST RESULTS}

Circulation tests in the flow loop were very successful. Important results include:

1. Spheres were continually circulated through the flow loop and test well for 8 hours with no problems and without breakage of the spheres.

2. A 10-mesh screen on the National Oilwell T180 shale shaker removed $100 \%$ of the $3 \mathrm{M}$ spheres ( 2 to $3 \mathrm{~mm}$ ) from the oilfield waterbase mud.

3. Centrifugal and triplex pumps successfully pumped the $25 \%$ sphere mixture. 
4. When the well was shut in, spheres eventually floated to the surface and were easily removed from the well.

5. Pressure drops with the mud mixture in the flowline and well were low, showing that spheres can be pumped to the seafloor with conventional oilfield triplex mud pumps.

6. Clean mud (no spheres) should be circulated through the pumps when they are shut down to prevent spheres from separating (floating upward) and plugging the inlets to the suction valve.

7. These tests were very successful, showing that it should be possible to develop a full-scale DGD system using conventional oilfield equipment (e.g., mud pumps, shale shakers, mud tanks, mud hoppers, etc.) that can be maintained by rig crews.

\subsection{CONCLUSIONS}

1. All components of the DGD system worked well in these flow-loop tests.

2. No problems were encountered in pumping spheres, circulating them through the well, or separating them from the mud at the surface.

3. It should be possible to develop a low-cost, reliable hollow sphere DGD system.

4. This DGD system should be field tested. 


\section{Top-Hole DGD Rig Study}

\subsection{CONVENTIONAL DEEPWATER RIGS}

Conventional deepwater rigs (Figure 75) are very large because they use 21-inch risers and require mud tank capacities as large as 30,000 bbl for pump-and-dump (P\&D) operations.

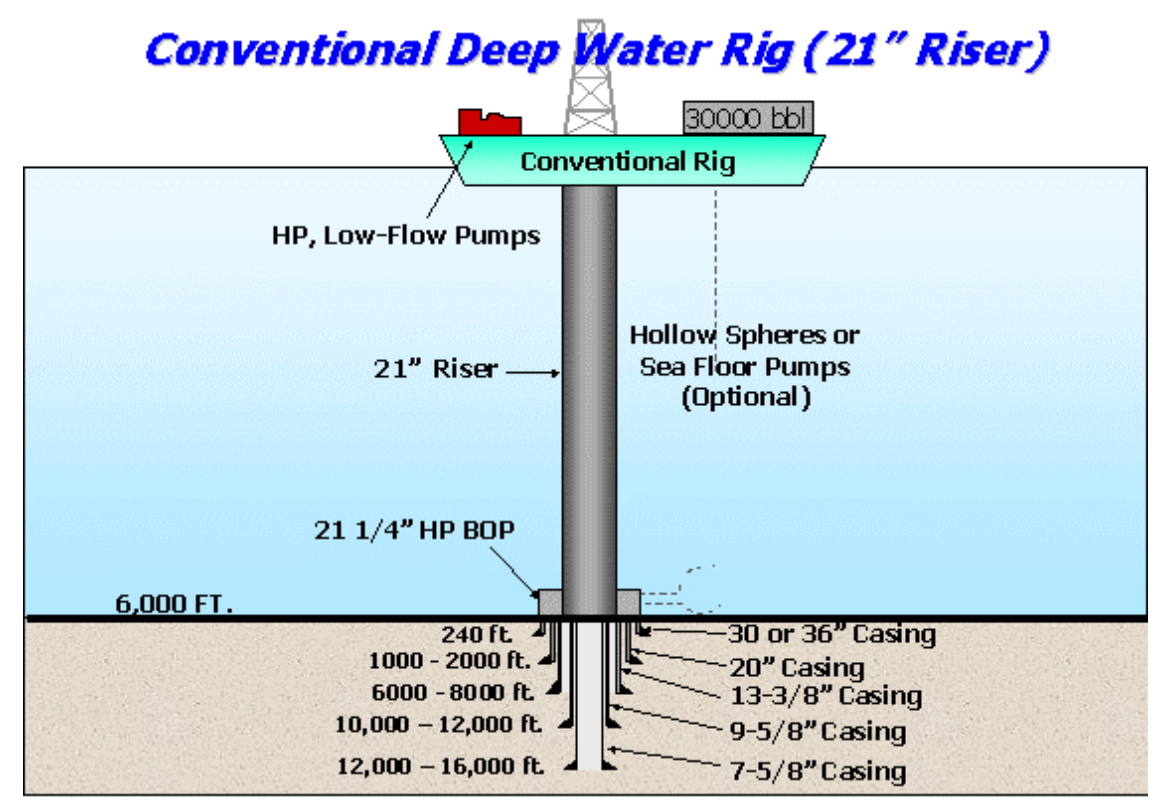

Figure 75. Conventional Deep-Water Rig with 21-inch Riser

Conventional rigs typically drill 20 -inch and larger casing sections without risers using P\&D drilling. The 13-3/8 inch casing and smaller sections are drilled using a 21inch riser to return mud back up to the rig.

Typical large deepwater rigs cost up to $\$ 350$ million to build, and have rental rates of $\$ 175,000$ to $\$ 200,000$ per day. The operator's cost of operating an offshore rig (including shore base, helicopters, supply boats, muds, service companies, etc.) is about equal to the daily rig rental, so the "daily spread cost" which includes rig rental and support costs totals about $\$ 350,000$ to $\$ 400,000$ for large deepwater rigs.

Reducing the size of a rig can significantly reduce both rig rental rate and support costs. When evaluating the impact of DGD on offshore well costs, it is important to evaluate the impact on both these costs. 
A major reason deepwater rigs are required to be large is to support the weight of 21 -inch risers used on these rigs. The use of DGD top-hole rigs could allow a reduction in riser size from 21 inches to 13-3/8 inches. Comparison data in Table 17 show that the heaviest 21 -inch riser weighs $218 \mathrm{lb} / \mathrm{ft}$ compared to only $79 \mathrm{lb} / \mathrm{ft}$ for the heaviest $13-5 / 8$ inch riser. This represents a $64 \%$ reduction in weight.

Table 17. Riser Weight in Air

\begin{tabular}{|c|c|c|c|}
\hline $\begin{array}{c}\text { Riser O.D. } \\
\text { (in) }\end{array}$ & Riser I.D. (in) & $\begin{array}{c}\text { Weight in Air } \\
\text { (lb/ft) }\end{array}$ & BOP Size (in) \\
\hline 21 & 19 to 20 & 218 to 112 & 18.75 \\
\hline 16 & 14 to $15-1 / 4$ & 164 to 64 & 13.85 \\
\hline $13-3 / 8$ & $12-1 / 4$ to $12-3 / 4$ & 79 to 46 & 11 \\
\hline
\end{tabular}

A 6,000 ft, 21-inch riser would weigh 1.3 million pounds in air compared to 0.47 million pounds for a 13-3/8-inch riser. This reduction in required weight capacity will significantly reduce the size and cost of the rig and of the buoyancy material required on the riser.

\subsection{TOP-HOLE RIG CONCEPT}

Several companies, including Conoco, Hydril, and Diamond Offshore, have proposed using smaller, riserless "top-hole" rigs to drill the first two or three casing sections either with pump-and-dump or DGD drilling (Figure 76). 


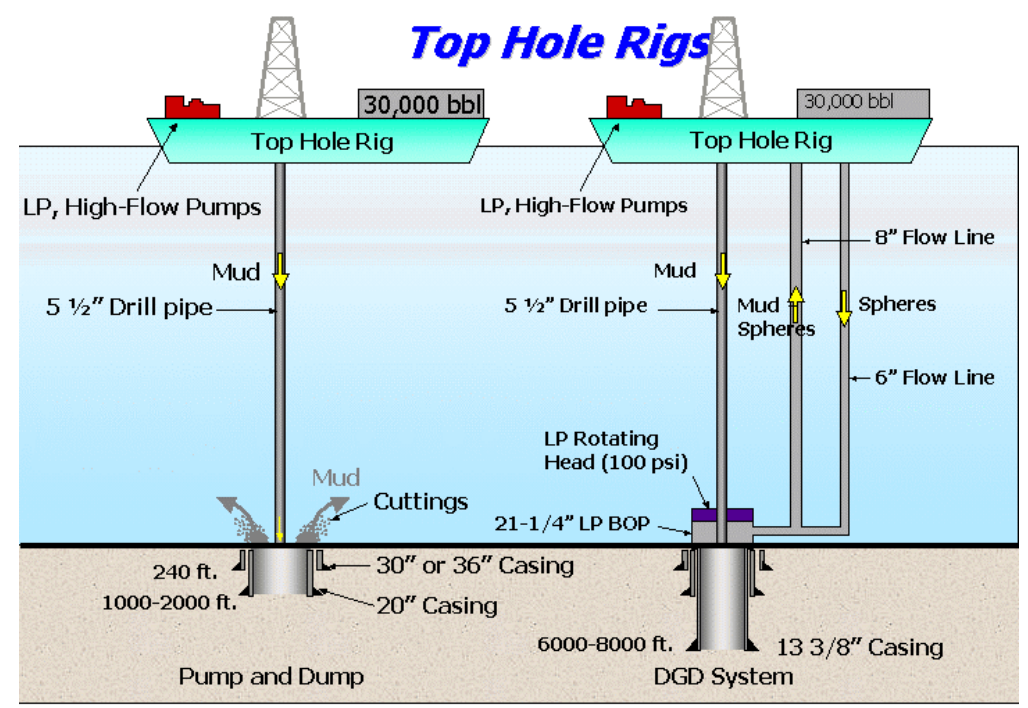

Figure 76. Top-Hole Rigs

After the upper sections of hole are drilled, a larger "deep-hole" rig with a conventional riser would be used to drill lower sections of the well (Figure 77). Use of top-hole rigs would allow smaller, less expensive rigs, thereby significantly reducing overall well costs.

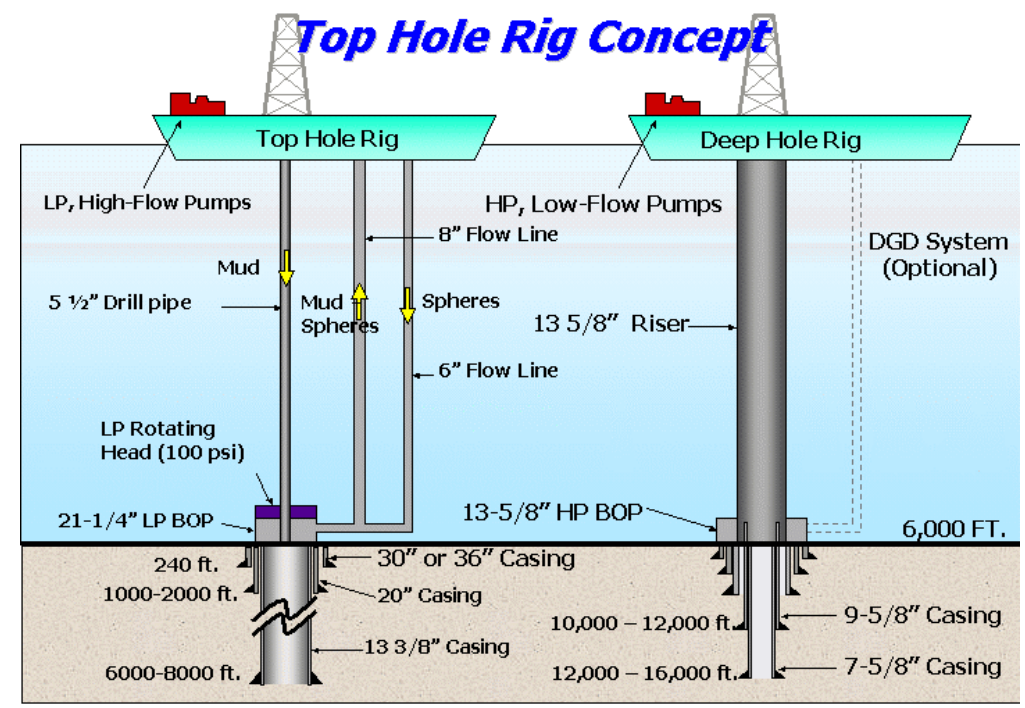

Figure 77. Top-Hole Rig Drilling Concept

The example well in Figure 77 includes five casing strings. If additional casing strings are required, 16 - and 26 -inch casing sections can be drilled with a top-hole rig and 11-3/4-inch and 6-inch casing sections can be drilled with a deep-hole rig. These extra strings should not be needed with DGD drilling. 
DGD systems can be used on one or both these rigs to reduce the number of casing strings. Riserless DGD top-hole rigs could use either hollow-sphere or seafloorpump DGD systems to reduce density of the mud in the riser to that of seawater as described below.

\subsection{TOP-HOLE RIG DESIGNS}

There are three possible designs for riserless top-hole rigs:

1. Riserless Top-Hole Rig (Pump and Dump)

2. Riserless Top-Hole Rig (Hollow Sphere DGD)

3. Riserless Top-Hole Rig (Seafloor Pumps DGD)

Top-hole rigs will drill the first two or three casing sections with pump-and-dump or with DGD. Pump-and-dump operations require up to 30,000 bbl mud storage, whereas DGD requires only a 2,000 bbl mud storage, allowing the top-hole rig to be much smaller.

The 30- or 36-inch casing strings will still be jetted with seawater. The 13-5/8 through 20 -inch casing sections will be drilled with DGD to reduce well problems and to increase casing depth.

\subsubsection{Riserless Top-Hole Rig (Pump and Dump)}

With a riserless top-hole pump-and-dump (P\&D) rig, mud and cuttings are dumped on the seafloor (Figure 78). Unweighted seawater will still be used to jet the 30- or 36-inch casing sections. 


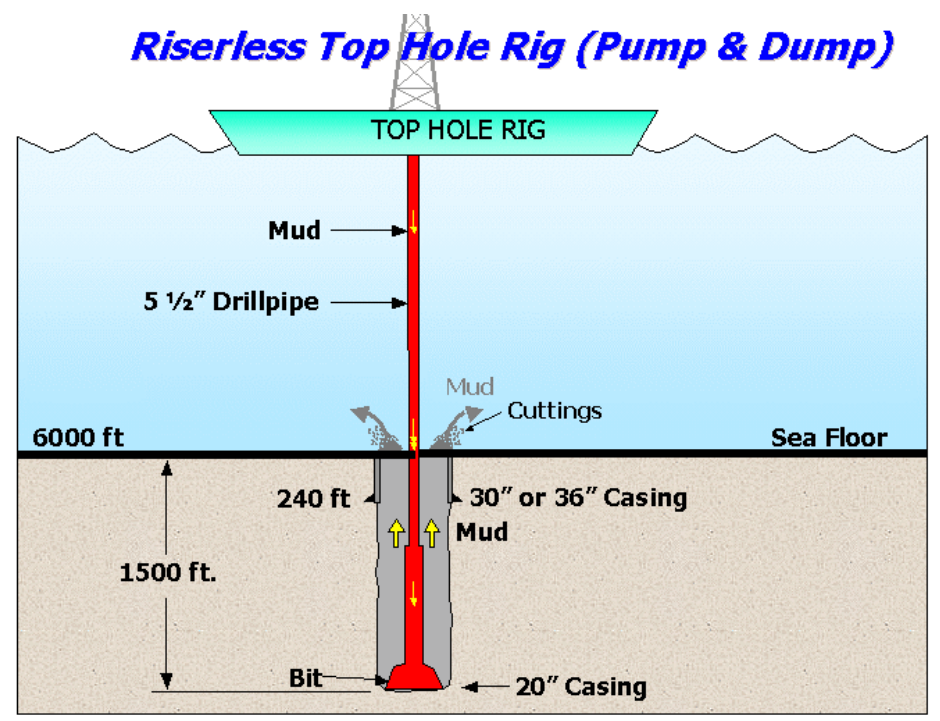

Figure 78. Riserless Top-Hole Rig

Weighted drilling mud (9 to $12 \mathrm{ppg}$ ) is typically used to drill the 20-inch casing section. Up to $30,000 \mathrm{bbl}$ of weighted mud costing up to $\$ 400,000$ is required with this P\&D operation since the mud is circulated once and then discarded. (DGD drilling would eliminate P\&D operations thereby saving much of this mud cost.)

\subsubsection{Riserless Top-Hole Rig (Hollow Sphere DGD)}

With riserless top-hole rigs incorporating a sphere-based DGD system, lightweight hollow or solid spheres (0.4 to $0.5 \mathrm{SG}$ ) are pumped down a 6-inch flow line to the seafloor. At the seafloor, the spheres are mixed with lightweight mud in the wellbore to reduce the density of the mud flowing up an 8-inch return flow line to that of seawater (8.6 ppg) (Figure 79). 


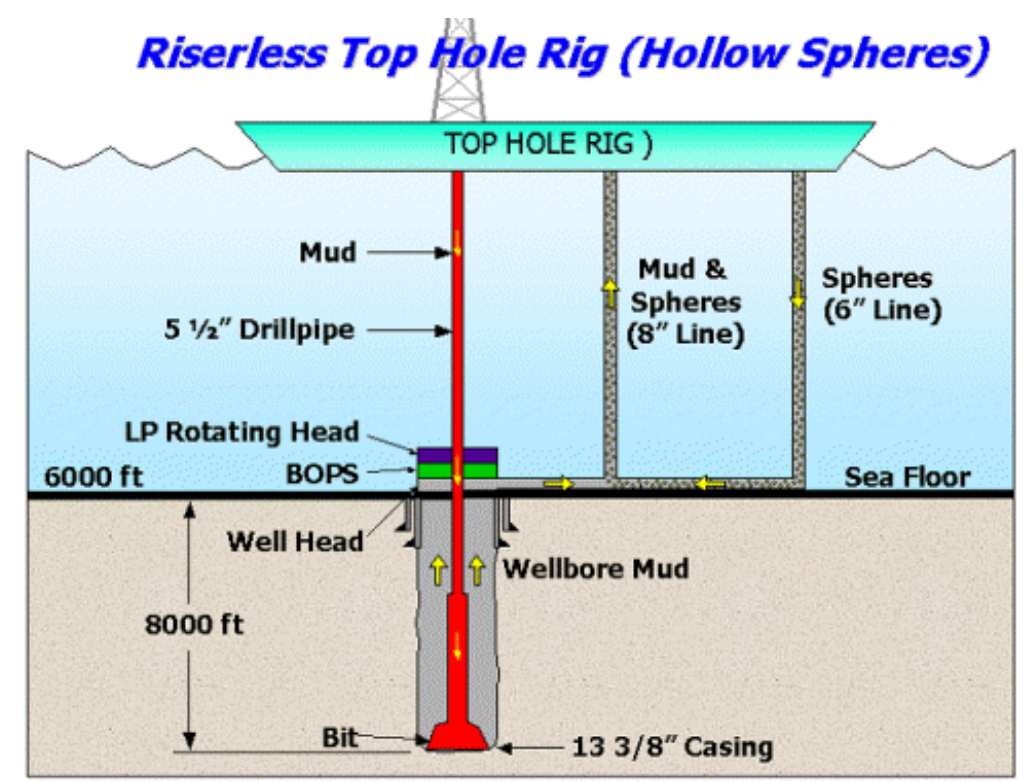

Figure 79. Riserless Top-Hole Rig (Hollow Sphere System)

With this DGD system, the 30- or 36-inch casing sections will still be jetted with seawater. The 20-inch casing seats will be drilled with the DGD system to 1) reduce well problems (e.g., shallow water flows, lost circulation, hydrates, bore stability), and 2 ) increase the depth to which 20 -inch casing can be run to reduce the number of casing strings required.

A 21-1/4-inch wellhead, 21-1/4-inch low-pressure BOP, and low-pressure rotating head will be attached to the 21 -inch casing. Next, the 13-3/8-inch casing section will be drilled to 6,000 to $10,000 \mathrm{ft}$ using a sphere DGD system. Drilling the 13-3/8-inch casing section with a top-hole rig will allow use of 13-5/8-inch instead of 21 -inch risers on the deep-hole rig, significantly reducing the size and cost of the deep-hole rig.

The sphere-based DGD system is smaller and costs less than seafloor pump DGD systems. Hollow spheres can reduce mud weight by up to $3 \mathrm{ppg}$, so they are preferred with 9- to 12-ppg muds. Seafloor pumps can effectively reduce mud weights by up to $10 \mathrm{ppg}$, so they are preferred with mud weights in excess of $12 \mathrm{ppg}$.

\subsubsection{Riserless Top-Hole Rig (Seafloor Pumps)}

With riserless top-hole rigs incorporating a seafloor pump DGD system, sophisticated pumps located on the seafloor reduce pressure in the wellbore annulus at the seafloor to that of seawater (8.6 ppg) (Figure 80). 


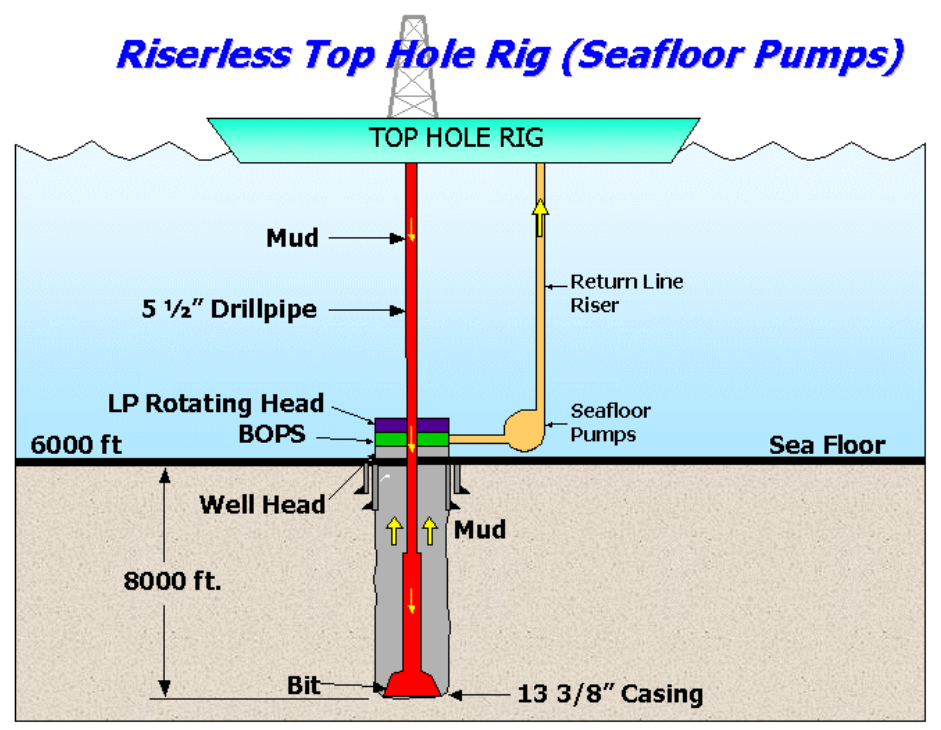

Figure 80. Riserless Top-Hole Rig (Seafloor Pumping System)

A drilling program with seafloor pumps is identical to that with a sphere-based DGD system. The 30- or 36-inch casing sections will still be jetted with seawater. 13$3 / 8$ and 20 -inch casing sections will be drilled with DGD to increase casing setting depths and reduce hole problems.

Seafloor-pump DGD systems are preferred with mud weights over $12 \mathrm{ppg}$ and sphere-based systems are preferred with mud weights under 12 ppg due to the simplicity and lower cost of the sphere system.

\subsection{DEEP-HOLE RIGS}

There are three basic deep-hole rigs that can be used in conjunction with tophole rigs:

1. Deep-Hole Rig (without DGD)

2. Deep-Hole Rig (Hollow Sphere DGD)

\section{Deep-Hole Rig (Seafloor Pump DGD)}

Deep-hole rigs can be equipped with hollow-sphere or seafloor-pump DGD systems to reduce the number of casing strings and save from $\$ 5$ to $\$ 15$ million (BP and Conoco estimates) in GOM deepwater wells. 
Each of these rigs has applications as described below.

\subsubsection{Deep-Hole Rig (Without DGD)}

Rocks typically become stronger with increasing well depth, so the benefit of DGD drilling generally decreases at deeper well depths. If a DGD top-hole rig is used to drill the 13-3/8 inch casing section, the rock may be strong enough so that a DGD system is not needed in deeper sections. For this situation, a deep-hole rig without DGD would be used (Figure 81).

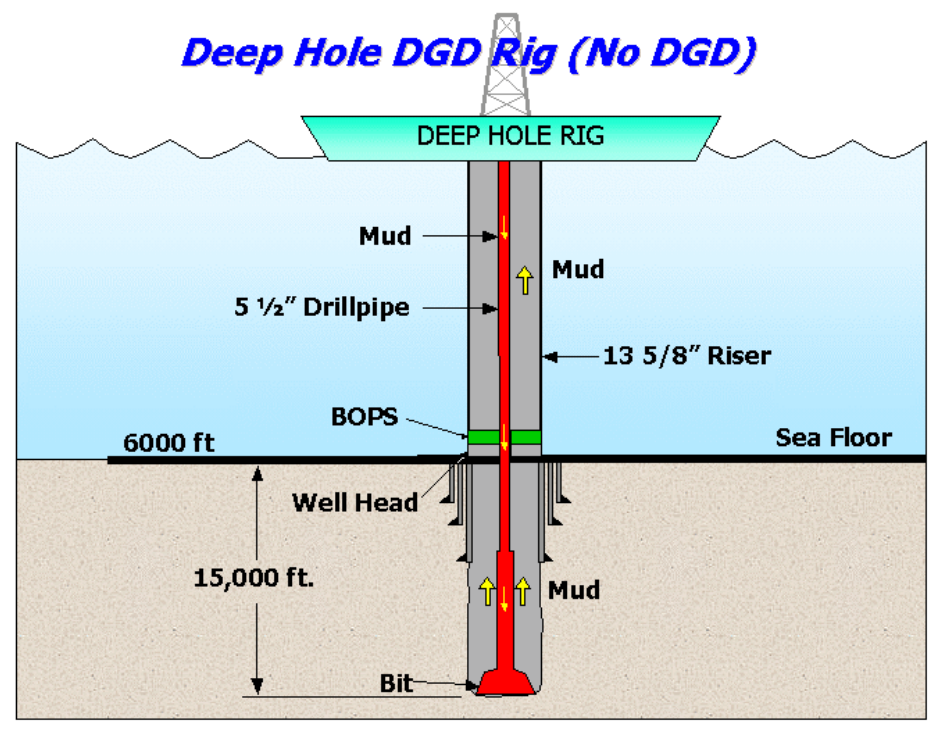

Figure 81. Rig without DGD for Deep Sections of Hole

Drilling with this deep-hole rig without DGD is the same as conventional deepwater drilling except that a smaller riser is used, so no special training of the crews is required. Drilling 13-3/8 inch casing sections with a top-hole DGD rig reduces riser size from 21 to $13-5 / 8$ inches. This significantly reduces the size and cost of the rig because of the reduced weight of the risers, riser tensioners, BOPs, mud volume, cement volume, deck space, and deck and derrick load-bearing capacity. The smaller riser will reduce handling problems with risers and BOPs, and reduce riser running time.

\subsubsection{Deep-Hole Rig (Hollow Sphere DGD)}

If DGD systems are required in deeper sections of the well (e.g., at Thunder Horse), a hollow-sphere DGD system can be used on the deep-hole rig using a 13-5/8inch riser (Figure 82). 


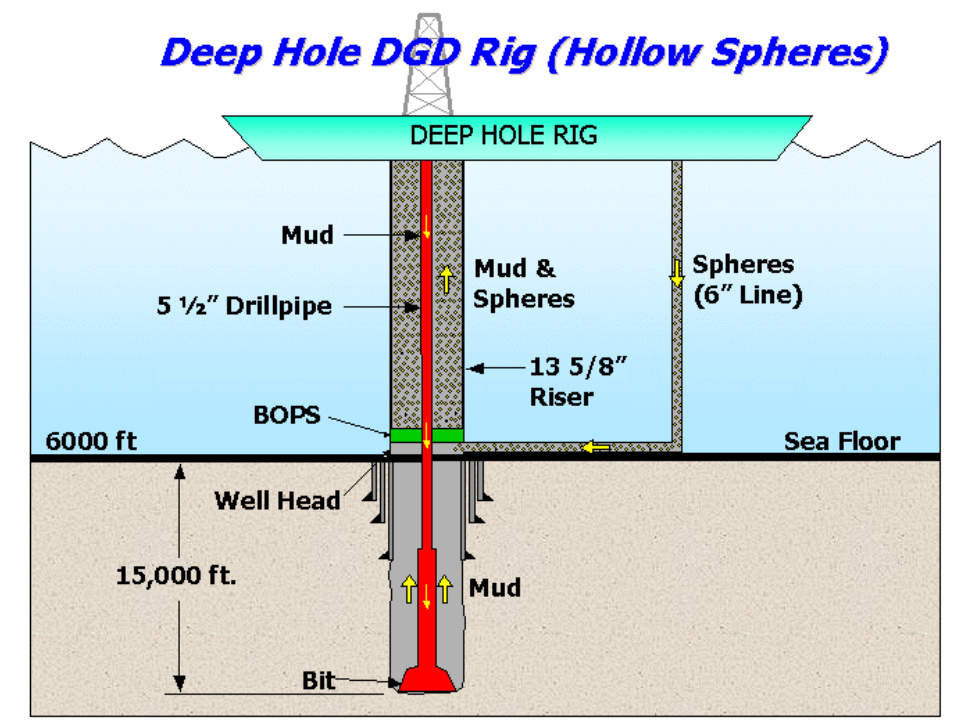

Figure 82. Deep-Hole DGD Rig (Hollow Sphere System)

Hollow-sphere systems have the advantage they are simple and low cost. The primary disadvantage is that they can effectively reduce mud weight only about $3 \mathrm{ppg}$. Fortunately, because of normal increases in rock strength with increased well depth, the DGD system may not be required to reduce mud density all the way to seawater gradient (8.6 ppg). For example, reducing density of a 14-ppg mud to $11 \mathrm{ppg}$ may be adequate in deeper sections of the well, allowing hollow spheres to be used in that application.

Hollow spheres are preferred where mud weight reductions of 1 to $3 \mathrm{ppg}$ are sufficient, whereas seafloor pumps are preferred where mud weight reductions need to exceed 3 ppg.

\subsubsection{Deep-Hole Rig (Seafloor Pump DGD)}

Figure 83 shows a DGD deep-hole rig incorporating a 13-5/8 inch riser with a seafloor pump DGD system. 


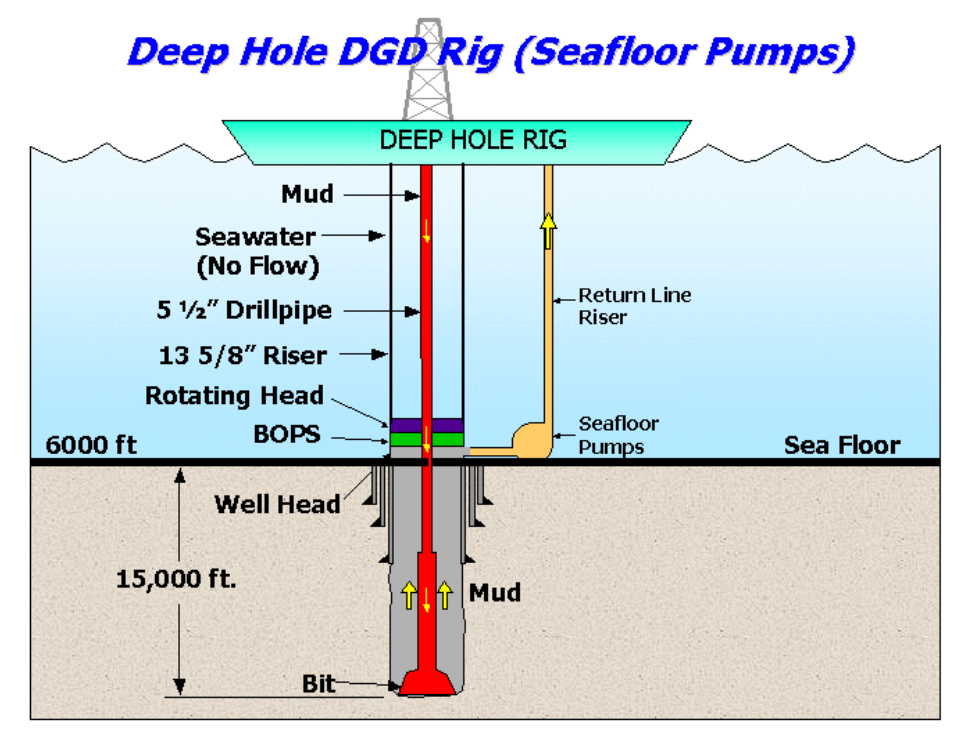

Figure 83. Deep-Hole DGD Rig (Seafloor Pumping System)

With this rig, the $13-5 / 8$ inch riser is filled with seawater to reduce differential pressure on the rotating head. Seafloor pumps maintain seawater pressure at the top of the wellbore by pumping mud to the surface rig in a "return line riser".

Seafloor-pump systems are preferred where mud weight reductions in excess of 3 ppg are required, whereas a hollow-sphere system is preferred where mud weight reductions of less than $3 \mathrm{ppg}$ are sufficient due to the simplicity and lower cost of the sphere system.

\subsubsection{Dolphin Drilling Slender Well Rig}

Dolphin Drilling Ltd. (Mitchell et al., 2002) has developed new "slender well" rigs that use 16-inch risers instead of 21 -inch risers (Figure 84 ). 


\section{Dolphin Drilling Slender Riser Rig}

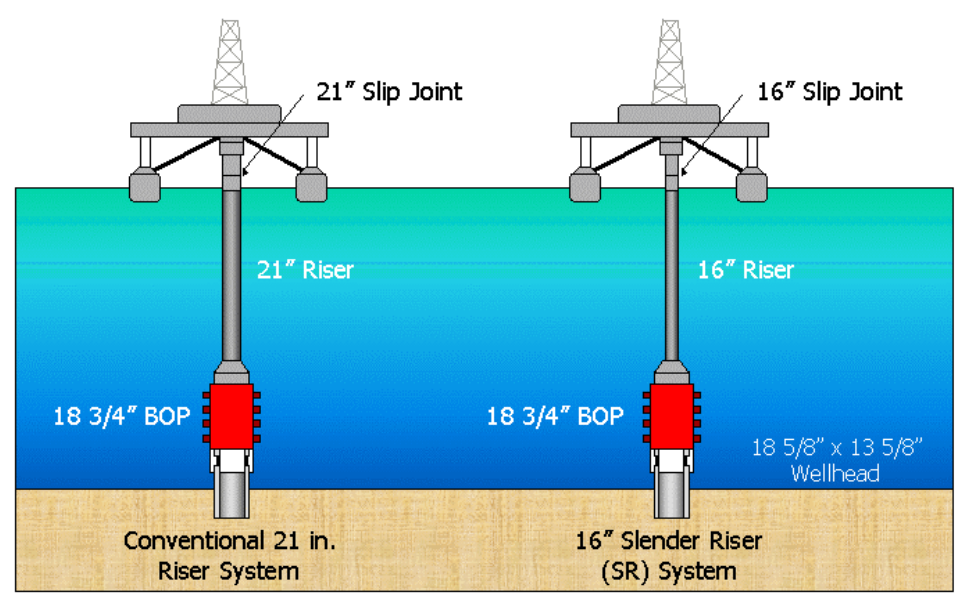

Figure 84. Dolphin Drilling's Slender Riser Rig

These rigs are similar to deep-hole rigs required with top-hole DGD rigs. Either $13-5 / 8$ or $18-3 / 4$ inch wellheads and BOPs can be used on the 16 -inch risers. Dolphin plans to use existing 18-3/4 inch BOPs.

The 1600-meter, 16 -inch risers (0.5-inch wall thickness) allow smaller Dolphin rigs to be used in deep water, reduce drilling time by $30 \%$, and cut field development costs by 20 to $40 \%$. Dolphin believes that use of these slender well rigs will make some conventional non-commercial fields into viable projects.

\subsection{OPTIMIZING RIG PUMPS}

Large high-pressure mud pumps are required on conventional deep-water rigs because the pumps must be capable of operation 1) at very high flow rates in upper sections of the hole (1,500 to 2,000 gpm) due to the large bit sizes (24 to 40 inches) and 2) at very high pressures $(5,000$ to $7,500 \mathrm{psi})$ in deeper sections of the well due to high friction losses in the drillstring and BHA. Use of top-hole rigs will allow pumps to be optimized with high-flow, low-pressure pumps used on top-hole rigs with large bits in the upper sections, and high-pressure, low-flow pumps used on the deep-hole rig in deeper sections with smaller bits.

If a riserless top-hole rig can drill the $13-5 / 8$ casing section as proposed, it would be possible to further reduce the riser size from 16 to $13-5 / 8$ inch on Dolphin's slender well rigs, further reducing their size and cost. 


\subsection{ENGINEERING CONSIDERATIONS FOR TOP-HOLE DGD RIGS}

\subsubsection{Advantages of Top-Hole DGD Rigs}

1. Reduced size and cost of top-hole rig by eliminating riser and BOPs.

2. Reduced size and cost of deep-hole rig by reducing mud capacity from 30,000 to $2,000 \mathrm{bbl}$ and using $13-5 / 8$ instead of 21 -inch risers.

3. Smaller risers will also reduce riser handling problems, mud and sphere volume requirements, and improve cuttings transport in the riser.

4. Eliminates need for Generation V rigs in most GOM deepwater applications.

5. Allows use of DGD rig on top-hole sections where DGD normally has the greatest impact.

6. Reduces trouble time (e.g., shallow water flows, lost circulation, hydrates, etc.).

7. DGD reduces riser tensioner loads by reducing riser size and mud weight in riser.

8. Reduces need for pump-and-dump and corresponding environmental concerns.

9. Allows faster deployment of DGD system and reduced deployment costs.

10. Reduces well costs by reducing number of casing strings and trouble time.

11. Allows use of more sophisticated muds for better wellbore stability.

12. DGD allows use of heavier muds for controlling shallow water flows.

13. Extends the depth of the conductor casing (26- or 20-inch).

14. Riserless drilling with 6-inch return flowline reduces sphere requirements.

15. Allows use of casing-while-drilling in top holes.

16. Amenable to using seawater-powered hydraulic hammers. 


\subsubsection{Items Eliminated on Top-Hole Rigs}

Since top-hole rigs drill only the upper sections of the well and are riserless, the following items can be eliminated from these rigs (Gault, 2002):

1. Riser

2. High-pressure BOPs

3. Multiplex (MUX) BOP controls

4. High-pressure surface choke system (simple bladder will be sufficient)

5. High-pressure kelly hose

6. Sophisticated PVT systems

7. Large tensioners (small tensioners may be required to run casing)

8. Complicated motion compensators (only simple compensators required)

9. Diverters

10. Electric logging units (top hole is not logged or LWD is used)

11. Mud logging units

12. Complicated mud treatment systems (use simple, seawater based mud systems)

13. Zero discharge requirements (no mineral based oils)

14. Large mud mixing and cleaning systems (only shale shakers required)

15. ROV

16. 30,000-bbl mud storage (if pump-and-dump eliminated)

Elimination of these items will significantly reduce the size and cost of a top-hole rig application. 


\subsubsection{Skills Eliminated with Top-Hole Rigs}

The following skilled persons can be eliminated on top-hole rigs (Gault, 2002):

1. Subsea engineer

2. Mud loggers

3. Electric logging crew

4. PVT technician

5. Maintenance requirement for equipment taken off rig

Eliminating these persons will significantly reduce the cost of operating top-hole rigs.

\subsubsection{Conventional Items Required on Top-Hole Rigs}

Top-hole rigs will still require the following items (Gault, 2002):

1. Cement units

2. Cement bulk storage

3. Gel bulk storage

4. Barite bulk storage (small amount for light mud)

5. Mud pumps

6. Generators

7. Standard size mud pits

8. Drill pipe

9. Heavyweight drill pipe for landing strings 


\subsubsection{Equipment Added to Top-Hole Rigs (Hollow Sphere System)}

The following oilfield equipment will need to be added to a top-hole rig for use with a hollow sphere DGD system:

1. Extra mud pumps

2. Extra solids-control equipment

3. Extra mud tanks

4. Sphere storage

5. Flowlines to seafloor (6")

6. Return flowlines from seafloor (8")

7. Flowline handling systems

8. Seafloor valves

9. Surface control panel

10. Surface display system (driller/toolpushers)

11. Low-pressure seafloor rotating head

12. Low-pressure BOPs (low frac pressures)

13. DGD crew

Estimated cost $=\$ 6$ million

Most of these items are conventional oilfield equipment that can be maintained by rig crews. This price includes $\$ 2$ million for the 6 - and 8-inch flowlines and handling systems. There should be minimal rig modification costs with the sphere DGD system. 


\subsubsection{DGD Equipment Added to Top-Hole Rigs (Mudlift DGD System)}

The following equipment must be added to a top-hole rig for use with the Mudlift DGD system (Gault, 2002):

1. Two snubbing jacks

2. Compensation system for snubbing jacks

3. Return line and seawater power line (tubing/casing with appropriate threads, 51/2-7 inch casing, 16,000 ft)

4. Hydril mud lift pumps (3-80 gal chambers, no dual redundancy required)

5. Electric spool/ROV cable (8000 ft)

6. Surface computer control cab

7. Display systems (driller/toolpusher)

8. Rotating head

9. Frame for subsea mud pumps and rotating head

10. Additional surface seawater mud pumps (two reconditioned mud pumps)

11. Possible additional generator capacity

12. Surface seawater centrifugal pump (to pump seawater to the rig)

13. Seawater holding pit

14. Surface piping for mud and seawater

15. Mud return line "T's" into low-pressure surface chokes and gas-handling system

16. TV camera on cage (replaces ROV)

\section{Estimated cost $=\$ 20$ million plus a royalty}


Much of this Mudlift equipment is specialized and must be maintained by skilled technicians (e.g., Mudlift pumps and controls). This cost estimate was made by a company involved with this system. It may not include all rig modifications required.

\subsubsection{Costs Due to Eliminating Services}

Table 18 shows a summary of typical savings due to eliminating certain services on top-hole rigs.

Table 18. Example Savings Due to Eliminating Services on Top-Hole Rigs

\begin{tabular}{|l|c|}
\hline ITEM & DAILY SAVINGS \\
\hline Wireline and Mud Logging & $\$ 37,000$ \\
\hline Mud Cost (no pump-and-dump) & $\$ 20,000(\$ 400,000$ total) \\
\hline ROV Rental & $\$ 15,000$ \\
\hline 15 Men (transportation and quarters) & $\$ 6,000$ \\
\hline 2 Galley Hands & $\$ 2,000$ \\
\hline TOTAL & $\$ 80,000$ \\
\hline
\end{tabular}

These are rough cost estimates, but they show that eliminating services will significantly reduce top-hole operating costs.

\subsubsection{Additional Opportunities for Top-Hole Rigs}

To expand the use of top-hole rigs and keep them busy, other capabilities that could be added include:

1. Well intervention and workover capabilities

2. Coiled tubing

3. Wireline tools

4. Seafloor coring (?)

5. High-pressure pumping (?)

6. Small, lightweight aluminum riser (?) 
7. Small downhole motors for well intervention

These added capabilities could enhance the economics of top-hole rigs and allow them to remain rented when not drilling top holes.

\subsubsection{Financial Incentives}

The use of top-hole DGD rigs capable of drilling 13-5/8 inch and larger casing sections has the potential to save $\$ 5$ to $\$ 15$ million on deepwater GOM wells (based on $\mathrm{BP}$ and Conoco estimates). This large cost reduction should give both operators and service companies the incentive needed to make the required capital investments to implement this system while maintaining a good profit margin.

\subsubsection{Timing}

A small number of top-hole rigs could drill all of the top holes in the GOM, so it is important for service companies to get to market first if they want to take advantage of this business. Ultimately, top-hole rigs with the most reliable and lowest cost DGD system will win out.

\subsection{ACKNOWLEDGEMENTS}

We gratefully acknowledge the assistance of Allen Gault (Conoco) who provided much of the information contained in this chapter. The assistance of Buddy King (Noble Corporation) and Dr. Tom Proehl (Triton) on rig operations, and Hans Deul (Noble Corporation) on rig design and operation was also very helpful. 


\section{Conclusions}

Previous to the DOE-funded development work described here, a $\$ 1.8$ million Phase I joint-industry project was conducted to design and implement a dual-gradient drilling (DGD) system based on adding lightweight spheres to mud in offshore risers to reduce mud density. Significant progress was made and a great variety of engineering hurdles were overcome during Phase I. At the completion of that effort, it was concluded that additional sphere separation tests were needed with weighted oilfield waterbase and oilbase muds to determine if the DGD system could work in practice with typical offshore drilling muds.

The DOE agreed to provide a $\$ 200,000$ grant for these tests. DOE-funded sphere separation tests, described here, showed that spheres could be pumped with conventional centrifugal and triplex mud pumps and separated effectively from both oilfield waterbase and oilbase muds using conventional oilfield shale shakers and hydrocyclones. These DOE tests were very important because without them, the feasibility of using shale shakers to separate spheres from oilfield muds would not have been demonstrated.

Below are listed important conclusions from individual test series described in this report. More detail is presented in the corresponding chapters.

\section{Flowline Pressure Drop Tests (Chapter 3)}

1. At low flow rates where laminar flow is present, the addition of 25 to $35 \%$ spheres into mud approximately doubles the pressure drop in flowlines since pressure drops with laminar flow are controlled by mud viscosity.

2. Spheres help maintain mud in laminar flow at higher flow rates. Consequently, at high flow rates, pressure drops in mud with spheres can be lower than in mud without spheres (i.e., without spheres, the flow has become turbulent).

3. Pressure required to pump spheres through flowlines equals friction pressure loss plus the u-tube pressure. This ranges from 1500 to $2500 \mathrm{psi}$, well within the capability of oilfield mud pumps, which operate at pressures up to 5000 psi. 
4. Many engineers assumed that pressure drops with mud/sphere mixtures would be significantly greater than for mud alone and would prevent commercialization of this DGD system. These tests show that this concern is not warranted.

\section{Sphere Flotation Tests (Chapter 4)}

5. In water, flotation velocities of $3 \mathrm{M}$ and Balmoral spheres were too high (22 and $46 \mathrm{ft} / \mathrm{min}$, respectively) due to water's low viscosity and lack of gel strength. This would result in rapid separation of the mud in the riser should circulation be stopped.

6. Low flotation velocities were observed in polymer and synthetic oil muds, which indicate that it should be possible to reduce sphere flotation velocities in waterbase muds to acceptable levels by adding polymers or other viscosifiers.

7. Tests showed that by proper mud design, reducing sphere flotation velocities to acceptable levels should not be a major problem when the DGD system is used with oilfield muds.

\section{Varco Shale Shaker Tests (Synthetic Oil Mud) (Chapter 5)}

8. A Varco shaker was successfully used to separate spheres from 13.0-ppg synthetic oil rates mud containing $25 \%$ spheres at flow rates up to $722 \mathrm{gpm}$.

9. All of the $3 \mathrm{M}$ spheres (which are 2 to $3 \mathrm{~mm} \mathrm{OD}$ ) were screened out of the mud with 10- and 20-mesh screens.

10. Performance of the Varco shaker was nearly identical with 10- and 20-mesh screens, showing that the flow rate of mud through these screens is limited by flow through the beads above the screen, not by the size of the openings in the screens.

11. With $257 \mathrm{gpm}$ flow, only wetted spheres came across the top of the screen and all liquid mud flowed through the screen. As flow rate was increased, more liquid mud flowed across the screen along with the spheres, reducing sphere concentration in the overflow. 
12. Based on these tests, Varco solids-control experts were very confident that they could develop a reliable sphere separation system for this DGD system using only shale shakers to separate the spheres from the mud.

\section{DRC Shale Shaker Tests (Waterbase Mud) (Chapter 6)}

13. A National Oilwell shale shaker was found to be able to remove spheres from oilfield waterbase mud at the high rates needed with this DGD system.

14. With $54 \mathrm{gpm}$ flow, only wetted beads came across the 10- and 20-mesh screens, with all of the liquid mud flowing through the screen.

15. With $210 \mathrm{gpm}$ flow, the concentration of spheres in the overflow was $50 \%$, an ideal mixture ratio to pump to the seafloor and re-inject into the riser.

\section{Varco Hydrocyclone Tests (Chapter 7)}

16. Hydrocyclone separation tests included a mixture feed rate of $500 \mathrm{gpm}$ including $20 \%$ spheres and $3 \%$ drill cuttings. $100 \%$ of the beads came out the overflow; $100 \%$ of the drill solids came out the underflow.

17. Spheres were passed through the centrifugal pump and hydrocyclone over 800 times with no detectable breakage or wear. This corresponds to the number of circulations in 2 to 6 wells.

18. The waterbase and oilbase muds tested produced no chemical degradation of the $3 \mathrm{M}$ spheres.

19. Two to four hydrocyclones would be able to handle flow rates required with this DGD system in the field (800-2000 gpm).

\section{Flow Loop Tests (Oilfield Waterbase Mud) (Chapter 8)}

20. No problems were encountered in pumping the spheres, circulating them through the well, or separating them from the mud when they returned to the surface. All components of the DGD system worked well in these tests.

21. The next logical step is to test the sphere-based DGD system in the field using conventional offshore equipment. 
As a result of the success of these DOE-funded tests, DGD technology based on hollow spheres is ready for full-scale field testing. Maurer Technology Inc. is currently proposing a Phase II project to oil companies to continue development. If Phase II tests are successful, Noble plans to commercialize this system with a service company partner that will market and operate the DGD system on Noble's and other drilling contractors' rigs. 


\section{References}

1. Bourgoyne Jr., Adam T.; Chenevert, Martin; Millheim Keith; Young, Jr., F.S.; 1984: Applied Drilling Engineering, SPE Textbook Series, Vol. 2.

2. Darley, H.C.H. and Gray, George R., 1988: Composition and Properties of Drilling and Completion Fluids (Fifth Edition), March.

3. Gault, Allen, ConocoPhillips, Personal Communication, 2002.

4. Mitchell, N.; Harchar, J.; Bentsen, G.; 2002: "Deepwater Slender Well Technology Cuts Costs," Offshore, August.

5. Peterman, Charles P., 1998: "Riserless and Mudlift Drilling - The Next Steps in Deepwater Drilling," OTC 8752, presented at the 1998 Offshore Technology Conference held in Houston, Texas, May 4-7.

6. Snyder, Robert E., 1998: "Riserless Drilling Project Develops Critical New Technology," World Oil, January. 